\title{
CONVECTION BATTERY RESEARCH, DEVELOPMENT, AND SIMULATION
}

\author{
A Dissertation \\ Presented to \\ The Faculty of the Graduate School \\ At the University of Missouri \\ In Partial Fulfillment \\ of the Requirements for the Degree \\ Doctor of Philosophy \\ By \\ MICHAEL JOSEPH GORDON \\ Dr. Galen Suppes, Dissertation Supervisor
}

May 2013 
The undersigned, appointed by the dean of the Graduate School, have examined the dissertation entitled

\title{
CONVECTION BATTERY RESEARCH, DEVELOPMENT, AND SIMULATION
}

\author{
presented by Michael J. Gordon \\ a candidate for the degree of Doctor of Philosophy, \\ and hereby certify that, in their opinion, it is worthy of acceptance.
}

Dr. Galen J. Suppes

Dr. Patrick J. Pinhero

Dr. John M. Gahl

Dr. Yangchuan Xing 
to my wife, Sarah 


\section{ACKNOWLEDGEMENTS}

I am indebted to Dr. Galen J. Suppes for giving me the privilege to perform research under his guidance. Without his insight and financial support, none of this research would have been possible. He is always enthusiastic and tries to push the limits of our research. The skills and knowledge that I have gained under Dr. Suppes are invaluable and will serve as the building blocks for the rest of my career.

I would also like to acknowledge my committee members: Dr. Patrick Pinhero, Dr. John Gahl, and Dr. Yangchuan Xing. All three have expert knowledge in electrochemical systems, and they have provided constructive feedback and suggestions to improve my research. Additionally, I would like to thank Dr. Gahl for being instrumental in the MOCAP program. Because of this program I was able to increase my electrochemical knowledge through classes specific to batteries, which were only available because of MOCAP.

Ali Tekeei has been a great mentor, both scientifically and in terms of everyday life. He is very humorous and his optimism always kept me moving forward.

I also want to thank the many other graduate students that contributed to this research. Bryan Sawyer pioneered the convection cell research and provided a foundation for this work, and Ramsey Hilton and Don Dornbusch helped to expand the convection cell research. I am especially grateful to them. Furthermore, I would like to thank all of my fellow chemical engineering graduate students, for all of the camaraderie. 
There are too many to name them all, but I don't think I could have made it through graduate school without them.

Moreover I am in appreciation to all of the undergraduate researchers that added to the convection cell research. Mike Heidlage, Dave Guinta, Ben Roseburrough, Brett King, Brett Gleason, Lucas Kriz, Phil Bascio, Chad Able, and Kate Nolan all had significant contributions through countless experiments.

I also want to express my deep appreciation to all of the ETS staff including Mike Klote, Rich Oberto, Mike Absheer, Brian Samuels, and Rex Gish. They are always able and willing to provide technical expertise on a moment's notice. I cherish all the knowledge that I have gained from them. I particularly want to thank Brian Samuels. He is an expert machinist and a great friend.

I would also like to thank many of the other faculty and staff members of the chemical engineering department. Dr. Stephen Lombardo, Dr. Paul Chan, Dr. Mary Meyers, Dr. Matthew Bernards, and Dr. David Retzloff are all excellent teachers and have given me the tools to succeed as a chemical engineer. The department administrative assistants Rita Preckshot and Jennifer Keyzer-Andre need to be recognized for everything that they have done to help my research. From ordering parts, to helping with travel arrangements, to throwing office parties, they do an outstanding job.

Finally, I would like to thank the National Science Foundation (Awards 0940720 and 1233250) and the California Energy Commission for their financial support. 


\section{TABLE OF CONTENTS}

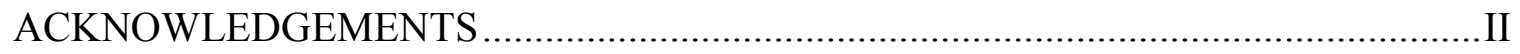

LIST OF FIGURES …................................................................................... VIII

LIST OF TABLES ................................................................................... XIV

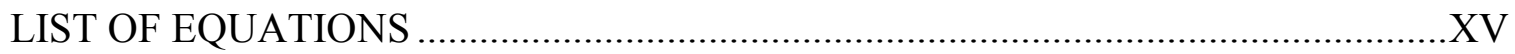

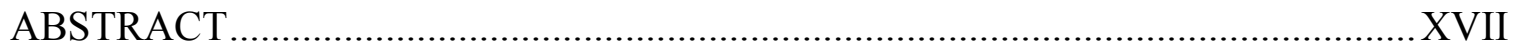

Chapter

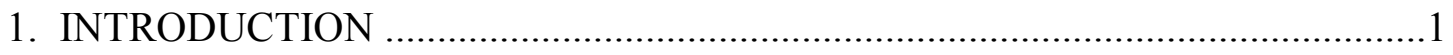

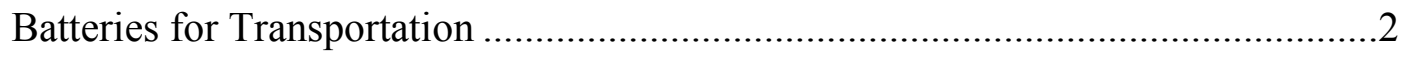

Batteries for Large-Scale Energy Storage Systems (LSESS) ...............................4

Lithium-ion Batteries and Flow Batteries - Background and Limitations ...............7

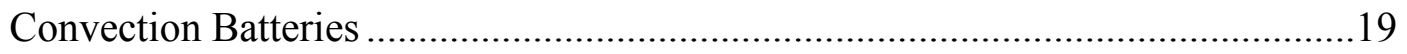

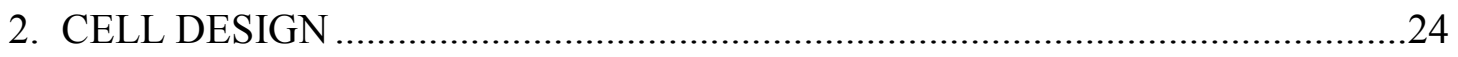




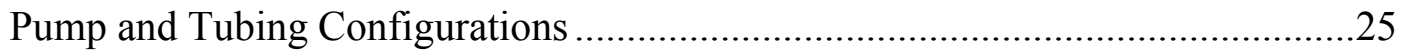

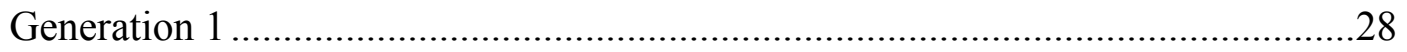

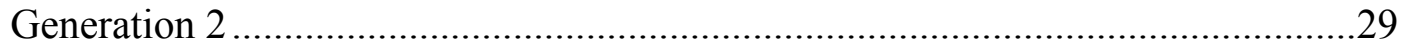

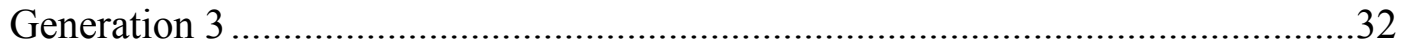

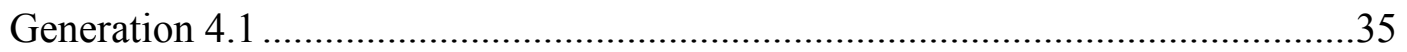

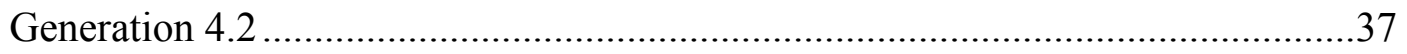

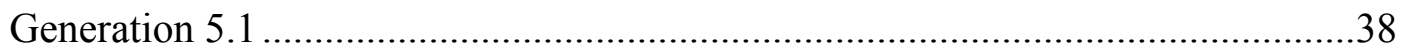

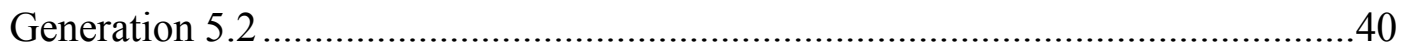

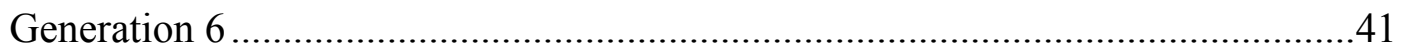

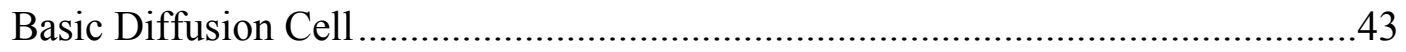

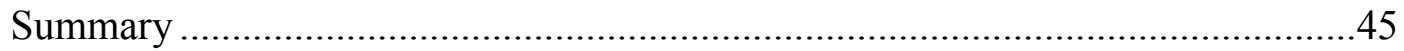

3. DESIGNING A LOW COST BATTERY TESTING SYSTEM WITH LABVIEW47

Version One ............................................................................................. 48

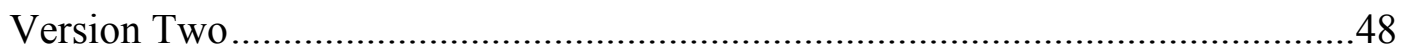

Version Three............................................................................................5

Summary and Future Improvements .......................................................64

4. INITIAL VALIDATION STUDIES OF CONVECTION CELLS ......................66

Flow versus No-Flow in $\mathrm{Zn} / \mathrm{MnO}_{2}$ Generation 4.1 Convection Cells ...................66

Studies on Separation Materials and Flow Direction........................................70

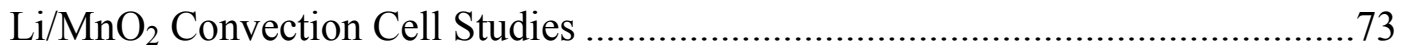

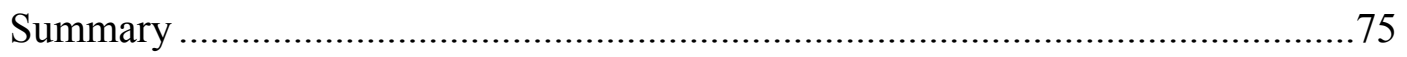

5. LI-ION BATTERY PERFORMANCE IN A CONVECTION CELL CONFIGURATION 


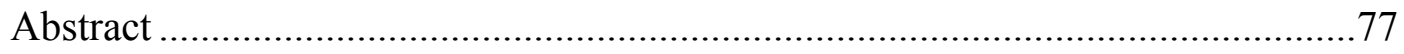

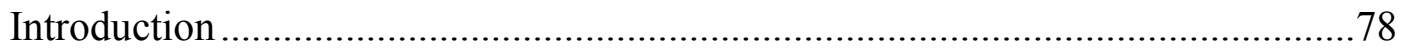

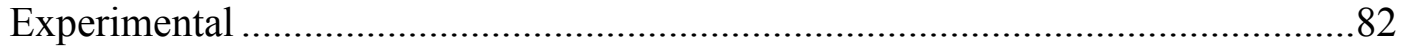

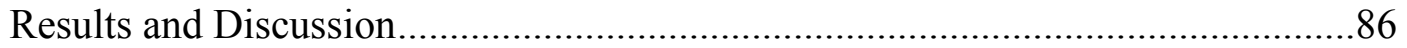

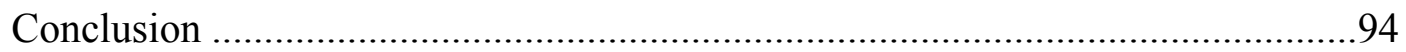

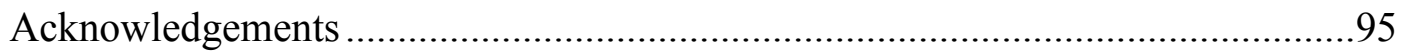

6. CONVECTION BATTERY - MODELING, INSIGHT, AND REVIEW .............96

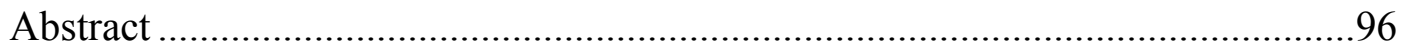

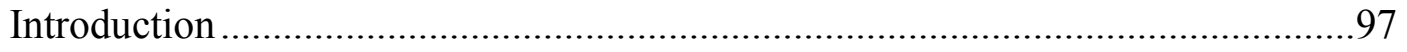

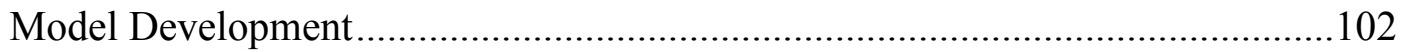

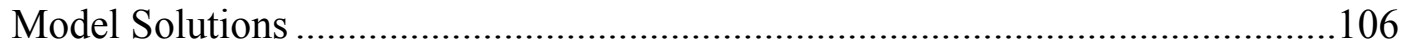

Diffusion Limit of Performance ........................................................................ 112

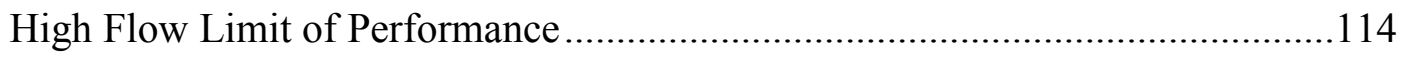

Impact of Solid Matrices on Ion Conductivity..............................................116

Implications on Convection Battery Performance …......................................119

Parallelism of Electrode Overpotentials......................................................121

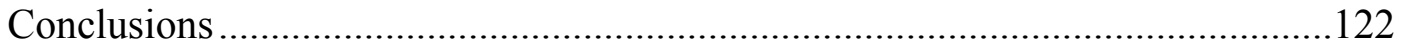

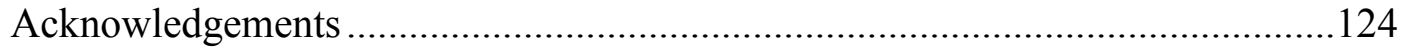

7. A COMPARISON OF MODELED AN EXPERIMENTALLY MEASURED OVERPOTENTIALS IN A MULTIPLE-REFERENCE ELECTRODE

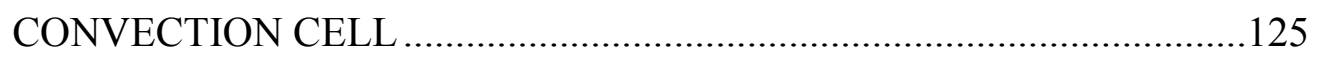


Introduction

Multiple-Reference Electrode Convection Cell .....

Experimental

Results and Discussion.

Conclusion

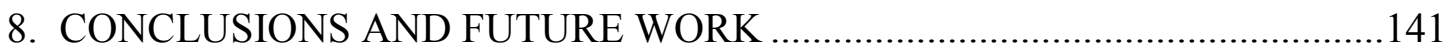

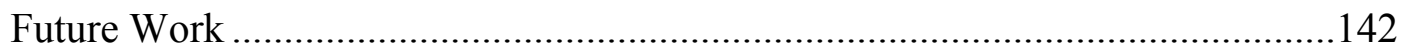

9. CONVECTION CELL DESIGN DIMENSIONAL SPECIFICATIONS ............144

Generation 3 Parts ................................................................................... 144

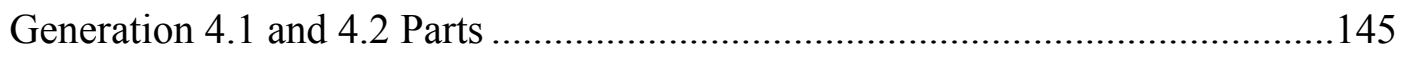

Generation 5.1 Parts .................................................................................. 147

Generation 5.2 Parts .................................................................................. 147

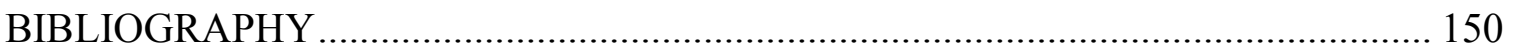

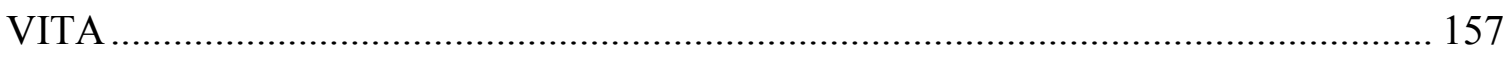




\section{LIST OF FIGURES}

Figure

Page

1.1 Total energy consumption by source (left), and fossil fuel energy use by sector (right) for the U.S. in $2011 .^{2}$

1.2 Current and target battery parameters for electric vehicle use. ${ }^{4}$............................ 3

1.3 Illustration of how a lithium-ion cell works when discharging. ${ }^{10}$........................ 9

1.4 The structure of pure graphite layers (left) and graphite intercalated with Li ions (right). ${ }^{19}$.

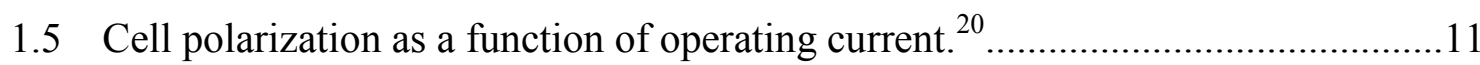

1.6 The construction of a typical spiral-wound cylindrical lithium-ion cell. ${ }^{21} \ldots \ldots \ldots \ldots .13$

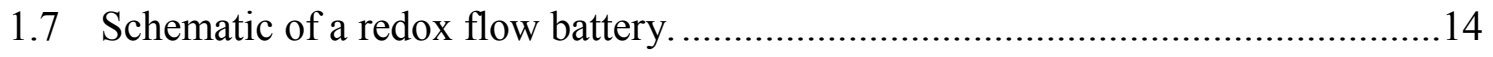

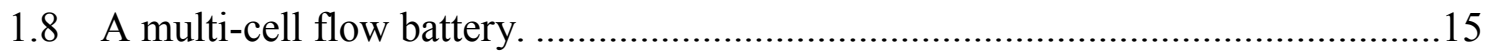

1.9 An illustration of how the flow cell can be expanded with additional tanks (dashed) to increase the energy or by expanding the cell stack (inside dashed square) to increase the power.........................................................16

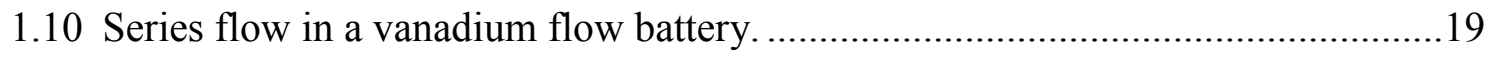

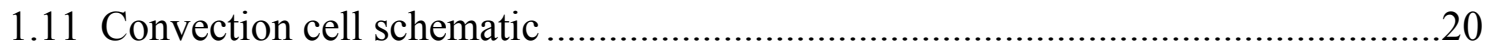

1.12 Flow patterns for flow-through electrodes (left), flow-by electrodes (middle), and convection cell flow-through electrodes (right). The grey areas are electrodes, the thick edges of the electrodes are the current collectors, the hatched areas are separators, the dotted arrows indicate the direction of current, and the electrolyte flow direction is shown by the solid arrows. .......21

2.1 A fully assembled convection cell with an open-reservoir configuration for the tubing (shown with a generation 4.1 convection cell). The arrows indicate the direction of electrolyte flow. 
2.2 A fully assembled convection cell with a closed-reservoir configuration (shown with a generation 5.1 convection cell). The arrows indicate the direction of electrolyte flow.

2.3 Initial convection cell design (generation 1) ...................................................28

2.4 Generation 2 convection cell. ...........................................................................

2.5 Fully assembled view (top) and cutaway view (bottom) of the generation 3 convection cell.

2.6 Cutaway side view (left) and fully assembled front view (right) of the generation 4.1 convection cell. ...................................................................35

2.7 Cutaway side view (left) and fully assembled front view (right) of the generation 4.2 convection cell with IXR. .....................................................38

2.8 The generation 5.1 convection battery and drying piston. Front view (left), rotated cutaway view (right), and cutaway view of the drying piston (center).

2.9 A diagram of the electrode tube and piston assembly (left) and photo of some $\mathrm{LiFePO}_{4}$ and graphite electrodes cast in the electrode tube assembly (right).

2.10 The front view (left) cutaway view (right) of the generation 5.2 convection cell with multiple reference electrodes.

2.11 The generation 6 convection cell or the scaled-up convection cell. Fully assembled (left) and cutaway view (right)

2.12 The basic diffusion cell used to screen materials for use in the convection cell. ..44

3.1 A schematic of the connections in the battery testing system. .............................48

3.2 A photo of the battery testing system (version two)...............................................49

3.3 A circuit diagram of the version two battery tester. ..............................................50

3.4 The front panel of the LabVIEW program for the version two battery testing system.

3.5 A photo of one of three control boxes in the battery testing system (version three).

3.6 The inside of one of the control boxes in the battery testing system (version three). 
3.7 The diagram of the circuit board in the control boxes used in the version three battery testing system. All relays are shown in the default open position......58

3.8 Circuit diagram for the 12-pin terminal block connections....................................59

3.9 Circuit diagram for the four-pin terminal block connections.................................59

3.10 Circuit diagram for the five-pin terminal block connections.................................59

3.11 Circuit diagram for the two-pin terminal block connections...............................60

3.12 The front panel of the LabVIEW program for version three of the battery testing system.

4.1 Thirty-minute discharge at $550 \Omega$ load with (solid) and without electrolyte flow (dashed) using $2 \mathrm{M} \mathrm{KOH}$ electrolyte. ${ }^{38}$

4.2 Electrolyte flow effects on the 4.1 convection cell potential under a $550 \Omega$ load at three different electrolyte concentrations [4 M KOH (solid line), $3 \mathrm{M}$ $\mathrm{KOH}$ (dash dotted line), and $2 \mathrm{M} \mathrm{KOH}$ (dashed line)]. ${ }^{38}$

4.3 Open-circuit and discharge voltage profile comparison between a generation $4.2 \mathrm{Zn} / \mathrm{MnO}_{2}$ convection cell with IXR and a generation $4.1 \mathrm{Zn} / \mathrm{MnO}_{2}$ convection cell without additional separator material. ${ }^{38}$

4.4 Voltage profiles for generation 4.2 convection cells with different IXRs as the separation material. Solid lines were obtained with an anode-to-cathode flow regime and dashed lines were obtained with a cathode-to-anode flow regime. ${ }^{40}$

4.5 Open circuit and discharge voltage profiles for the $\mathrm{Li} / \mathrm{MnO}_{2}$ convection cells and diffusion cells at $2150 \Omega$ (a), $986 \Omega$ (b), $265 \Omega$ (c), and $98 \Omega$ (d). The convection cells are shown as solid lines and diffusion cells as dashed.

5.1 A schematic of the convection cell

5.2 Schematic of the test cell for the convection battery and drying piston. Front view (left), rotated cutaway view (right), and cutaway view of the drying piston (center).

5.3 Voltage profiles of a convection cell with flow (bottom) and a control cell without flow (top) at a constant discharge resistance of $990 \Omega$. The initial 30 minutes is an open circuit of the discharged cell, followed by subsequent charge and discharge cycles. For the diffusion control studies, the pump was on during charging to ensure that the state of charge at the start of each discharge was the same as the convection cell. 
5.4 Specific capacity upon discharge vs. cycle number at a constant-resistance discharge of $990 \Omega$ for a convection cell and two control cells.

5.5 Specific discharge capacity vs. cycle number for a cell without convection during the first five discharge cycles and with convection for the last three cycles at a constant-resistance discharge of $990 \Omega$

5.6 Specific discharge capacity vs. discharge resistance for the first cycle of convection cells and control cells.

5.7 Comparison of discharge voltage profiles at several different constant discharge resistances. Solid lines represent convection cells and dashed lines represent the control diffusion cells.

6.1 Illustration of convection versus flow battery cells emphasizing the null overlap in combinations of reagents and electrolytes compatible with each type of cell.

6.2 Comparison of flow patterns for standard flow battery design as compared to standard and baffled convection battery designs. A basis is assumed of 1 liter void volumes in electrodes and a $1 \mathrm{~W}$ basis for the flow battery

6.3 Concentration profiles for porous electrode theory model using a combination of parameter values from literature and high diffusivity.

6.4 Performance curves for the convection versus diffusion battery cell using same loadings and test cell. Flow was turned off on the convection cell to obtain diffusion cell performance. The symbols are for experimental constant-resistance discharge with capacity being measured to a cut-off voltage of 2.0 volts from a previous publication. ${ }^{41}$ The lines are model fits using a constant-current discharge.

6.5 Overpotential in the separator as a function of time for different velocities, with positive flow in the left graph and negative flow in the right graph......107

6.6 Simulated concentration profiles (concentration of $\mathrm{Li}^{+}$which is equal to anion concentration for binary electrolyte) for positive and negative flow

6.7 Cell voltages as provided by simulation for various positive and negative velocities to emphasize the effect on total overpotential in the cell.

6.8 Illustration of control volume (shaded area) used to interpret performance.

6.9 Impact of different packing media in the separator on performance of zinc alkaline convection cells. ${ }^{40}$ 
6.10 Illustration of transport in the separator of a convection battery where convection occurs through pores and anion migration is dominated by a path through the ion membrane material phase. Migration through the polymer phase of the separator is believed to be the most effective migration mechanism.

6.11 Illustrative PSS performance curves. The lowest of the lines represents a diffusion cell performance curve and limiting current with the breakdown of overpotentials as indicted. The lowest straight line is the performance curve for a convection battery that has no bulk diffusion limitation. The dashed like is the performance curve for the convection battery with materials optimized for increased anion diffusivity.

6.12 Illustration of different paths from the pore of an electrode to the current collector for realization of the potential difference $\phi_{\mathrm{A}}-\phi_{\mathrm{B}} \ldots \ldots \ldots \ldots \ldots \ldots \ldots \ldots \ldots . . . . . . . . . . . .121$

7.1 The multiple-reference electrode convection cell design.

7.2 Constant-current discharge voltage profiles for the convection cell at various currents with flow and without flow. Modeled data are shown by solid lines and experimental data are shown as dotted lines. The top solid line and the top dotted line in each graph were obtained with flow. The bottom lines were obtained without flow.

7.3 Cycling data from the multi-reference electrode convection cell 2. There are eight reference electrode measurements represented by the solid lines that are too close to differentiate. The overall cell voltage is represented by the dashed line.

7.4 A close-up view of the voltage of the eight reference electrodes in cell one and the eight in cell two

7.5 Experimental reference electrode voltage versus electrode distance at $0.7 \mathrm{~h}$ into the convection cell discharge. The data above and left of the dashed line are from cell one. The data below and to the right are from cell two....135

7.6 Reference electrode voltage over time at 15 different positions within the convection cell. The voltage profiles decrease with distance from the positive current collector

7.7 The modeled reference electrode voltages versus distance from the positive current collector at three different times into the discharge. The dashed lines indicate the separator boundary.

7.8 Modeled overpotentials compared to experimental cell voltage (dashed line) at a discharge current of $2.7 \mathrm{~mA} / \mathrm{cm}^{2}$ in a convection cell with flow. 
A.1 Dimensional drawings for the 316 SS electrode body of the generation 3 convection cell. Dimensions are in inches.

A.2 Dimensional drawings for the 316 SS piston of the generation 3 convection cell. Dimensions are in inches.

A.3 Dimensional drawings for the HDPE coupling of the generation 4.1 and 4.2 cells. Dimensions are in inches.

A.4 Dimensional drawings for the 316 SS piston of the generation 4.1 and 4.2 cells. This part is also used in both of the generation 5 cells. Dimensions are in inches.

A.5 Dimensional drawings for the $316 \mathrm{SS}$ compression plate of the generation 4.1 and 4.2 cells. This part is also used in both of the generation 5 cells. Dimensions are in inches.

A.6 Dimensional drawings for the 316 SS electrode tubes of the generation 4.1 and 4.2 cells. This part is also used in both of the generation 5 cells. Dimensions are in inches.

A.7 Dimensional drawings and measurements for the HDPE coupling of the generation 5.1 convection cell. Dimensions are in inches.

A.8 Dimensional drawings for the Teflon coupler of the generation 5.2 cell. Dimensions are in inches.

A.9 Dimensional drawings for the Teflon electrode tube 1 of the generation 5.2 cell. Dimensions are in inches.

A.10 Dimensional drawings for the Teflon electrode tube 2 of the generation 5.2 cell. Dimensions are in inches.

A.11 Dimensional drawings for the 316 SS compression plate of the generation 5.2 cell. Dimensions are in inches. 


\section{LIST OF TABLES}

\section{Table}

Page

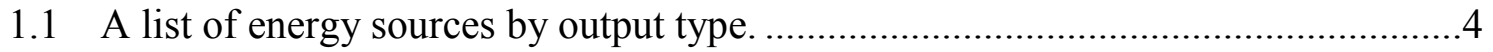

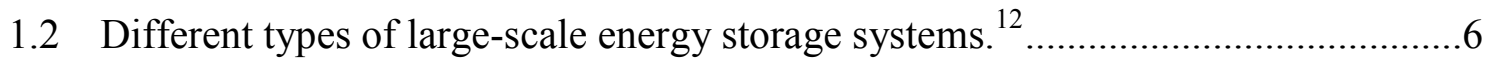

1.3 Response time data for different types of dispatchable power systems. ${ }^{18}$...............

3.1 A sample input file for the version three LabVIEW file. .................................64

5.1 Permeabilities and compositions of dry electrodes and electrode powder materials under a pressure of $1200 \mathrm{kPa}$. The graphite is large-particle graphite with $250-425 \mu \mathrm{m}$ particle sizes................................................. 87

6.1 Design options for the convection battery architecture. .................................99

7.1 Electrode paste compositions (percentages are by mass)................................129 


\section{LIST OF EQUATIONS}

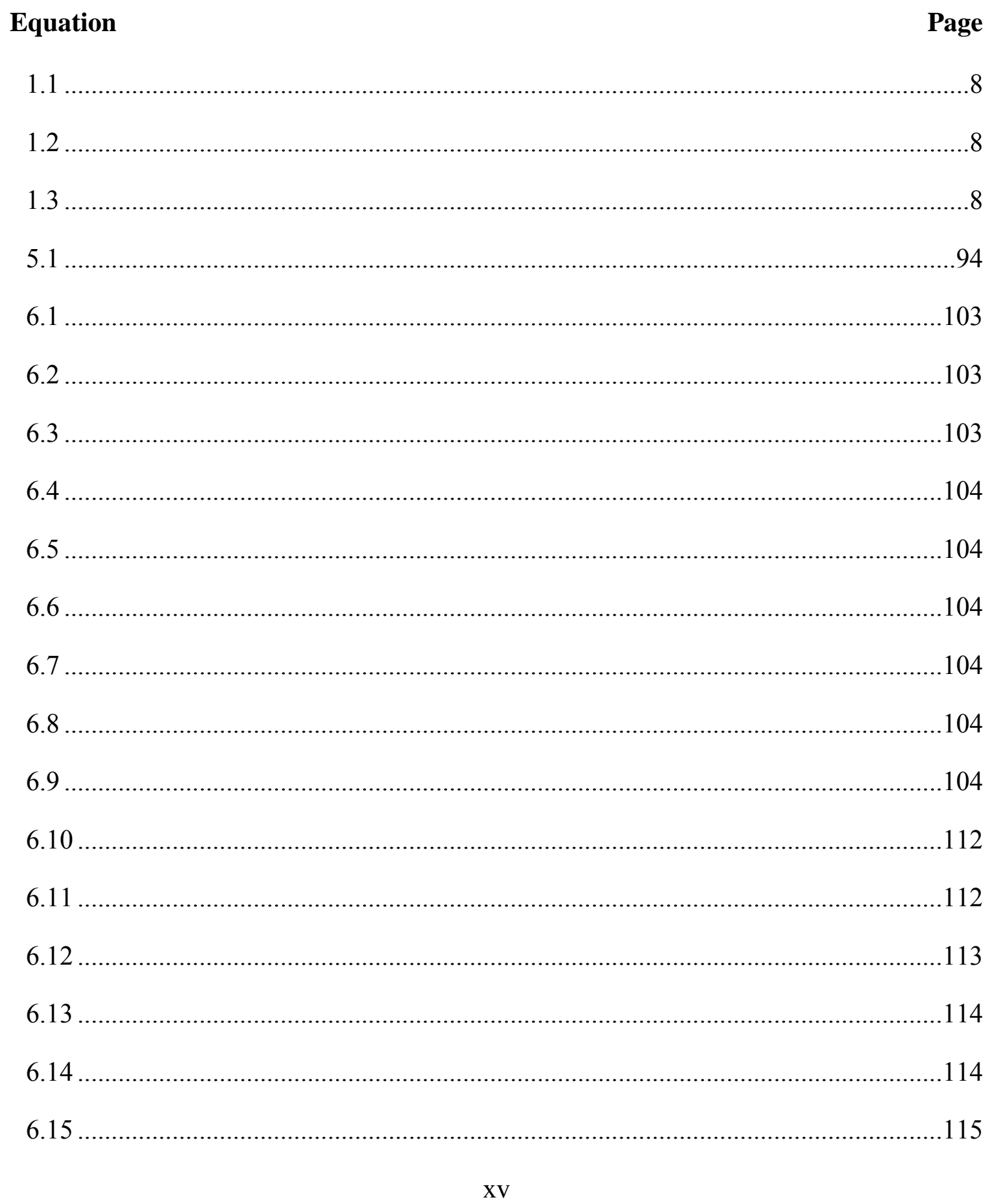




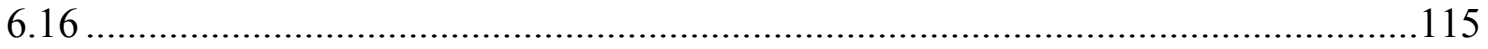

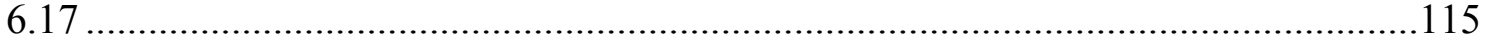

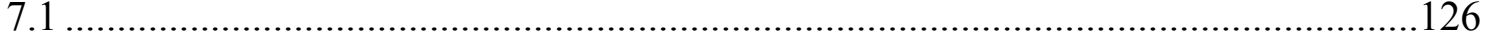




\begin{abstract}
In 2011 , fossil fuels accounted for $82 \%$ of the energy consumption in the US, and the majority of that usage was for transportation and electricity generation. In order to offset this staggering statistic, advancements in batteries are needed to allow electric vehicles and alternative energy sources to decrease the nation's dependency on unsustainable fossil fuels.

The research in this dissertation focuses on convection cells that have the potential to provide some of the needed breakthroughs in batteries. The convection cell utilizes electrolyte flow to decrease concentration overpotentials in batteries through the reduction of concentration gradients in the electrolyte. Reduced concentration overpotentials translate into more uniform potentials throughout the thickness of the electrodes. This allows for the use of thicker electrodes, which results in less current collector and separator material in the cell, and could mean significant reductions in the cost and weight of large-scale batteries for electric vehicle or grid storage applications.

The initial validating studies on the convection cells are reviewed, and show that flow reduces the overpotential in $\mathrm{Zn} / \mathrm{MnO}_{2}$ and $\mathrm{Li} / \mathrm{MnO}_{2}$ cells regardless of flow direction. Also, it is indicated the convection cell performance can be further enhanced by using separator materials to increase the ionic-conductivity of the electrolyte.
\end{abstract}


New work on $\mathrm{LiFePO}_{4}$ convection cells reveals that the flow of electrolyte enhances performance for both charge and discharge. In addition, a model of the $\mathrm{LiFePO}_{4}$ convection cell is developed and shows that the flow of electrolyte virtually eliminates concentration gradients in the cell, and confirms the initial findings with the $\mathrm{Zn} / \mathrm{MnO}_{2}$ that when a high enough flow rate is used the direction of flow has no detectable impact.

A new multiple-reference electrode cell is used to directly measure the electrolyte potential during cycling. It is compared to the model calculations and found that the model is limited in predicting internal resistances in the cell. There are multiple parameters in the model that should be measured specifically for the convection cell in order to increase the accuracy of the model.

Overall though, this research shows that the convection cell has the potential to provide the needed breakthrough in batteries to offset fossil fuel usage. 


\section{CHAPTER 1}

\section{INTRODUCTION}

It is quite evident, though, that this squandering cannot go on indefinitely, for geological investigations prove our fuel stores to be limited. So great has been the drain on them of late years that the specter of exhaustion is looming up threateningly in the distance...

-Nikola Tesla, Our Future Motive Power

Nikola Tesla recognized the need for renewable energy sources as a replacement for fossil fuels over 80 years ago. ${ }^{1}$ While the current estimates of fossil fuel supplies indicate that these resources will last well beyond the current generation, the reserves are finite nonetheless. According to the U.S. Energy Information Administration, in 2011, $82 \%$ of the total energy consumed in the U.S. was from fossil fuels. ${ }^{2}$ The majority of fossil fuel consumption is in the transportation and electricity generation sectors as shown in Figure 1.1. In the future, widespread use of alternative energy sources and electric vehicles could significantly offset the use of fossil fuels in these sectors. However, advancements in battery technologies are an integral part to this shift away from fossil fuels to sustainable energy sources and electric vehicles. 

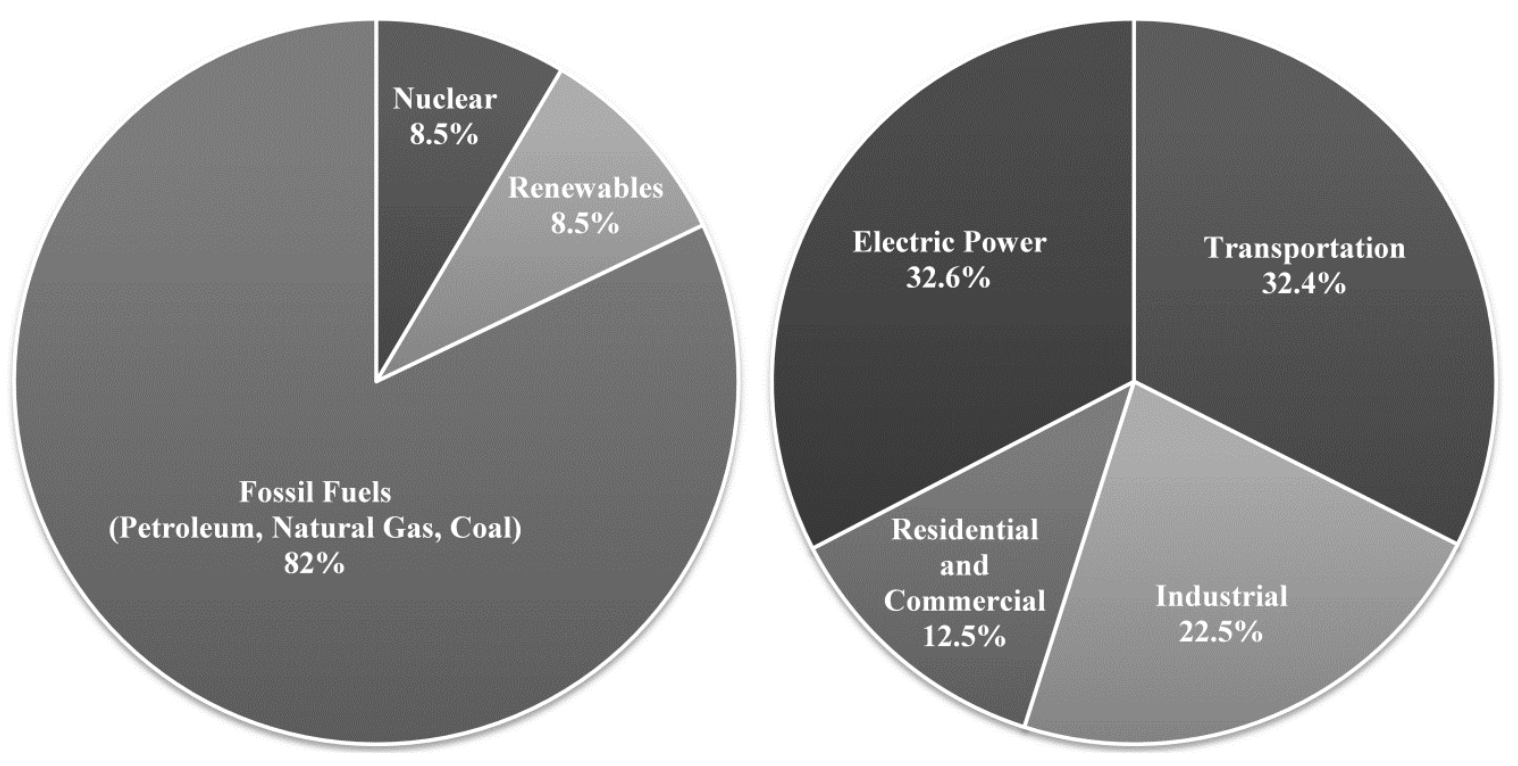

Figure 1.1 Total energy consumption by source (left), and fossil fuel energy use by sector (right) for the U.S. in 2011. ${ }^{2}$

\section{Batteries for Transportation}

Battery-powered electric vehicles $(\mathrm{BEV})$ provide a clean sustainable alternative to gasoline powered vehicles. Currently, lithium-ion batteries are the best option for BEVs, and the commercial availability of BEVs are on the rise. ${ }^{3}$ Despite this, BEVs still suffer limitations; they are prohibitively expensive for the majority of motorists, have limited driving ranges, and are slow to charge. The Department of Energy's (DOE) goal for the future is to make an electric vehicle that has a range of 280 miles and would be able to be charge in just under an hour at a rate of 300 miles/hour of charge, and would be similar in price to an equivalent gasoline powered vehicle. ${ }^{4}$

Two of the top selling electric cars are the Nissan Leaf and the Chevrolet Volt, which both have lithium-ion battery packs. General Motors offers the Chevrolet Volt at an MSRP of $\$ 39,145$ minus a tax credit up to $\$ 7,500$. It can get up to $38 \mathrm{miles} / \mathrm{charge}$ 
and charges in 4-16 $\mathrm{h}$ (2-10 miles/hour of charge) depending on the charging system. ${ }^{5}$ The Nissan Leaf has a 73 miles/charge range and can be charged in $0.5-8 \mathrm{~h}$ (9-146 miles/hour of charge) depending on the charger used. It has an MSRP of $\$ 28,800$ and is also eligible for the $\$ 7.500$ tax $_{\text {credit. }}{ }^{6}$ A lifecycle analysis done on the Nissan Leaf and a comparable conventional vehicle revealed that the lifetime cost of the Leaf was $\$ 52,203.95$ compared to $\mathrm{s} \$ 48,720.17$ for the conventional vehicle. ${ }^{7}$ This assumed a 15 year, 180,000 mile lifetime for each vehicle and does not include the tax credit for the Leaf. In order for BEVS to become widely used and appreciably reduce fossil fuel consumption, advancements in lithium-ion batteries or alternative batteries are imperative.

According to the DOE, the size and weight of current lithium-ion battery packs need to be cut in half, and there needs to be a four-fold reduction in cost in order to make BEVs as affordable as current gasoline powered vehicles. ${ }^{4}$ A list of the current lithiumion battery specifications and the DOE targets are listed.

Figure 1.2 Current and target battery parameters for electric vehicle use. ${ }^{4}$

\begin{tabular}{lcc}
\hline & Lithium-ion & DOE Target \\
\hline Cost & $\$ 500 / \mathrm{kWh}$ & $\$ 125 / \mathrm{kWh}$ \\
Specific Energy & $100 \mathrm{Wh} / \mathrm{kg}$ & $250 \mathrm{Wh} / \mathrm{kg}$ \\
Energy Density & $200 \mathrm{Wh} / 1$ & $400 \mathrm{Wh} / 1$ \\
Specific Power & $400 \mathrm{~W} / \mathrm{kg}$ & $2000 \mathrm{~W} / \mathrm{kg}$ \\
\hline
\end{tabular}




\section{Batteries for Large-Scale Energy Storage Systems (LSESS)}

Worldwide electricity usage is projected to increase by $84 \%$ by $2035 .^{8}$ In order to reduce fossil fuel use in the electricity generation industry, investments in solar, wind, geothermal, hydroelectric, and nuclear power sources are necessary. In parallel, advancements in large-scale energy storage systems, particularly batteries, are needed for load leveling, peak shaving, and energy arbitrage. ${ }^{9-13}$

There are three main types of energy sources in terms of their variability and control: intermittent sources, base-load sources, and dispatchable sources. Intermittent sources have variable outputs that cannot be controlled, and base-load sources output a constant stream of energy. Conversely, dispatchable power sources have energy outputs that can be manipulated on demand to balance the output of constant and intermittent sources with the grid demand. A list of the major electricity generation sources by category is listed in Table 1.1. The majority of dispatchable power in the U.S. is from fossil fuels - natural gas or coal. The output from coal plants is variable down to about $30 \%$ of capacity, whereas a natural gas power plant or "peaker plant" can be turned on and off much quicker. With the exception of hydroelectric power however, alternative energy sources cannot be controlled easily to match the grid demand.

Table 1.1 A list of energy sources by output type.

\begin{tabular}{ccc}
\hline Intermittent & Base-load & Dispatchable \\
\hline Wind & Geothermal & Natural Gas \\
Solar & Nuclear & Hydroelectric \\
& & Coal \\
\hline
\end{tabular}


Hydroelectric power is very flexible, but there are few if any opportunities to expand this resource. Most of the world's rivers have already been dammed or cannot be dammed due to environmental or population relocation concerns. The future in North America and Europe is mainly limited to small scale dams. Much of the remaining capacity in the world is located in developing countries in Asia and Africa. ${ }^{14,15}$

In addition to dispatchable energy sources, a variety of large-scale energy storage systems (LSESS) are used for load leveling to balance the grid. Load leveling matches the output of energy sources with the demand by using LSESS. LSESS store excess grid energy at times of low demand, and subsequently release that energy when demand increases beyond the generation capabilities of the grid. This prevents grid blackouts and saves money by reducing the amount of generational capacity that is needed. Some of the LSESS options are listed in Table 1.2. ${ }^{12}$ In addition to load leveling, LSESS can be used in the grid for peak shaving and energy arbitrage. Peak shaving is when stored energy is used by industrial customers to offset their power usage during peak times when energy costs are higher, and energy arbitrage is storing excess energy when prices are low, and selling that energy for a higher profit to other markets when prices increase. ${ }^{16}$ 
Table 1.2 Different types of large-scale energy storage systems. ${ }^{12}$

\begin{tabular}{|c|c|c|c|c|c|c|}
\hline Technology & $\begin{array}{l}\text { Typical } \\
\text { power, } \\
\text { MW }\end{array}$ & $\begin{array}{l}\text { Discharge } \\
\text { time }\end{array}$ & $\begin{array}{c}\text { Storage capacity } \\
\text { cost, } \$ \mathbf{k W h}-1\end{array}$ & $\begin{array}{l}\text { Life time, } \\
\text { cycle/years }\end{array}$ & $\begin{array}{c}\text { Efficiency, } \\
\%\end{array}$ & Drawbacks \\
\hline Flywheels & 1 & $<5 \min$ & $1,000-2,000$ & $\begin{array}{l}100,000 / \\
>10\end{array}$ & $>90$ & $\begin{array}{l}\text { Cost, power } \\
\text { applications }\end{array}$ \\
\hline $\begin{array}{l}\text { Compressed air } \\
\text { energy storage } \\
\text { (CAES) }\end{array}$ & 2,700 & $2-10 \mathrm{~h}$ & $90-200$ & $\begin{array}{l}>5,000 / \\
>>10\end{array}$ & 50 & $\begin{array}{l}\text { Site specific, } \\
\text { storage and } \\
\text { transmission cost }\end{array}$ \\
\hline $\begin{array}{l}\text { Pumped-storage } \\
\text { hydroelectricity }\end{array}$ & $\begin{array}{l}4,000 \text { (up } \\
\text { to } \\
22,500)\end{array}$ & $4-12 \mathrm{~h}$ & $75-100$ & $\begin{array}{l}>10,000 / \\
>25\end{array}$ & $75-80$ & $\begin{array}{l}\text { Site specific, } \\
\text { transmission cost, } \\
\text { environment }\end{array}$ \\
\hline Super capacitors & 0.25 & $<1 \mathrm{~min}$ & $500-3,000$ & $\begin{array}{l}500,000 / \\
>20\end{array}$ & $>90$ & $\begin{array}{l}\text { Explosion hazard, } \\
\text { low energy } \\
\text { density, cost }\end{array}$ \\
\hline $\begin{array}{l}\text { Superconductive } \\
\text { electromagnetic } \\
\text { storage (SMES) }\end{array}$ & $10^{\mathrm{a}}$ & $1-30 \mathrm{~min}$ & $2,000-10,000$ & $\begin{array}{c}100,000 / \\
>20\end{array}$ & 97 & $\begin{array}{l}\text { High capital cost, } \\
\text { cryogenics }\end{array}$ \\
\hline $\begin{array}{l}\text { Chemical } \\
\text { (hydrogen) }\end{array}$ & $10^{\mathrm{a}}$ & $>5 \mathrm{~h}$ & & 13 & $40-50$ & $\begin{array}{l}\text { Low density } \\
\text { storage, high cost, } \\
\text { safety }\end{array}$ \\
\hline $\begin{array}{l}\text { Secondary batteries } \\
\text { (lead-acid, Li-ion, } \\
\text { NAS) }\end{array}$ & $0.5-1$ & $1-8 \mathrm{~h}$ & $250-3,500$ & $\begin{array}{c}1,000- \\
4,500 / 7-20\end{array}$ & $75-80$ & $\begin{array}{l}\text { High cost, low } \\
\text { cycle life }\end{array}$ \\
\hline $\begin{array}{l}\text { Flow battery } \\
\text { (vanadium redox } \\
\text { battery) }\end{array}$ & 12 & $10 \mathrm{~h}$ & $150-2,500$ & $\begin{array}{c}500-2,000 / \\
10\end{array}$ & 70 & $\begin{array}{l}\text { Low energy } \\
\text { density }\end{array}$ \\
\hline
\end{tabular}

${ }^{\mathrm{a}}$ Projected

When considering LSESS for these grid applications, the response time of the system must be considered. Systems that can discharge faster are more valuable in many applications. $^{17,18}$ For instance, in load leveling applications at a wind farm or solar plant, additional power may be required on a time scale of minutes or seconds, so a slowdischarging, large-capacity system is not as effective as a low-capacity, fast-discharging system. Table 1.3 lists the ramp rate data in terms of the percent of rated power that can be achieved in a minute from a variety of power sources in California. ${ }^{18}$ The best hydroelectric plants can ramp up to full power in a minute, but as discussed previously, further hydroelectric applications are limited. This is where the advantages of batteries are able to come into play. Batteries are able to output their rated power almost 
instantaneously, and are efficient, flexible, compact, and they can provide frequency control. This gives them a distinct advantage over fossil fuels and other LSESS.

Table 1.3 Response time data for different types of dispatchable power systems. ${ }^{18}$

\begin{tabular}{lccc}
\hline & \multicolumn{3}{c}{ Ramp \%/min } \\
& MIN & AVG & MAX \\
\hline Hydroelectric & 2.5 & 32 & 100 \\
Gas Combustion Turbine & 13.4 & 20.4 & 27.9 \\
Gas Steam Turbine & 0.1 & 1.9 & 7.6 \\
\hline
\end{tabular}

A variety of batteries are used in LSESS applications. Some of these batteries include lithium-ion, lead-acid, sodium nickel chloride, and flow batteries. A recent analysis determined that flow batteries may be the most cost-effective batteries for energy applications and lithium-ion batteries may be the most cost-effective option for high power applications. ${ }^{12}$ Similarly to the batteries for transportation, advancements in batteries for LSESS are needed to lower the cost. This would ultimately lower the cost of implementing more alternative energy sources in the grid and lower fossil fuel consumption.

\section{Lithium-ion Batteries and Flow Batteries - Background and Limitations}

Batteries, in particular lithium-ion batteries and flow batteries, can be used in the transportation and electricity generation sector to displace a large amount of fossil fuels, and are already being used in some applications. However, in order to implement widespread use of batteries in these areas and achieve a substantial reduction in the use of fossil fuels, significant advancements in batteries are needed. In order to understand how 
lithium-ion batteries and flow batteries can be improved, a thorough explanation of their background and limitations is needed.

\section{Lithium-ion Batteries Background}

A schematic of the lithium-ion battery operation is given in Figure 1.3. The negative electrode on the left consists of a graphitic carbon, and the positive electrode on the right consists of a lithium metal oxide, such as $\mathrm{LiCoO}_{2}, \mathrm{LiMn}_{2} \mathrm{O}_{4}$, or $\mathrm{LiFePO}_{4}$. The electrolyte is a lithium salt, typically $\mathrm{LiPF}_{6}$, dissolved in a combination of alkyl carbonate solvents. The following three equations describe the reactions at the two electrodes and the overall combined reaction for a generic lithium-ion cell where $\mathrm{MO}_{2}$ can be a number of metal oxides:

Negative Electrode

$\mathrm{Li} \underset{\text { Discharge }}{\stackrel{\text { Charge }}{\rightleftarrows}} \mathrm{Li}^{+}+\mathrm{e}^{-}$

Equation 1.1

Positive Electrode

$\mathrm{LiMO}_{2} \underset{\text { Discharge }}{\stackrel{\text { Charge }}{\rightleftarrows}} \mathrm{e}^{-}+\mathrm{Li}^{+}+\mathrm{MO}_{2}$

Equation 1.2

Overall

$$
\mathrm{Li}+\mathrm{MO}_{2} \rightarrow \mathrm{LiMO}_{2}
$$

Equation 1.3 


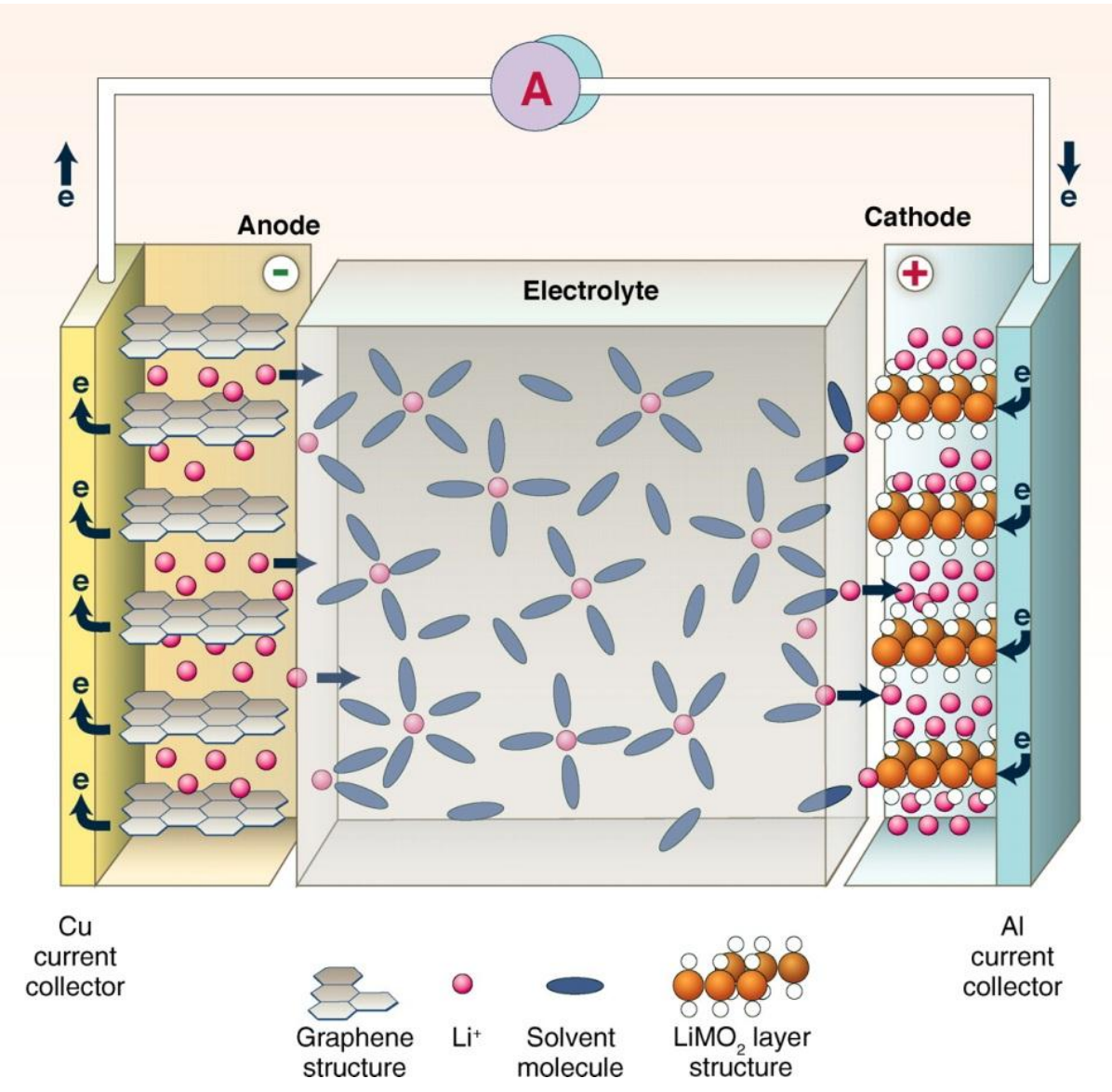

Figure 1.3 Illustration of how a lithium-ion cell works when discharging. ${ }^{10}$

Lithium-ion batteries are built in the discharged state with graphite on the negative current collector and the lithium metal oxide on the positive electrode. When charging the cell, a voltage potential is placed across the two electrodes of the cell and the lithium metal oxide reacts at the surface of the electrode to form a lithium ion in solution and an electron as in Equation 1.2. In order to balance the electrolyte a lithium ion at the negative electrode simultaneously "reacts" or intercalates into the carbon as in Equation 1.1. Pure graphite consists of a stack of graphene sheets that are alternately offset as shown in Figure 1.4 on the left. In the intercalation process, the lithium ion enters between the graphene layers. To balance the charge of the lithium ion, an electron 
enters into the graphene structure, and the graphene layers are aligned to make room for the lithium ion in the center of the carbon rings as shown in Figure 1.4 on the right. In order for these reactions to occur ions travel through the electrolyte and electrons travel through the charge circuit to balance the charge and form current. The battery is fully charged when all of the lithium metal oxide has reacted. The discharge process is the reverse of the charge process, but occurs spontaneously when the load circuit is connected.

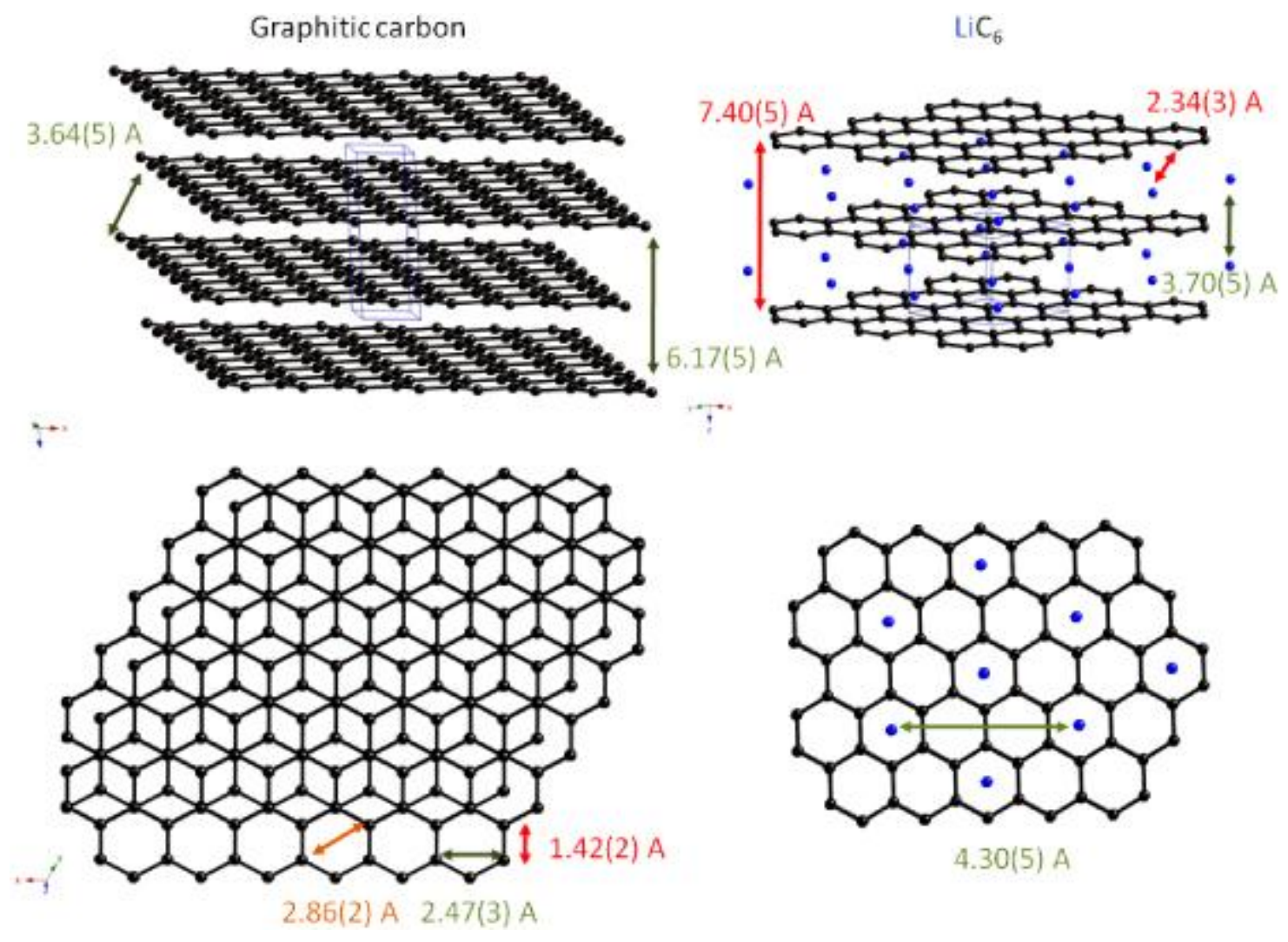

Figure 1.4 The structure of pure graphite layers (left) and graphite intercalated with Li ions (right). ${ }^{19}$ 


\section{Lithium-ion Batteries Limitations}

When a charged battery is at rest an equilibrium potential or open-circuit potential exists between the electrodes. In an ideal battery, the voltage would stay at the equilibrium potential throughout the discharge until all of the active material reacted, at which point the voltage would drop to zero. In a practical battery however, this is not the case; during discharge, the cell drops below the open-circuit potential. The difference between the open-circuit voltage and the discharge voltage is the cell overpotential or cell polarization. The overpotential is the voltage that is lost to overcome the internal resistance of the battery. As seen in Figure 1.5, the cell overpotential can be broken up into three main parts: activation overpotential, ohmic overpotential, and concentration overpotential. The activation overpotential, also known as kinetic overpotential or charge-transfer overpotential, is the potential required to overcome the activation energy for the electrochemical reaction to occur. The ohmic overpotential is the potential required to conduct ions through the electrolyte and to conduct electrons through the electrodes internally, and the concentration overpotential is the potential required to increase ion transport.

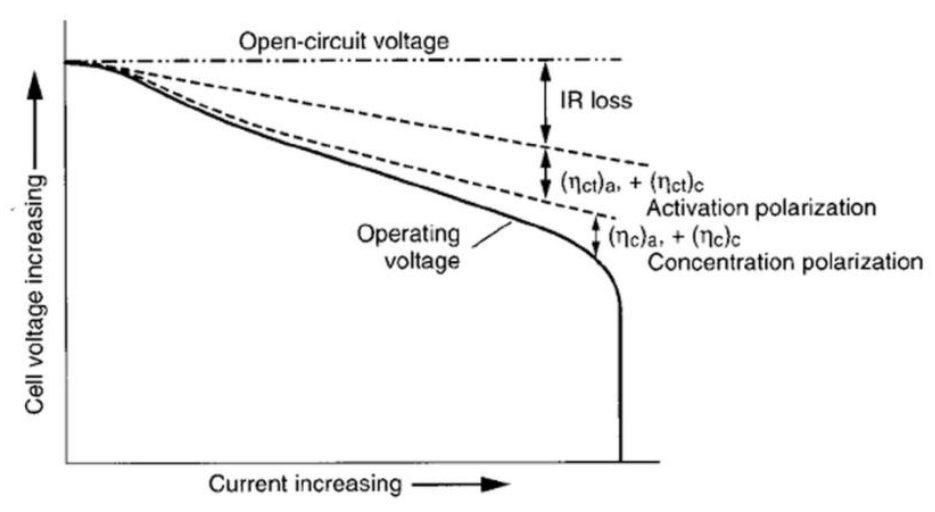

Figure 1.5 Cell polarization as a function of operating current. ${ }^{20}$ 
In time these overpotentials increase to a point where the cell voltage drops below a useful level marking the end of discharge. In an ideal battery with no overpotentials the battery would discharge until all of the active material is used up, but this cannot be achieved in practice. The overpotentials cause the discharge to end prematurely, leading to a decreased utilization of the cell.

A cutaway illustration of a typical spiral-wound cylindrical lithium-ion cell is given in Figure 1.6. Negative and positive electrodes on foil current collectors are wound in a spiral with a separator between them. The spirally wound electrodes and separator are placed in a canister and saturated with electrolyte. The electrolyte is stagnant, so large concentration overpotentials caused by diffusion limitations in the cell lead to lower than ideal capacity of the cell. To minimize the concentration overpotentials in the cell, the electrodes and separator are made as thin as possible to minimize the diffusion distance in the cell. This leads to an increase in the total amount of current collector and separator materials, which ultimately results in higher materials and manufacturing costs. 


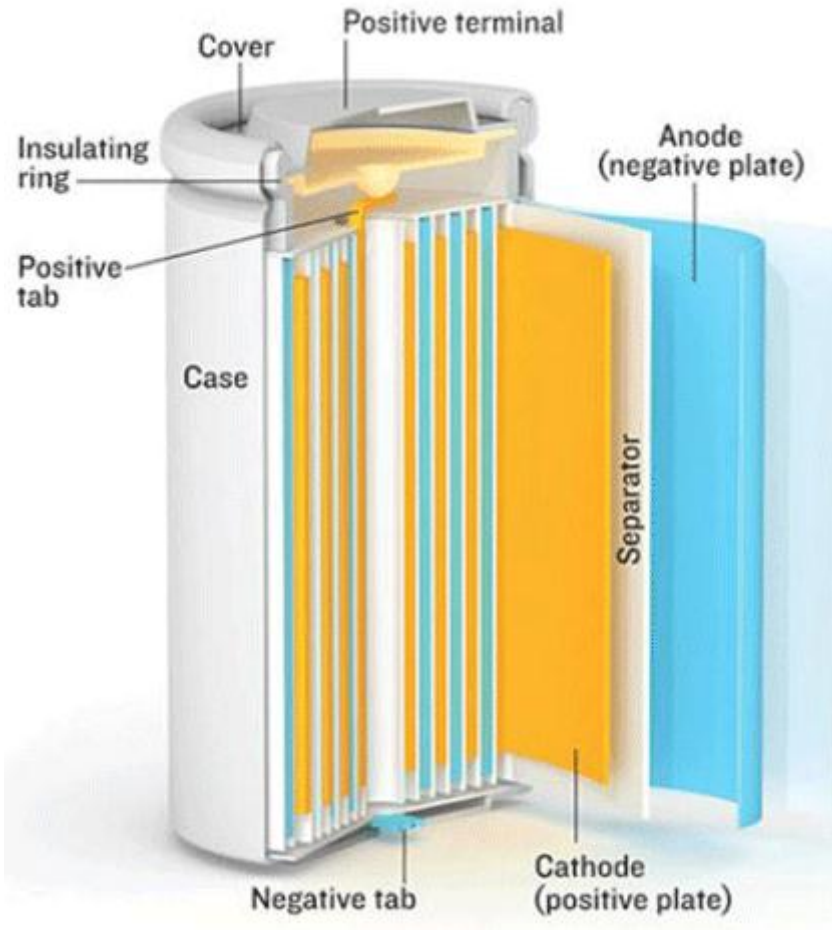

Figure 1.6 The construction of a typical spiral-wound cylindrical lithium-ion cell. ${ }^{21}$

Another reason for the thinner electrodes, in addition to the loss in realized capacity, is that the concentration overpotentials create non-uniform current distributions in the electrodes that lead to side reactions which cause irreversible capacity losses by reducing the amount of total active material. ${ }^{22}$ The concentration gradients and nonuniformity in potential is amplified by using thicker electrodes. This phenomenon is different than the loss of utilized capacity caused by dropping below the cutoff voltage, because it is not an irreversible loss.

If the concentration overpotentials could be reduced in the cell, more of the theoretical capacity in the active material could be utilized, and furthermore, thicker electrodes could be used to decrease the materials and manufacturing costs. This would 
make lithium-ion batteries much more appealing for transportation and grid storage applications.

Another issue that needs to be addressed is the safety of lithium-ion batteries. Because of the highly-reactive nature of lithium, thermal-runaway reactions can occur that lead to fire or explosion of the cell. Different strategies have being used to address this risk, such as using separators with thermal shutdown, ${ }^{23-25}$ but there is always still some danger.

\section{Flow Batteries Background}

A flow battery is traditionally characterized as one or more electrochemical cells in which all of the electroactive species in one or more of the half-cells is dissolved in the electrolyte, which is circulated through the cells. The flow is typically parallel to the inert electrodes, and electrolyte is stored in external tanks as shown in Figure 1.7. An ion selective membrane separates the electrolyte and allows common ion transfer to balance the electrolyte charge.

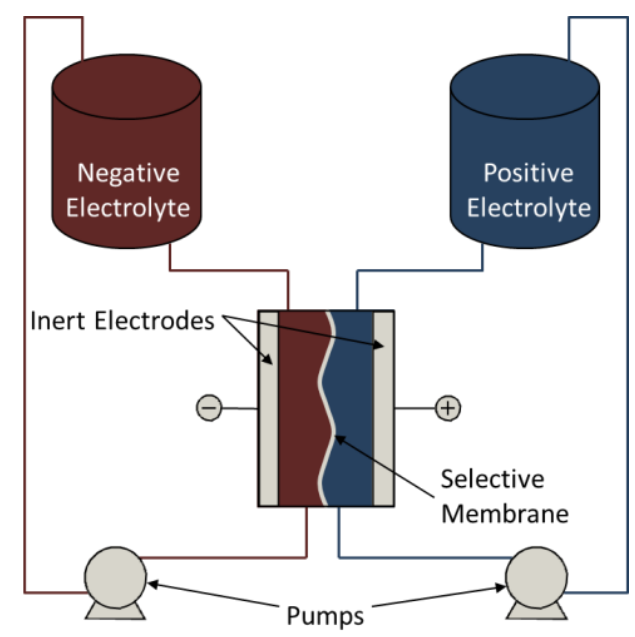

Figure 1.7 Schematic of a redox flow battery. 
There are mainly two types of flow batteries: redox flow batteries, in which the electroactive species associated with both of the electrodes are dissolved in the electrolyte, and hybrid flow batteries, in which one or more of the electroactive species are in the solid phase. ${ }^{26}$ Examples of redox flow batteries include the all vanadium flow battery ${ }^{20,27,28}$, the vanadium/polyhalide or vanadium/bromine flow battery ${ }^{29-31}$, the iron/chromium flow battery ${ }^{29,32}$, and the bromine/polysulfide flow battery ${ }^{29,33}$. Examples of hybrid redox flow batteries are the zinc/bromine flow battery ${ }^{20,29}$, the zinc-cerium flow battery $^{29}$, and the soluble lead-acid flow battery ${ }^{29,34}$.

Multiple cells can be added together in series using bipolar electrodes in series as shown in Figure 1.8. With bipolar electrodes, one side is the cathode for a cell, and the opposite side is the anode for the next cell in series. In flow cells the bipolar electrodes are typically plastics with impregnated carbon to make them conductive yet resistant to corrosion from the electrolytes.

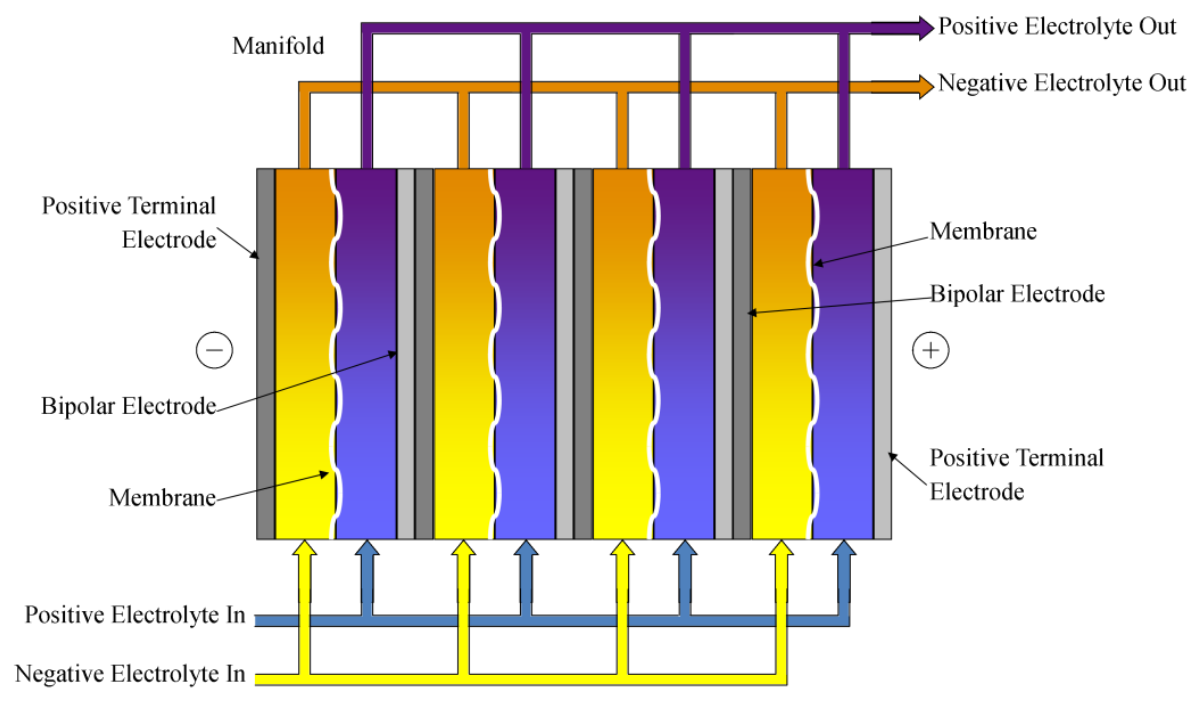

Figure 1.8 A multi-cell flow battery. 
The main advantage of the flow battery is its ability to decouple the energy and power of the battery when designing the system. In batteries with solid electrodes the energy and power are related to the mass and surface area of the active material respectively. Therefore the two properties are inherently related. The energy in the flow battery can be increased by increasing the amount of electrolyte in the system, and the power can be controlled independently by changing the surface area of the electrodes. This is illustrated in Figure 1.9. This is not possible in the hybrid-flow battery though, because it is limited by the one solid electrode.

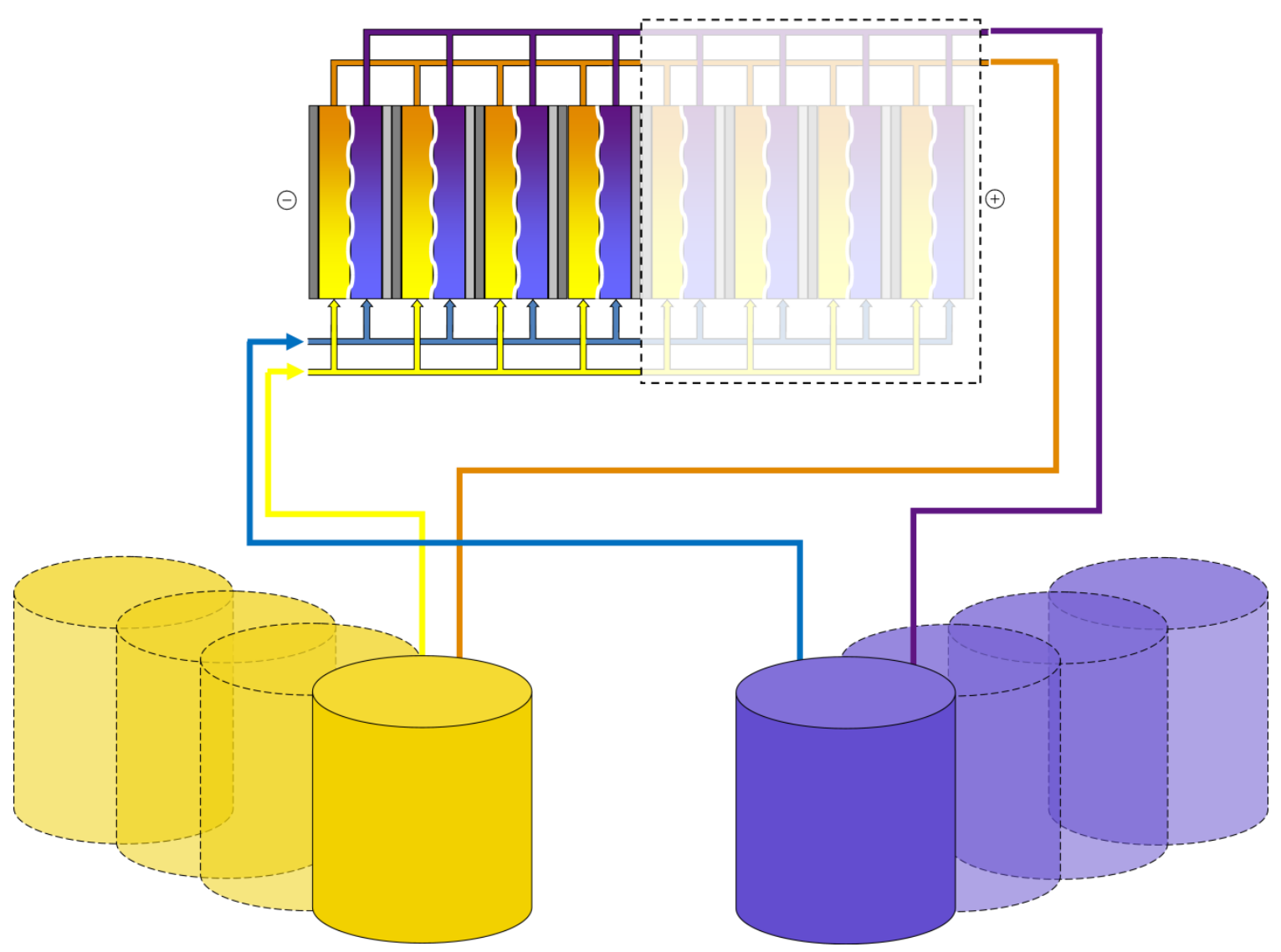

Figure 1.9 An illustration of how the flow cell can be expanded with additional tanks (dashed) to increase the energy or by expanding the cell stack (inside dashed square) to increase the power. 
In battery chemistries with solid active materials, uneven charging of cells can cause premature cell failure, possibly leading to safety issues. However, in flow batteries, the electrolyte in the cells is connected hydraulically in parallel and mixed together as seen in Figure 1.8, which prevents uneven charging. Because of the flow, the electrolyte concentration in each cell is similar. Therefore, there are very small voltage differences, and there are no "memory" effects between cells. Memory effects on charging occur in normal battery packs because if one cell is slightly overcharged compared to the rest of the cells in the battery, then the performance of that cell will be diminished compared to the rest because of chemical changes that are specific to that cell. To mitigate problems caused by this phenomenon in normal cells, special circuits may be required to control each cell individually. In contrast a redox flow cell does not need individual cell control because there are no chemical changes to the electrodes. If one cell is charged at a higher rate than the rest there are no permanent effects because the electrolyte is shared by all of the cells. Hybrid flow batteries however, do have memory effects between cells. This is due to uneven charging caused by the nonhomogeneous reactions that occur on one of the electrodes.

All of the electroactive species in redox flow batteries are dissolved in the electrolyte, which gives the redox flow battery the advantages of long cycle lifetimes. In batteries with solid electroactive materials the redox reactions are heterogeneous which often cause a variety of interfacial phenomena. Since the reactions of the redox flow batteries are in the solution phase then the cycle life is not hindered as in other batteries. Typical flow batteries can be run for over 10,000 cycles. A 6 MWh vanadium redox flow battery facility in Japan ran for over 270,000 short cycles. ${ }^{35}$ 


\section{Flow Battery Limitations}

One of the drawbacks of flow batteries is that they suffer from low energy densities and specific energies. The all-vanadium redox flow batteries that have successfully been commercialized have energy densities between 15 and $25 \mathrm{Wh} / \mathrm{L}$ and specific energies between 20 and $35 \mathrm{Wh} / \mathrm{kg},{ }^{30}$ whereas commercial lithium batteries have energy densities that range from 118 to $640 \mathrm{Wh} / \mathrm{L}$ and specific energies from 61 to 219 $\mathrm{Wh} / \mathrm{kg}{ }^{20}$

Another disadvantage of flow batteries is that the redox species in the electrolyte must be kept separate by a selective membrane. This adds to the manufacturing costs of the cell and introduces the potential for leakage current due to the mixing of electrolyte. Also back mixing of the electrolyte can occur. ${ }^{29}$ This is when electrolyte with depleted reactants is circulated back to the reservoir, thus lowering the overall concentration of reactants in the electrolyte and the cell potential. This could potentially be avoided by using two separate tanks for each electrolyte; one for the charged electrolyte and one for the discharged electrolyte.

Also shunt, leakage, or bypass currents contribute to self-discharge in flow batteries. Shunt currents are capacitive non-faradaic currents in batteries. Shunt currents occur when a single electrolyte mixture is pumped through several half cells that are electrically connected in series, but hydraulically connected in parallel as shown in Figure 1.8. Significant amounts of current can flow because of the large voltage differences in most flow battery stacks. These shunt currents also lead to uneven plating in hybrid flow batteries. The shunt currents can be minimized by decreasing the pipe size 
between cells, but this increases required pumping power. Another method is to pump the electrolyte in series through the half cells like in Figure 1.10.

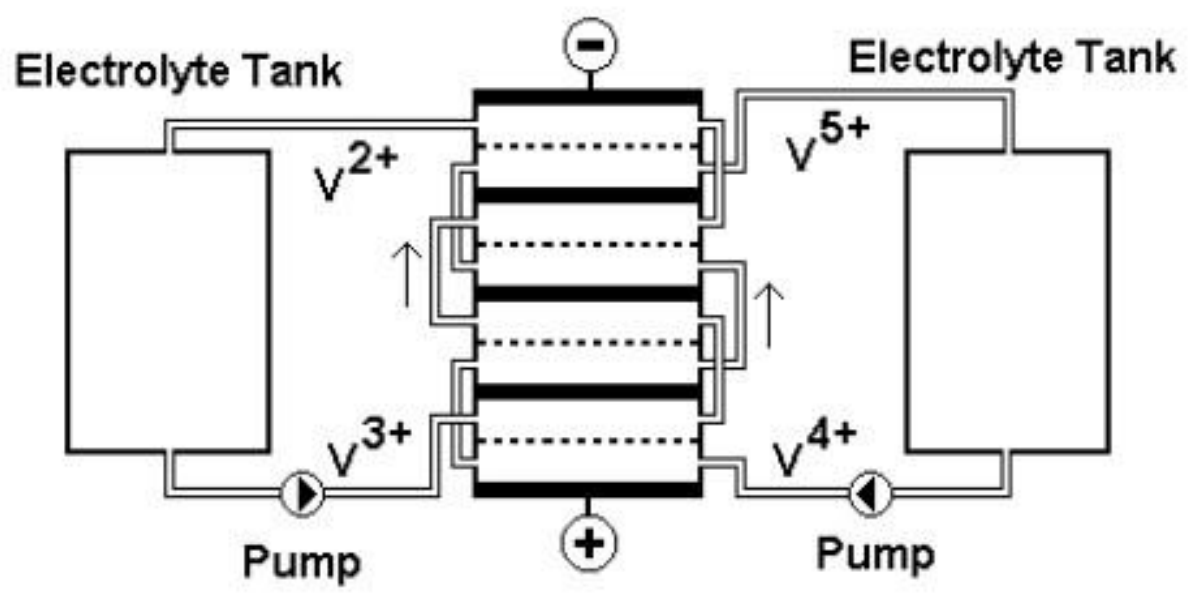

Figure 1.10 Series flow in a vanadium flow battery.

The vanadium redox flow battery and the zinc/bromine flow battery are basically the only commercialized flow batteries. Because of the limited power density, they are only used in a few electric utility applications for load leveling of intermittent renewable energy sources and shaving of peak loads. It has been suggested that flow batteries could be used for transportation purposes with rapid refueling of spent electrolyte, ${ }^{36}$ but this and more widespread grid applications would only be possible if breakthroughs are made in flow batteries.

\section{Convection Batteries}

The Suppes group at the University of Missouri is working on a new type of cell design, termed a convection cell or convection battery, which is aimed at overcoming the limitations of batteries in transportation and large-scale-energy storage applications. ${ }^{37-42}$ 
In the convection cell, electrolyte from a reservoir is circulated directly through the porous electrodes and separator, as pictured in Figure 1.11, to decrease diffusion or concentration overpotentials. By doing this, the convection cell has the potential to outperform lithium-ion cells and flow cells in transportation and large-scale electrical energy storage applications.

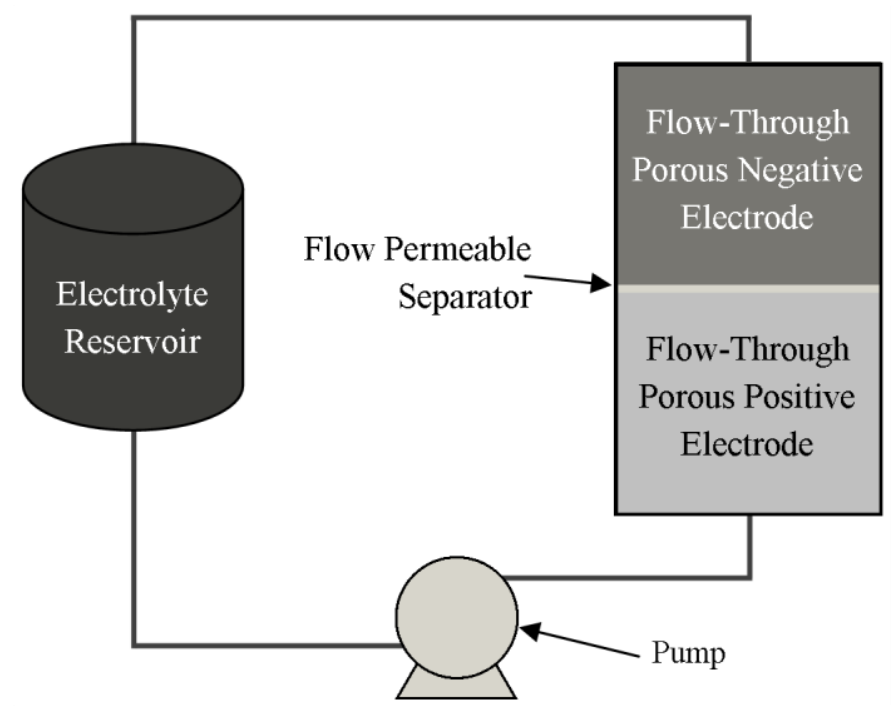

Figure 1.11 Convection cell schematic

Both the convection cells and flow cells utilize electrolyte flow, but beyond that they are substantially different. The fundamental difference between the two is that the chemistries are inherently different; a single-electrolyte chemistry with solid electrodes must be used in the convection cell, while a flow cell uses a two-electrolyte chemistry in which all of the electroactive species for one or both electrodes are dissolved in the electrolyte. Accordingly, different separators are required in flow cells and convection cells.

Flow cells require an ion-selective membrane to keep the two electrolytes separate while allowing specific ions to pass in order to balance the charge in the cell. In 
contrast, with a single electrolyte in a convection cell, a simple non-conductive separator that is permeable to flow is sufficient for the cell operation. Consequently, the flow patterns are different as indicated in Figure 1.12. In a flow battery either flow-through or flow-by electrodes can be used in the cell, ${ }^{43}$ but flow cannot cross the separator in either configuration, so while concentration overpotentials in the electrodes are minimized due to flow, large concentration overpotentials can occur in the separator. In the convection cell configuration, flow-through electrodes are used in conjunction with flow-through separators to directly reduce concentration overpotentials in both the electrodes and the separator.
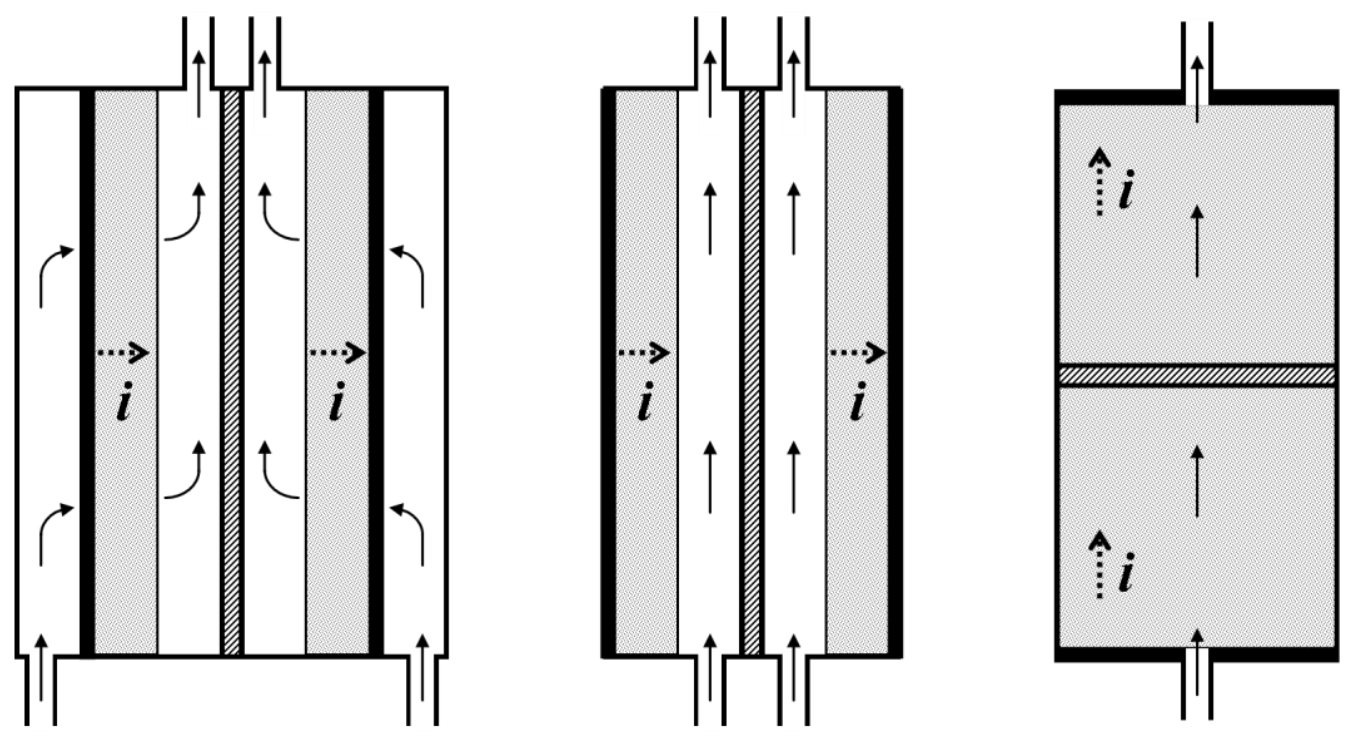

Figure 1.12 Flow patterns for flow-through electrodes (left), flow-by electrodes (middle), and convection cell flow-through electrodes (right). The grey areas are electrodes, the thick edges of the electrodes are the current collectors, the hatched areas are separators, the dotted arrows indicate the direction of current, and the electrolyte flow direction is shown by the solid arrows. 
The convection cell is essentially a diffusion-based cell with an added reservoir and pump to circulate electrolyte through the cell. As in a diffusion-based cell, both electrodes are solid in the convection cell and a single electrolyte is used. This means that the convection cell is compatible with many of the chemistries already used in diffusion-based cells such as lithium-ion chemistries. When the convection battery is understood sufficiently, new and improved chemistries could be easily incorporated into the convection cell configuration.

When used in conjunction with the lithium-ion chemistry, the flow in the convection cell can decrease the concentration overpotentials that are created in conventional diffusion-based lithium-ion batteries to achieve increased performances. As discussed earlier, this can lead to the use of thicker electrodes, thicker separators, increased capacity utilization, increased cycle lifetime, and decreased costs for both materials and manufacturing. The use of thicker electrodes is recognized as a primary means to decrease the cost and weight of batteries by reducing the amount of separator and current collector materials utilized. ${ }^{44-46}$

This lithium-ion convection cell is the first of its kind. Recently hybrid ${ }^{47,48}$ and redox $^{49}$ lithium-ion flow batteries have been researched, but these suffer from the inherently low energy densities and other limitations of flow batteries as discussed earlier.

One other benefit of the convection cell is that thermal gradients in the cell can be easily managed with flow of electrolyte. Thermal gradients can be problematic in batteries, and even become hazardous as in lithium-ion batteries. This could be managed 
in convection cells by controlling the flow and having the ability to quickly drain the electrolyte or pump it full of suppressant chemicals in an emergency situation.

One drawback of the convection cell is that a pump is required, which detracts from the net energy and adds to the total weight of the cell. However, as the convection cell is scaled-up, it is believed that the increase in performance obtained with flow would outweigh the energy, weight, and capital costs associated with the pump.

The work presented in this dissertation has been done to develop a more fundamental knowledge of the convection cell, so that these benefits can be realized. The goal is to increase the understanding to a level at which an optimized cell could be created that would be able to be used in the applications discussed and drastically offset the usage of fossil fuels in the future. 


\section{CHAPTER 2}

\section{CELL DESIGN}

In the beginning stages of the convection cell research, the cell design was crude, making use of off-the-shelf components from the hardware store, but after many iterations, the convection cell has become much more sophisticated. Studying the progression of different designs can provide insight into the operation of the flow cell that can be used to improve future designs.

Before looking at the specifics of each cell design though, it is useful to understand the basic components and design criteria that are essential to making a convection cell work. Like in any battery, a convection cell must have positive and negative electrodes that are connected to a current collector. Furthermore, the electrodes need to be permeable to bulk flow and need to be physically contained, so that they are not eroded away by the electrolyte flow. In addition, a separator is needed between the electrodes that is permeable to bulk flow, is electrically non-conductive, and physically separates the electrode materials. The convection cell also requires inlet and outlet ports, tubing, and a pump. 


\section{Pump and Tubing Configurations}

Various types of pumps and tubing can be used with each cell design. However, for the research presented in this dissertation, Masterflex peristaltic pumps with Masterflex tubing were used. Specifically, a Masterflex L/S high-performance pump head (77250-62) mounted on a Masterflex L/S precision variable-speed drive (07528-30) was used with L/S 16HP (3.1 mm inner diameter) and L/S 17 (6.4 mm inner diameter) Norprene tubing.

The use of a peristaltic pump is convenient because it allows the cell to be fully assembled in a closed loop prior to attaching the pump. For moisture-sensitive chemistries, such as lithium-ion, this enables the cell to be fully assembled in a glove box and then removed and tested outside the glove box. Without this feature, the cell would require the pump to be transferred in and out of the glove box or the cell would have to be tested inside the glove box. Both of these options would be troublesome and testing cells inside the glove box's limited space would limit the number of cells that could be tested at once.

For the present work, the pump and tubing were connected using two different configurations. The first configuration used is the open-reservoir configuration, displayed in Figure 2.1. The tubing on both the inlet and the outlet of the cell is the 3.1 mm inner diameter L/S $16 \mathrm{HP}$ Norprene tubing. This configuration is used with $\mathrm{Zn} / \mathrm{MnO}_{2}$ convection cells because the cell materials are not moisture-sensitive. Additionally, the open reservoir is needed when using $\mathrm{Zn} / \mathrm{MnO}_{2}$ cells because side reactions generate hydrogen gas. This leads to a loss of electrolyte, and the gas can build pressure if not 
vented. Since some of the electrolyte is lost to side reactions during operation, there is a large excess of electrolyte in the reservoir keeps the pump primed, and the cell saturated.

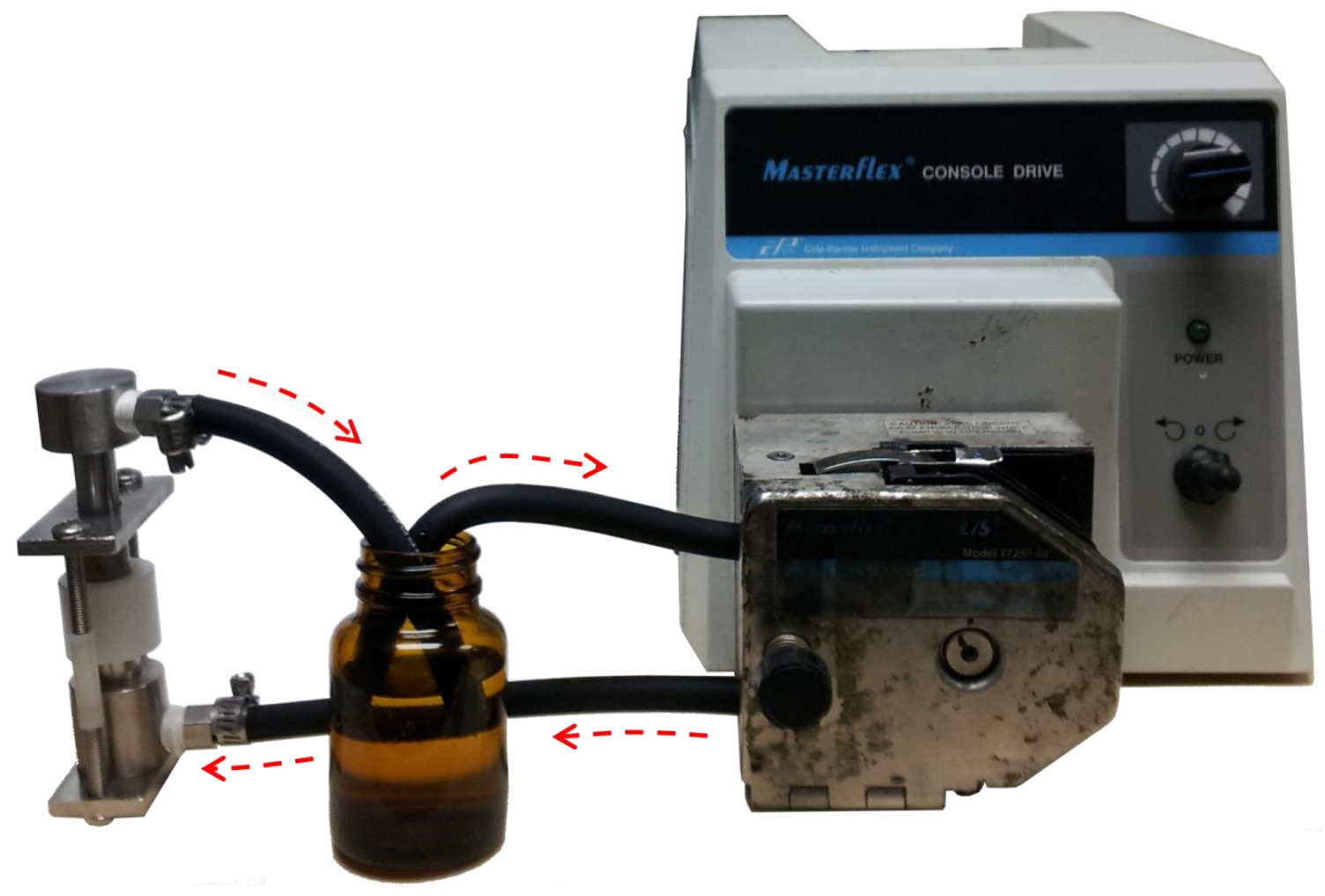

Figure 2.1 A fully assembled convection cell with an open-reservoir configuration for the tubing (shown with a generation 4.1 convection cell). The arrows indicate the direction of electrolyte flow.

The closed-reservoir configuration in Figure 2.2 is used for cells with lithium-based chemistries. In this configuration, $3.1 \mathrm{~mm}$ inner diameter L/S 16HP tubing is connected to the bottom port of the convection cell, and larger diameter L/S 17 tubing is used to seal over the ends of the glass reservoir. A barbed reducer below the reservoir is used to connect the larger diameter tubing to the small diameter high-pressure tubing. 
The glass reservoir is a $7 \mathrm{ml}$ Fisherbrand class A volumetric pipette with the ends cutoff, leaving about an inch of tubing on either side of the bulb to connect with the tubing.

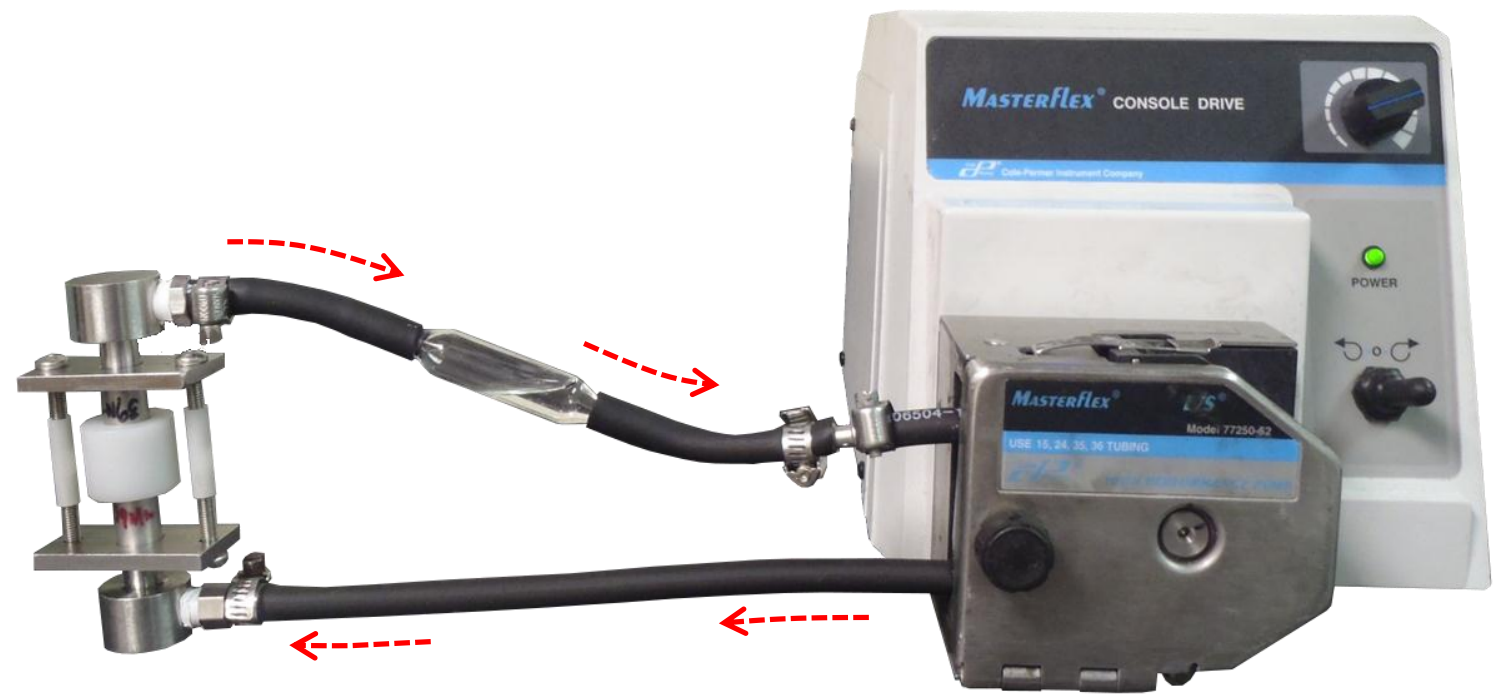

Figure 2.2 A fully assembled convection cell with a closed-reservoir configuration (shown with a generation 5.1 convection cell). The arrows indicate the direction of electrolyte flow.

The closed-reservoir is necessary with lithium-based chemistries because of the reactivity of the lithium and organic electrolytes with water. Moreover, the organic electrolytes used in lithium batteries are very expensive, so this configuration can be used with smaller amounts of electrolyte to save on experimental costs. The tubing itself could potentially act as the reservoir without the glass one, but the glass reservoir is also a convenient "window" to verify the electrolyte flow and note any visual changes in the electrolyte. 


\section{Generation 1}

The original convection cell design, generation 1, with packed-bed electrodes is shown in Figure 2.3. It consists of two pieces of copper tubing that are separated by sections of rubber hose, which are held together with metal hose clamps. The copper electrode tubes serve as current collectors and are packed with granular electrode materials. The rubber tubes are packed with glass wool to insulate the electrode material and to keep them from being washed away by the electrolyte flow.

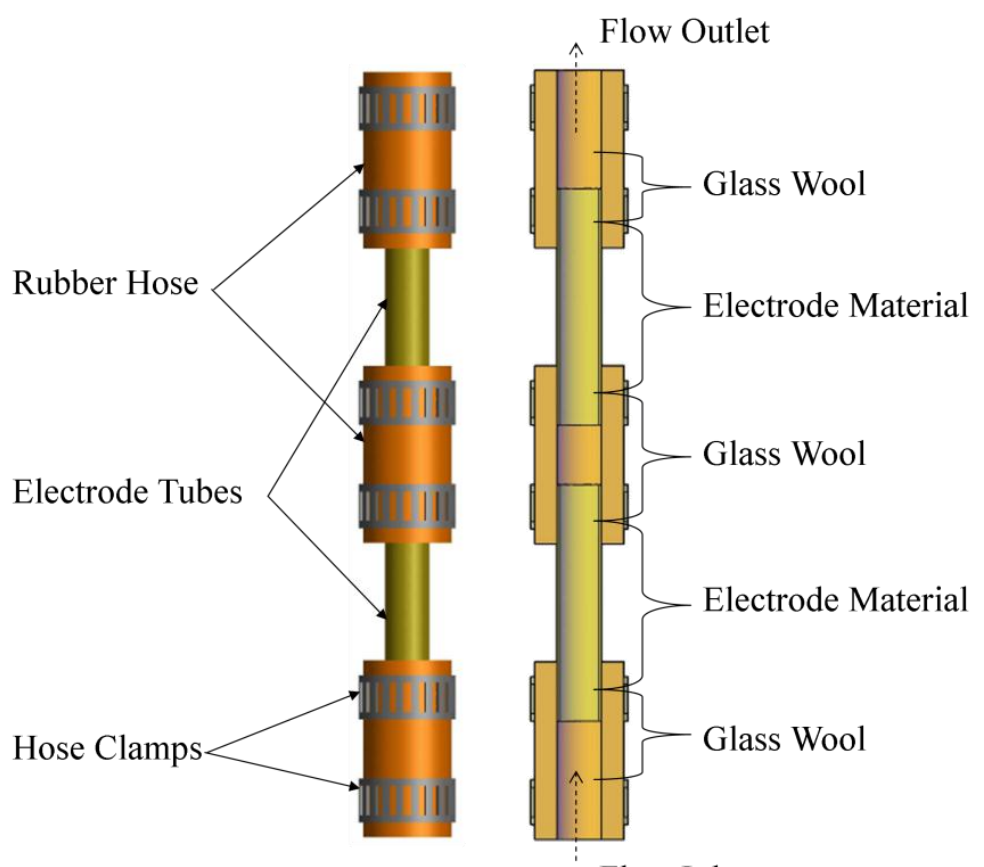

Flow Inlet

Figure 2.3 Initial convection cell design (generation 1).

This cell design was used with $\mathrm{Zn} / \mathrm{MnO}_{2}$ chemistry, with $\mathrm{Zn}$ granules packed in the negative electrode and $\mathrm{MnO}_{2}$ and carbon powder packed in the positive electrode. Aqueous $\mathrm{KOH}$ electrolyte was introduced into the cell and circulated using a Masterflex peristaltic pump. 
The data obtained from the original convection cell were sporadic. This was attributed to a lack of inter-particle connectivity through the cell, variability in the packing and thickness of the electrodes and separator, and the non-rigid nature of the cell. This design was short-lived before improvements were made in the next design iteration.

\section{Generation 2}

The generation 2 convection cell, shown in Figure 2.4, was used with the $\mathrm{Zn} / \mathrm{MnO}_{2}$ chemistry. It utilizes stainless steel pipe nipples connected together with plastic pipe fittings. The granular or powdered electrode materials are packed into the stainless steel fittings and glass wool is used on either side of the electrode materials to insulate and prevent mixing of the electrode material. Compression is applied to the electrode materials and glass wool packing through the compression cylinder by placing the cell under a small hydraulic press. 

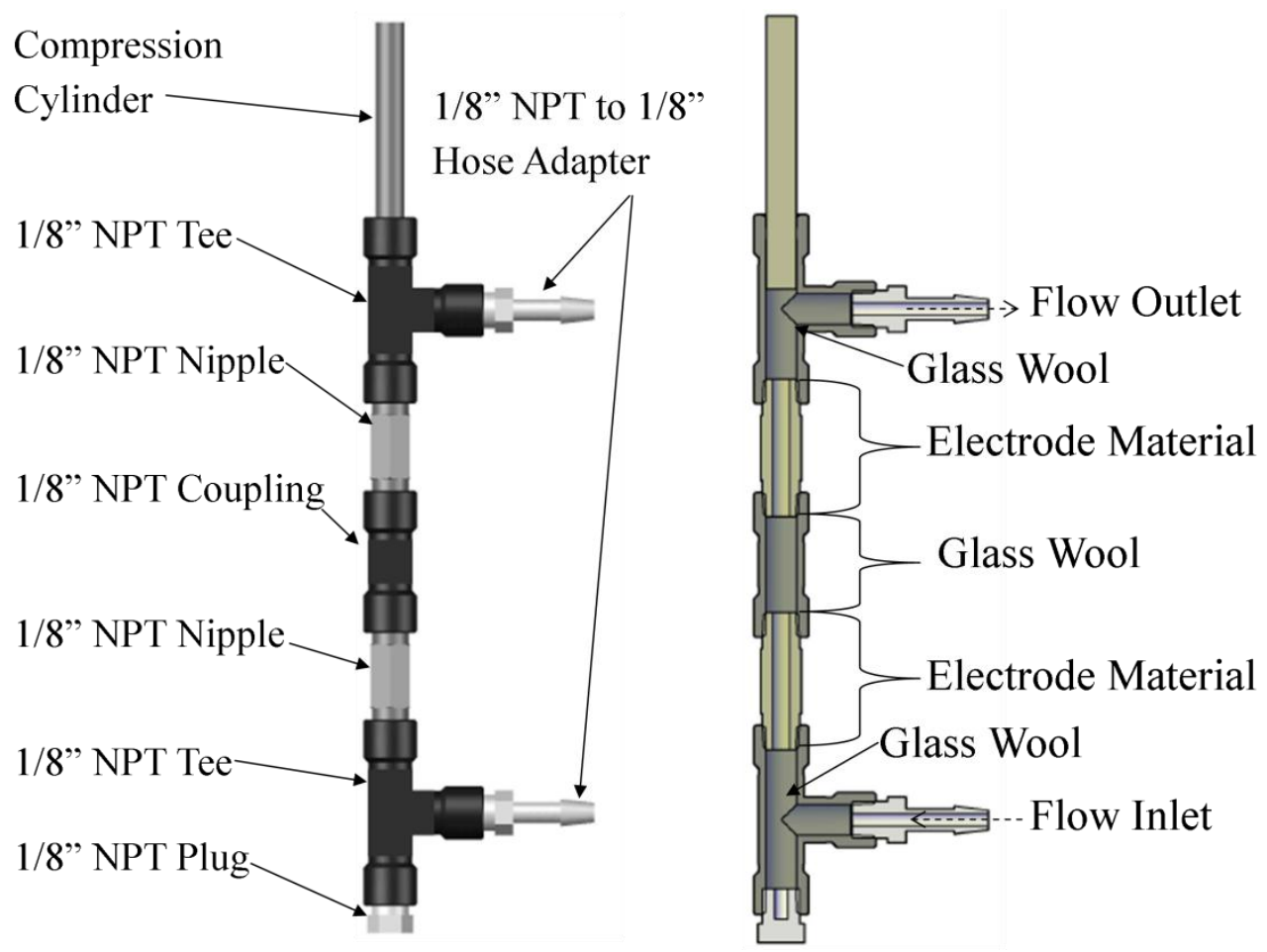

Figure 2.4 Generation 2 convection cell.

Use of fixed pipe fittings and side-entry ports for the electrolyte makes this design rigid and allows for compression of the electrode material. Because of the rigid design, this cell can be assembled in a much more repeatable fashion than the original convection cell. Also, flowing electrolyte through side ports allows for vertical compression to be applied to the electrodes, which improves connectivity between the particles.

This cell has several disadvantages though. First of all, a large amount of glass wool is required to fill the bottom tee, the separator coupling, and the top tee which adds variability to the cell. This is to keep the electrode packings in place and to keep the compression cylinder from blocking the outlet port. The glass wool must also be tightly packed to transmit the compression force from the top to the bottom of the cell. Unsurprisingly, the glass wool is not completely packed during the cell assembly, so it 
compacts down further when force is applied by the compression cylinder. This causes considerable variation in the height of the electrodes and in the separation of the cell. In general, glass wool as a separator or packing material creates ill-defined boundaries that inherently lack repeatability.

Another disadvantage of this cell is that there is an uneven pressure distribution through the cell when compression is applied. The cell wall is not smooth because of the nature of the pipe fittings as seen in Figure 2.4. This creates significant friction between the wall and glass wool. This prevents most of the compression force from reaching the bottom electrode. The hydraulic press used to apply pressure also contributes to variation with respect to the pressure in the cell. The press used for this cell has a 4 ton capacity, and the pressure applied to the cell is at the bottom end of the pressure range of this press. This makes it difficult to apply a repeatable force. The problem with getting a press with a smaller pressure range and tighter control is that a press of that nature is typically too small for the convection cell to fit under the press. Also, the packing of the cell can shift slightly during cell operation. This movement is translated in the press piston and results in loss of pressure. Ideally, free weights or regulated pneumatic pressure could be used to apply a constant force in a different cell design.

An additional issue with this cell is that the stainless steel nipples, i.e. the current collectors, have a poor connection to the electrodes. While pressure is applied vertically to the packing materials to increase inter-particle connectivity of the electrodes, it doesn't increase the connectivity between the electrode particles and the side walls of the pipe nipples that collect current. This causes a large ohmic overpotential that kills the cell performance. 
Finally, in the generation 2 cell there is no seal between the NPT (national pipe thread) tee on the top of the cell and the compression cylinder. Since the cell uses the open-reservoir configuration pictured in Figure 2.1, the outlet port is on the low-pressure end of the cell and at the highest point. Originally, it was assumed that the path of least resistance for the flow would be through the outlet port, so a seal would not be needed for the compression cylinder. However in practice a small portion of the electrolyte leaks through the top because the glass wool is packed into the horizontal part of the tee up to the hose barb adapter, which is enough resistance for some of the flow to be diverted out of the top of the tee. This can be overcome by placing the cell in a some kind of secondary containment and using enough excess electrolyte in the reservoir so that the total leakage of the cell operation is tolerable, but this is very messy and far from ideal.

\section{Generation 3}

The generation 3 convection cell, displayed in Figure 2.5, was the first custommachined convection cell. The dimensional drawings for this cell are in appendix A. The compression pistons and electrode bodies are 316 stainless steel (SS) and the pipe nipple and hose barb adapters are nylon. Current is collected through the compression pistons.

This cell was used with the $\mathrm{Zn} / \mathrm{MnO}_{2}$ chemistry; specifically it was used for some separator length studies. ${ }^{38}$ Potentially, this cell could also be used with lithium chemistries because it uses Buna-n O-rings on the compression pistons to make a closed cell design. 
Of the several significant features in this cell, the first is the use of separate bodies for the two electrodes. This enables it to be used for studying the effects of very large separation distances. The two electrode bodies are connected with a nylon pipe nipple, but the nipple can be replaced with a NPT hose barb adapter on each body with piece of hose connecting them. By using different lengths of hose the separation length can be varied from the length of the pipe nipple $(2.5 \mathrm{~cm})$ to an infinite (relatively speaking) length of hose.

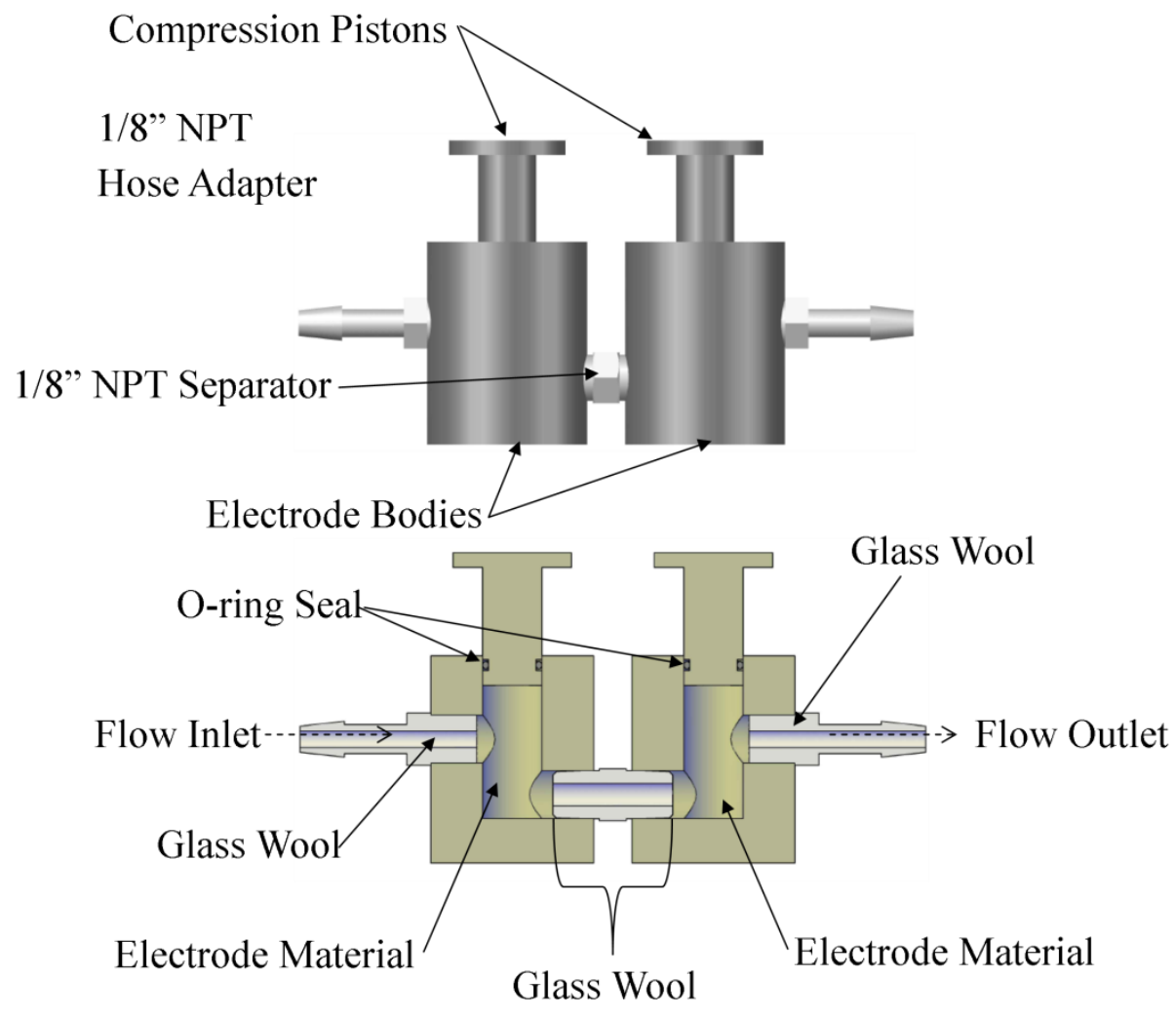

Figure 2.5 Fully assembled view (top) and cutaway view (bottom) of the generation 3 convection cell. 
The next feature of this cell is that the compression piston in each electrode body allows a separate force to be applied directly to each electrode. Plus the only resistance to the compression forces is the friction from the piston O-rings, which is minimal compared to the frictional resistances that are realized in the second generation cell. Since the friction is minimized, free weights can be used to accurately apply the compression force instead of the press, thereby increasing the overall repeatability of the cell results.

One problem with the compression though, is that glass wool is used to keep the electrode material in place at the inlet and outlet ports. This causes variations in cell packing as discussed in relation to the second generation cell. And moreover, these ports relieve some of the pressure within the packing material. Ideally the cell should be axis symmetric with smooth walls to apply pressure evenly throughout the cell.

A consequence caused by the location of the flow ports is that the flow pattern in this cell is non-ideal. The flow inlet and outlet have to be in the middle of the height of the cell so that the piston does not interfere with the cell and so the O-rings can seal properly. This leaves some electrode material above the inlet that probably doesn't have flow. This is problematic because air can get trapped in the top. Furthermore, there is most likely no flow in the electrode material just below the inlet and the outlet.

The last deficiency in this cell is the fact that the minimum separator distance is about $2.5 \mathrm{~cm}$. While this cell is good for studying large separation distances as discussed above, it is more advantageous to use separation distances below $2.5 \mathrm{~cm}$ because even if the flow eliminates concentration overpotential losses, the ohmic overpotential can still become an issue. 


\section{Generation 4.1}

The generation 4.1 convection cell, shown in Figure 2.6 and in Figure 2.1 connected to the pump, was used for studies with both $\mathrm{Zn} / \mathrm{MnO}_{2}{ }^{38,40}$ and $\mathrm{Li} / \mathrm{MnO}_{2}$ cells, and is characterized by a uniaxial closed-cell design. This cell provides a much more reliable and repeatable performance over previous designs.

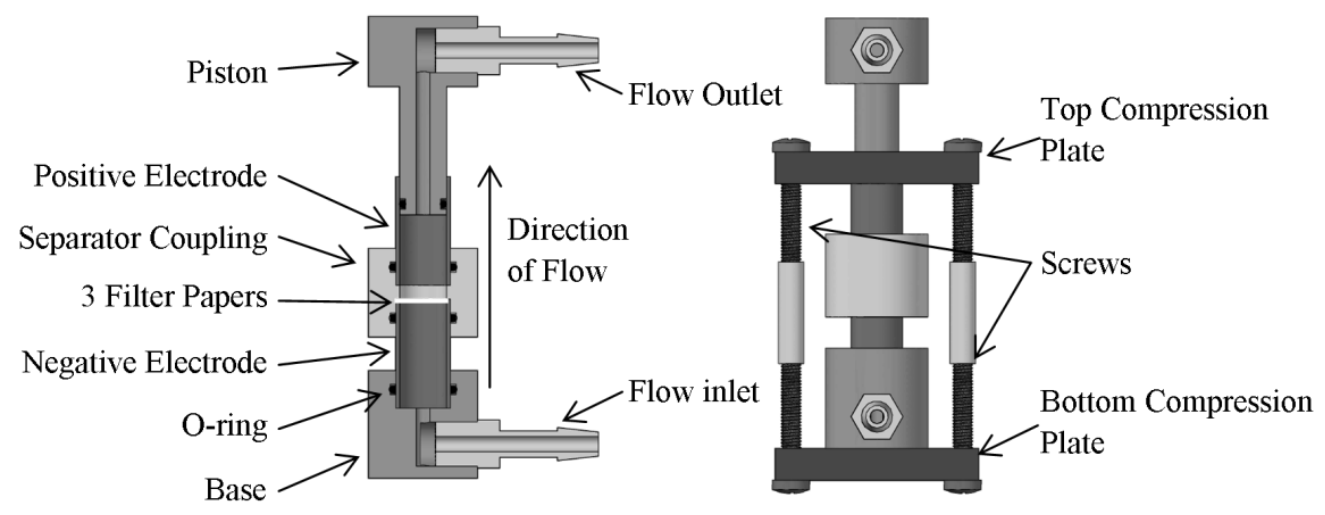

Figure 2.6 Cutaway side view (left) and fully assembled front view (right) of the generation 4.1 convection cell.

The base, electrode tubes, piston, and hose barbs are all $316 \mathrm{SS}$, and the separator is high-density polyethylene (HDPE). In the initial studies ${ }^{38,40}$ the piston was made from HDPE but it was later replaced with the more robust stainless steel version. The cell parts are sealed with O-rings, and the cell is connected to the external circuit through the electrode tubes or the pistons. Dimensional drawings for this cell are included in Appendix A.

In this cell, granular or powdered electrode material is packed into the entire length of the bottom electrode tube. Pieces of filter paper with a $12.7 \mathrm{~mm}$ diameter are used for the separator. A lip in the separator coupling ensures that the electrode tubes do not short. The filter paper is sandwiched between this lip and the bottom electrode tube. 
The two compression plates, held together by screws and two threaded nylon couplers, keep the electrode tubes in contact with the separator and the lip of the separator coupling without short circuiting the cell. The top electrode tube is only partially filled with electrode material because the O-ring on the piston needs sufficient room to seal to the inside of the electrode tube. However, the top electrode must also be filled enough to ensure that the electrode material extends above the separator coupling lip and makes sufficient contact with the electrode tube. A piece of $9.5 \mathrm{~mm}$ diameter filter paper is used between the base and the bottom electrode and between the piston and the top electrode to keep the electrode materials from being erode away by flow. Free weights on top of the piston apply force to the electrode materials inside the tubes, but no force is applied to the tubes themselves by the piston.

One benefit of the generation 4.1 convection cell is that the electrode height can be easily controlled in this configuration. The electrode tubes and the filter paper provide well-defined boundaries for the electrode materials, which is a significant advancement over the previous generations that utilized glass wool. The bottom electrode is fixed, but the top electrode can be varied because of the piston.

Another significant advantage of this configuration is that the flow pattern is straight through the cell and perpendicular to the separator. This maximizes the benefit of flow. The only possible drawback is that because the electrolyte enters and exits through a small hole in the center of the base and piston respectively, the velocity profile may not be fully developed near the electrode tube wall at the entry and exit ports. However, because a low flow rate is used in the convection cell, the effects of this should be minimized. 
One drawback of this cell is that the bottom electrode is fixed. The only way to vary it is to make different sized electrode tubes, but this is difficult and would not work for thin electrodes. In addition, if the bottom electrode material is not packed tight enough, the force from the piston through the top electrode will push the separator into the bottom electrode. The separator can flex to an extent, but if there is too much movement, the separator will be compromised, and the cell will short.

Another issue is that ability to vary the thickness of the top electrode is limited. Because the electrode material must extend above the separator coupling lip, thin electrodes can't be used.

\section{Generation 4.2}

An illustration of the generation 4.2 convection cell is given in Figure 2.7. This cell is the same as the generation 4.1 cell, but with an added separator coupling, filter paper, and tube so that different separator materials and lengths can be studied. This allows the middle section between the filter paper separators to be filled with material that can affect the cell performance, such as ion-exchange resins (IXR). One study was done on effects of IXR in the separator of $\mathrm{Zn} / \mathrm{MnO}_{2}$ using this cell. ${ }^{40}$ In the future, additional couplings and tubes could be added to this cell with alternating electrodes to make a multi-cell convection battery with a common electrolyte. 

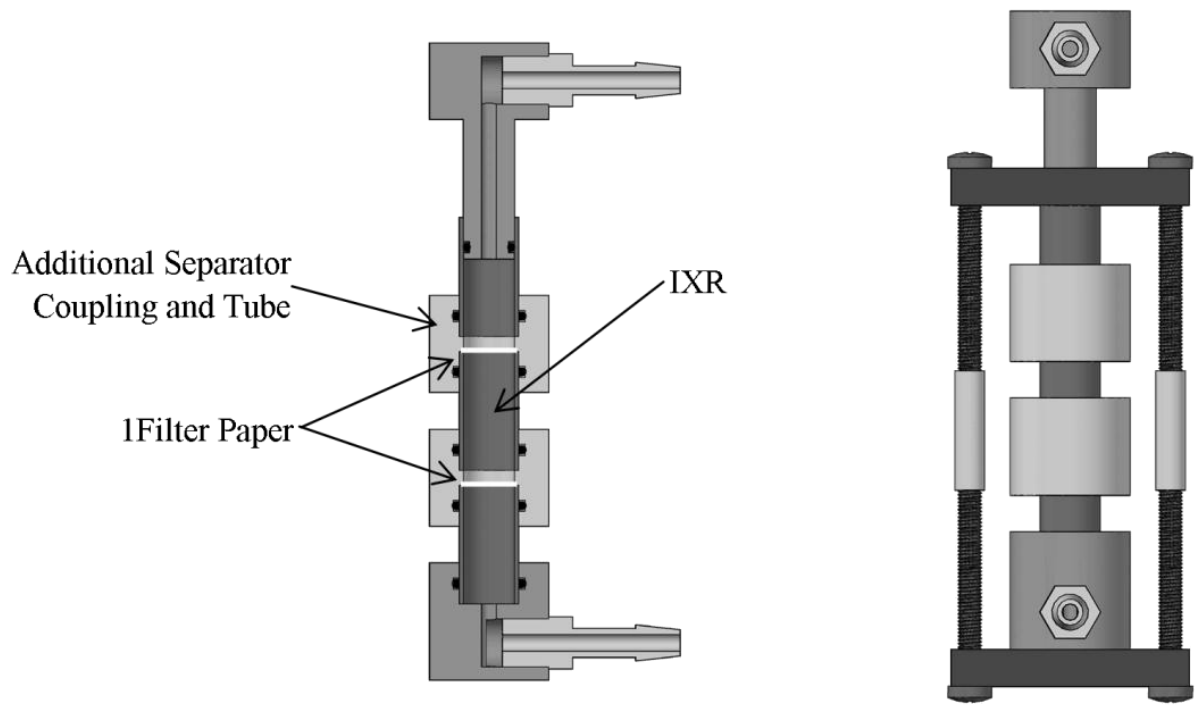

Figure 2.7 Cutaway side view (left) and fully assembled front view (right) of the generation 4.2 convection cell with IXR.

\section{Generation 5.1}

The generation 5.1 convection cell solves the issues associated with the fixed electrode and the separator coupling lip in the fourth generation cells. As seen in Figure 2.8 and in the photo of the fully assembled system in Figure 2.2, dual pistons are used to enable each electrode length to be varied independently. Additionally, there is no lip on the separator coupling so that thinner electrodes can be used. Detailed dimensional drawings for this cell can be found in appendix A. 


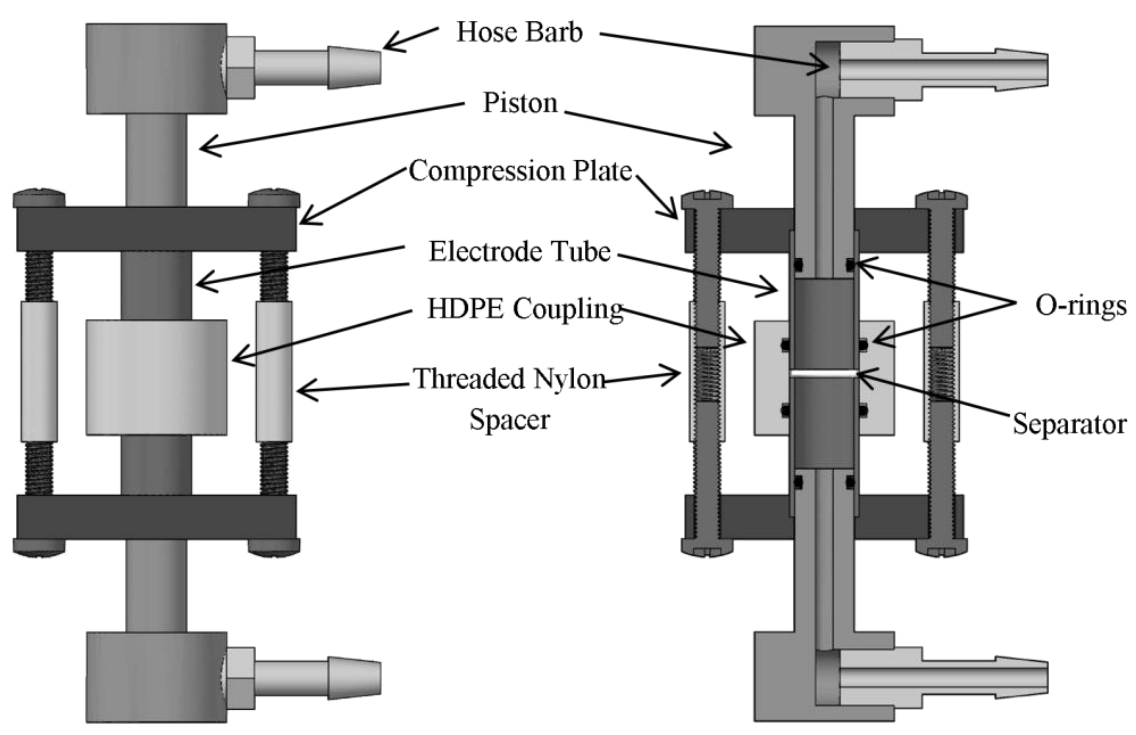

Figure 2.8 The generation 5.1 convection battery and drying piston. Front view (left), rotated cutaway view (right), and cutaway view of the drying piston (center).

This cell is also the first convection cell to be designed for use with solid electrodes as opposed to granular or powder electrodes. The solid electrodes are made by casting an electrode paste into the electrode tube and piston assembly (shown in Figure 2.9). The paste consists of the electrode powders or granules, binder, and solvent. In the electrode and piston assembly, the drying piston is the same length as the electrode tube so that when the piston is inserted into the electrode tube the two parts are flush at the top. Adding washers between the electrode tube and the shoulder of the piston causes the electrode tube to extend above the piston by the thickness of the washers. The electrode paste is then cast into the tube and scraped flush with the top so that the electrode thickness is precisely equal to the thickness of the washers. Prior to casting the electrode a piece of Teflon sheet is placed on the piston to keep the electrode from sticking to it. The electrode assemble is then dried in a vacuum oven or on a hot plate and a solid 
porous electrode is formed. The piston is then removed and a solid electrode remains that is flush with the top of the electrode. This is then inserted into the cell with the electrode end towards the separator, and the cell piston is compresses against the back end of the electrode inside the tube. Casting the electrode in the same tube that is used in the cell is convenient because this ensures that channeling of the electrolyte flow between the cell wall and the electrode is minimized.
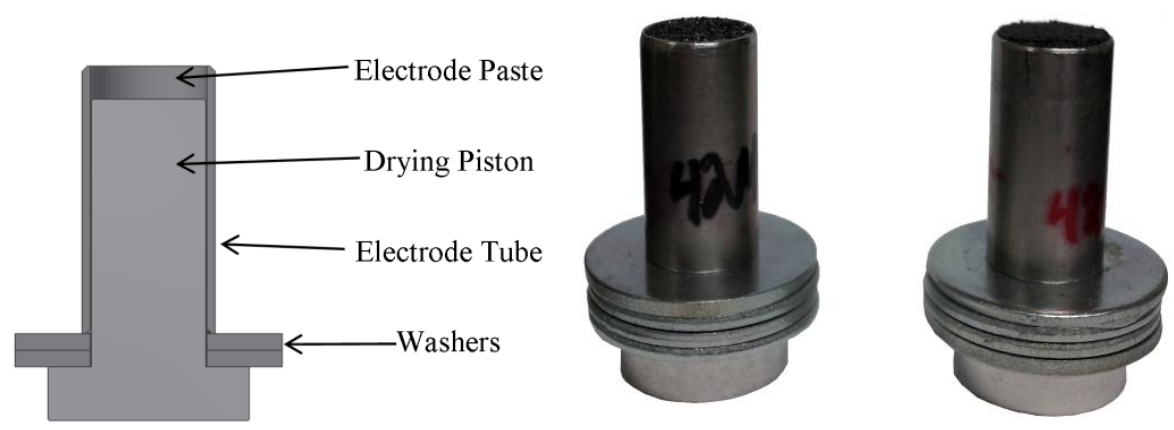

Figure 2.9 A diagram of the electrode tube and piston assembly (left) and photo of some $\mathrm{LiFePO}_{4}$ and graphite electrodes cast in the electrode tube assembly (right).

\section{Generation 5.2}

The principal difference between the generation 5.1 and 5.2 convection cells is the separator coupling and electrode tubes. The generation 5.2 convection cell, displayed in Figure 2.10, has ports in the separator coupling and electrode tubes to allow for eight different lithium reference electrodes to be used in the cell. They are rotated around the cell spaced 45 increments, and are spaced every one millimeter from the center of the cell. The separator coupling and the electrode tubes are made out of Teflon. As with the previous cells, detailed drawings are in Appendix A. This cell design is discussed in 
further detail in chapter 7, but is also included here so the reader can see the full progression of convection cell design. .

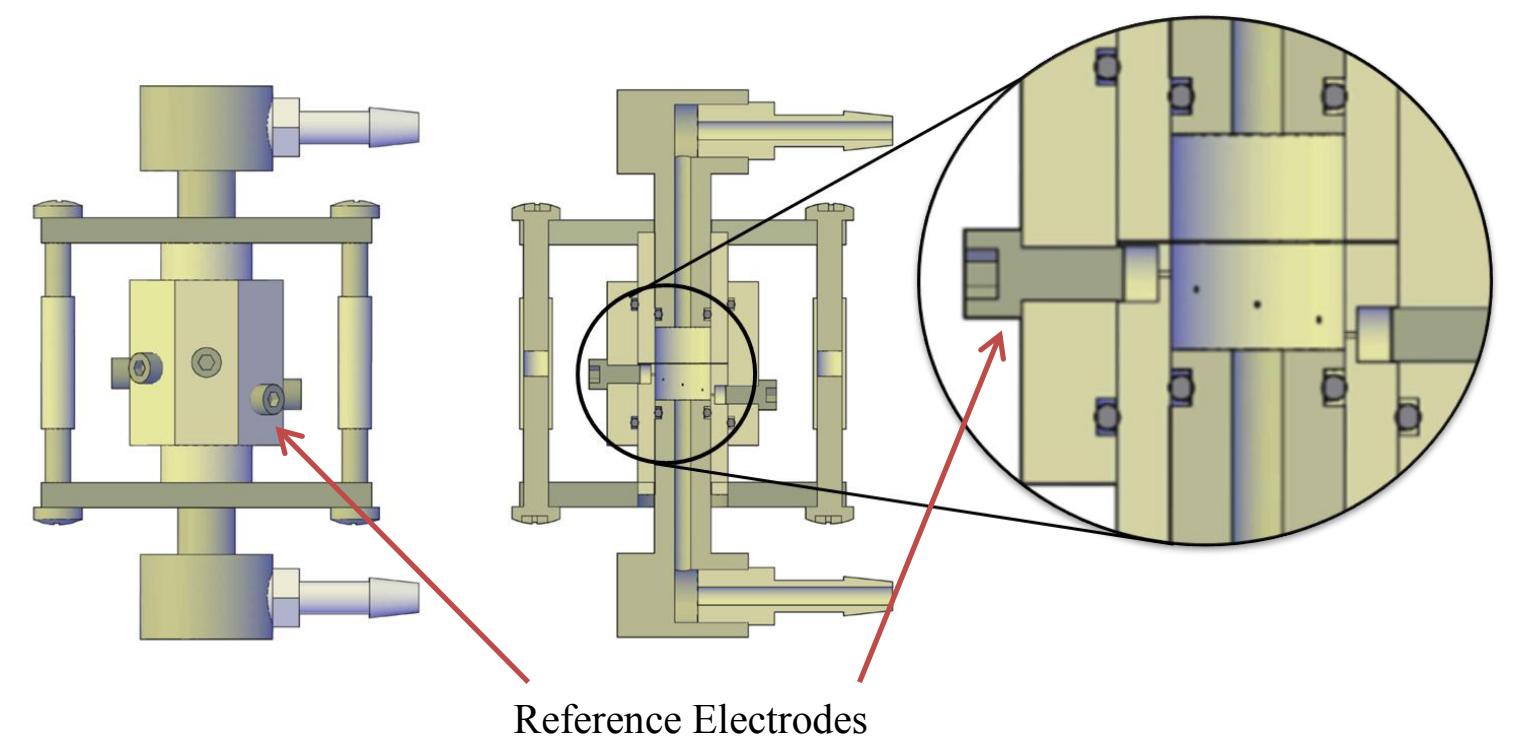

Figure 2.10 The front view (left) cutaway view (right) of the generation 5.2 convection cell with multiple reference electrodes.

\section{Generation 6}

The latest generation of convection cell, generation 6, is shown in Figure 2.11. This is also known as the scaled-up convection cell. The cell is all $316 \mathrm{SS}$ except the separator coupling, which is HDPE. 

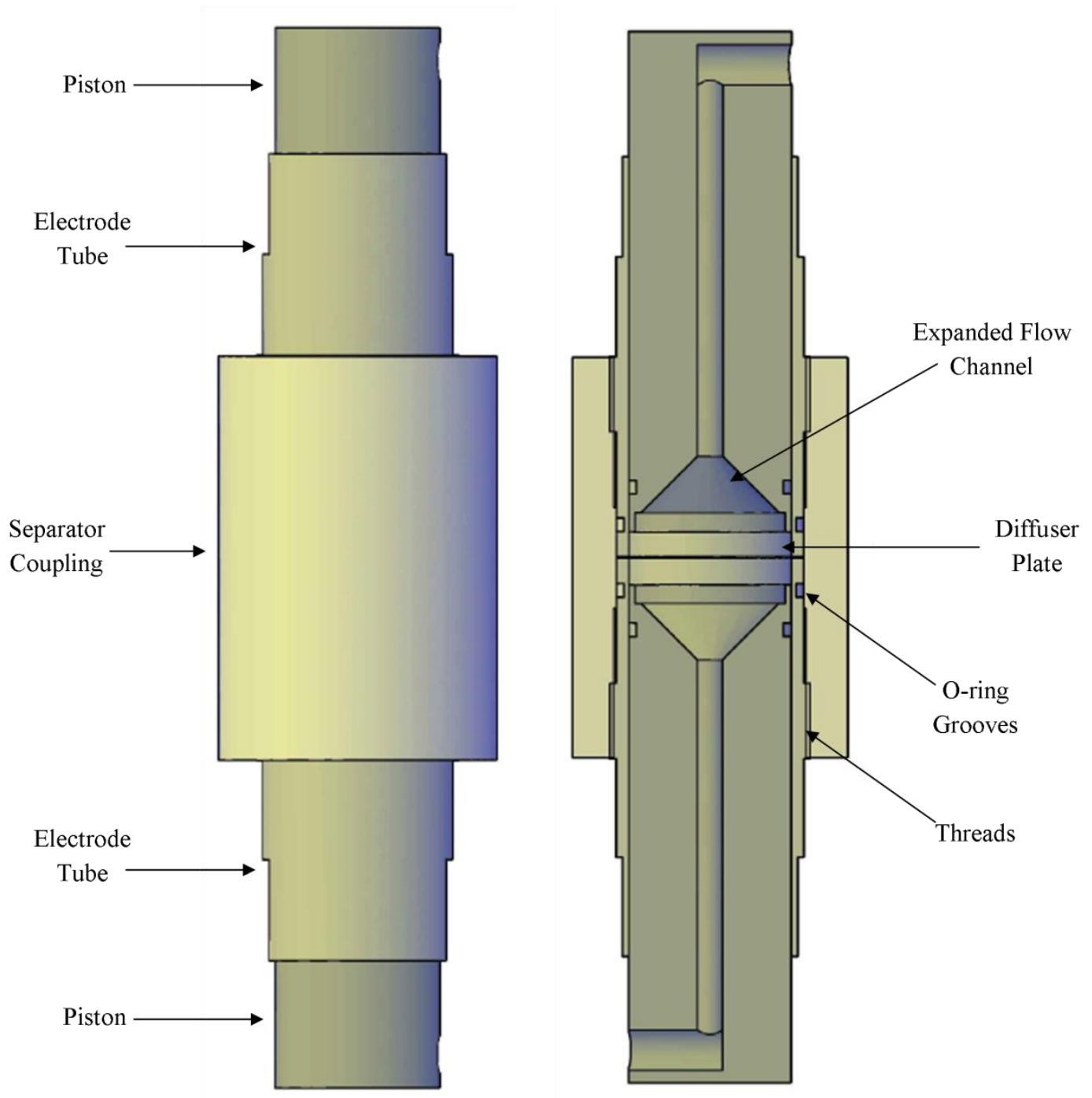

Figure 2.11 The generation 6 convection cell or the scaled-up convection cell. Fully assembled (left) and cutaway view (right)

In this cell the electrode tubes are screwed into the separator coupling. This replaces the need for the compression plates in previous designs. In addition the O-ring grooves are made in the outside of the electrode tubes instead of the inside of the separator coupling, which simplifies the machining process. 
Another feature of this cell is that flow channel in the piston is optimized to fully develop the plug-flow profile prior to reaching the electrode. This is done by expanding the flow channel in the piston to the full width of the electrode towards the end of the piston, and using a diffuser plate that is press-fit inside the piston to hold the electrode in place and allow an even dispersion of flow.

The generation 6 cell is designed to be used with free weights to apply pressure to the electrodes. Because of the large area of this cell, the pressure is considerable reduced, when used with the same weights as previous cells. If the cell is used with solid porous electrodes with an adequate connection to the current collecting pistons, then only little pressure may be required. However, if this becomes an issue, as with granular electrode materials, a large unwieldy amount of weight may be required. If a large pressure is required in future designs, pneumatic pressure could be used to overcome this.

This cell was only used once, and it was found that the electrode materials were not sufficiently permeable to allow flow. Since then, new electrode mixtures with acceptable permeabilities have been formulated, but this cell has not been tested with the new materials. This is partially because the large amount of materials needed to run the cell makes it expensive and time consuming. It would be valuable to wait until the materials are optimized further before experimenting with this cell.

\section{Basic Diffusion Cell}

The convection cell is designed for use with thick electrodes and requires a large amount of electrolyte in any of the current designs, so a diffusion cell was made that could be used to screen materials before the materials are used in the convection cell to 
cut down on experimentation costs. The cell is illustrated in Figure 2.12, and it is called the "basic" diffusion cell, so as not to be confused with a convection cell without flow which is sometimes referred to as a diffusion cell when operated without flow.

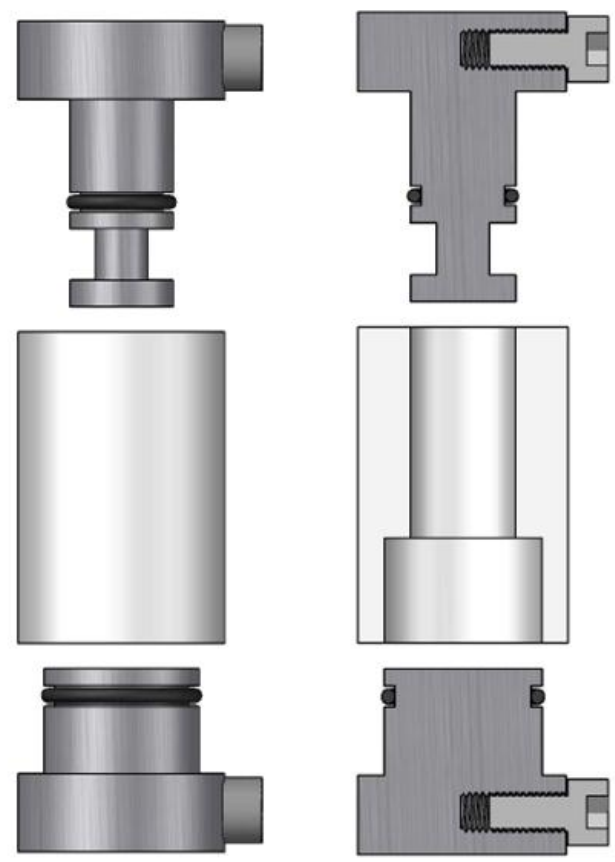

Figure 2.12 The basic diffusion cell used to screen materials for use in the convection cell.

The basic diffusion cell consists of a 316 SS bottom piston with a Buna-N O-ring, a 316 SS top piston, and non-conductive HDPE body. The screws are needed so that alligator clips from the testing system can connect to cell. The bottom piston has an indentation and is sealed with an O-ring to hold in the electrolyte. The groove in the top piston provides a "reservoir" for excess electrolyte in the cell. This keeps the cell saturated if any electrolyte is reacted away and also keeps the electrolyte from being pushed out of the cell and making a mess when the top piston is inserted. The inside of 
the body is stepped so that the separator can be seated against and provide a seal to prevent granular or powdered electrode material from going around the separator.

This cell is also designed to be used with powdered, granulated, or solid porous electrodes, since each type can be utilized in the convection cell. The indentation in the bottom electrode is the same diameter as the top electrode. The bottom electrode sits inside the indentation so that the cross-sectional area of the bottom and top electrodes are equal. Also, if solid porous electrodes are used, the electrode paste mixture is placed in the indentation and scraped flush with the top of the piston to provide consistent electrode thicknesses.

\section{Summary}

The convection cell design has become much more advanced since the inception of the original concept in the spring of 2009. It has gone from the generation 1 cell design, with crude off-the-shelf parts, to designs with precise custom-machined components. This evolution in cell design along with the parallel development of a better testing system as described in the next chapter greatly enhanced the reliability of the data obtained with the flow cell and new opportunities for research.

In the future, new cell designs will be needed for further improvement of the convection cell. At some point, when the convection cell is better understood, the cell will need to be scaled up beyond the size of the generation six cell and optimized to reduce size, mass, and pump energy to a minimum. The designs to date are made specifically to be used on a bench scale to do fundamental research, and the pump and 
size parameters are not a significant concern at this point. This review of convection cell designs is meant to aid in these future efforts. 


\section{CHAPTER 3}

\section{DESIGNING A LOW COST BATTERY TESTING SYSTEM WITH LABVIEW}

Three different battery testing systems were used to study the convection cells to date: a system with constant-voltage charge/ constant-resistance discharge, a system with constant-current charge/ constant-resistant discharge, and a system with constant-current charge/ constant-current discharge system. Each system used custom-built circuitry that was controlled and measured using LabVIEW software in conjunction with a National Instruments data acquisition (DAQ) card and a SCB-68 connector block. The connections of the main components are shown in Figure 3.1. The LabVIEW software in the computer is connected to the PCI-6229 DAQ card, which is in turn connected to the SCB-68. The SCB-68 is wired to the custom-built circuitry, which is connected to the test cell. The DAQ card has $5 \mathrm{~V}$ digital input/output channels, analog input channels, and analog output channels. These channels are manipulated by LabVIEW to control the test circuit and take measurements. All of the different testing systems used the same DAQ card and SCB-68 setup. The difference was in the circuitry. 


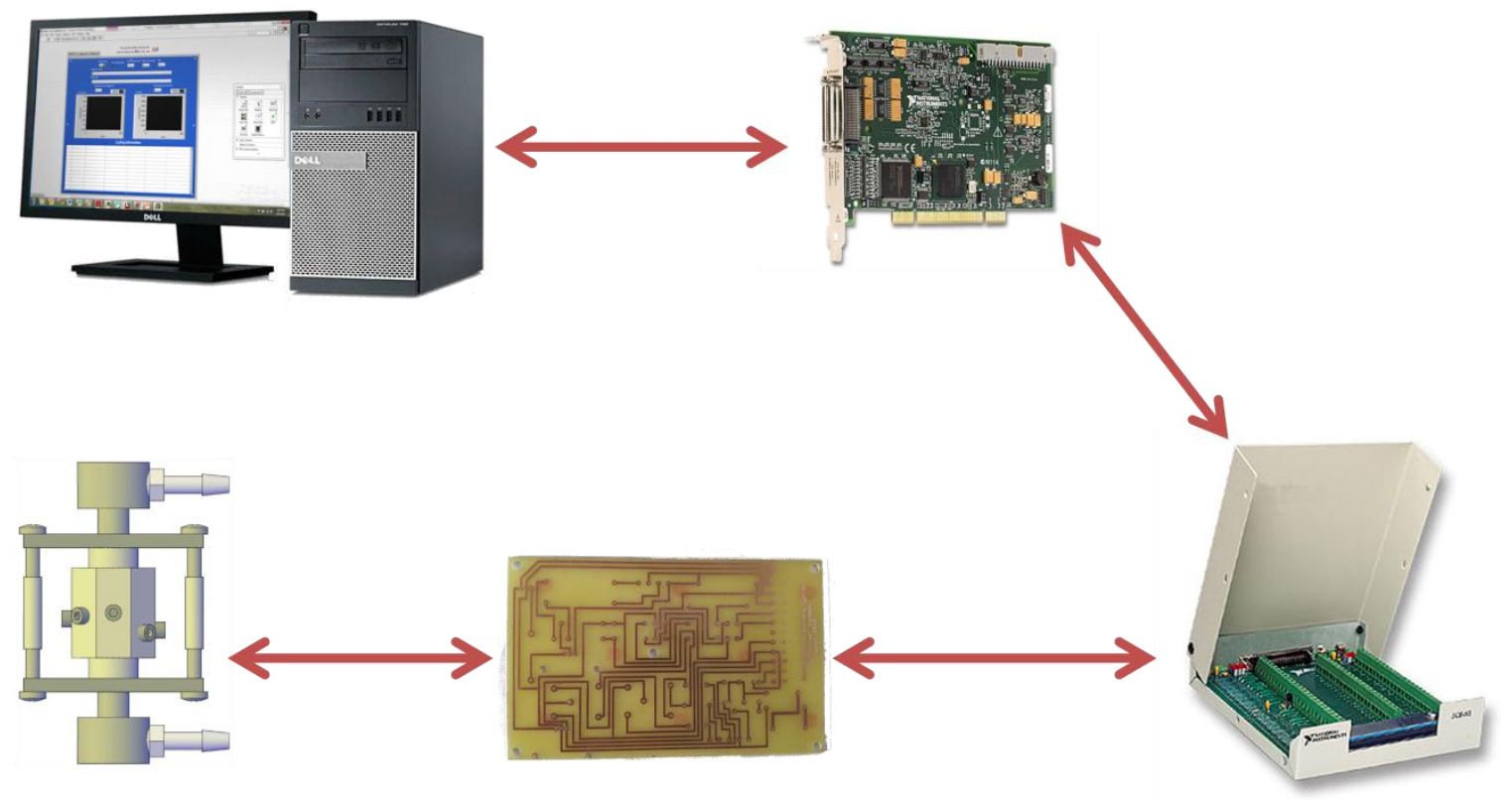

Figure 3.1 A schematic of the connections in the battery testing system.

\section{Version One}

In the convection cell studies with $\mathrm{Zn} / \mathrm{MnO}_{2}$ chemistry a simple constantresistance discharge and constant voltage charge system was used to test the cell performance. This was the first version system and is described in the dissertation of Bryan Sawyer. $^{39}$

\section{Version Two}

When the cycling studies on the convection cell were started, a new redesigned system was used with the ability to charge at constant current and test up to three cells simultaneously. This system is referred to as version two of the battery testing system and is pictured in Figure 3.2. The constant-current charge used in this version is preferred over the constant-voltage charge method used in the first system because constant-current charging is the most widely used method and a voltage cutoff can be used to determine 
the end of charge when using the constant-current method. This system was used for the studies with the $\mathrm{Li} / \mathrm{MnO}_{2}$ chemistry presented in chapter 4 and the studies presented in chapters 5 and 6 , which used the $\mathrm{LiFePO}_{4}$ chemistry.

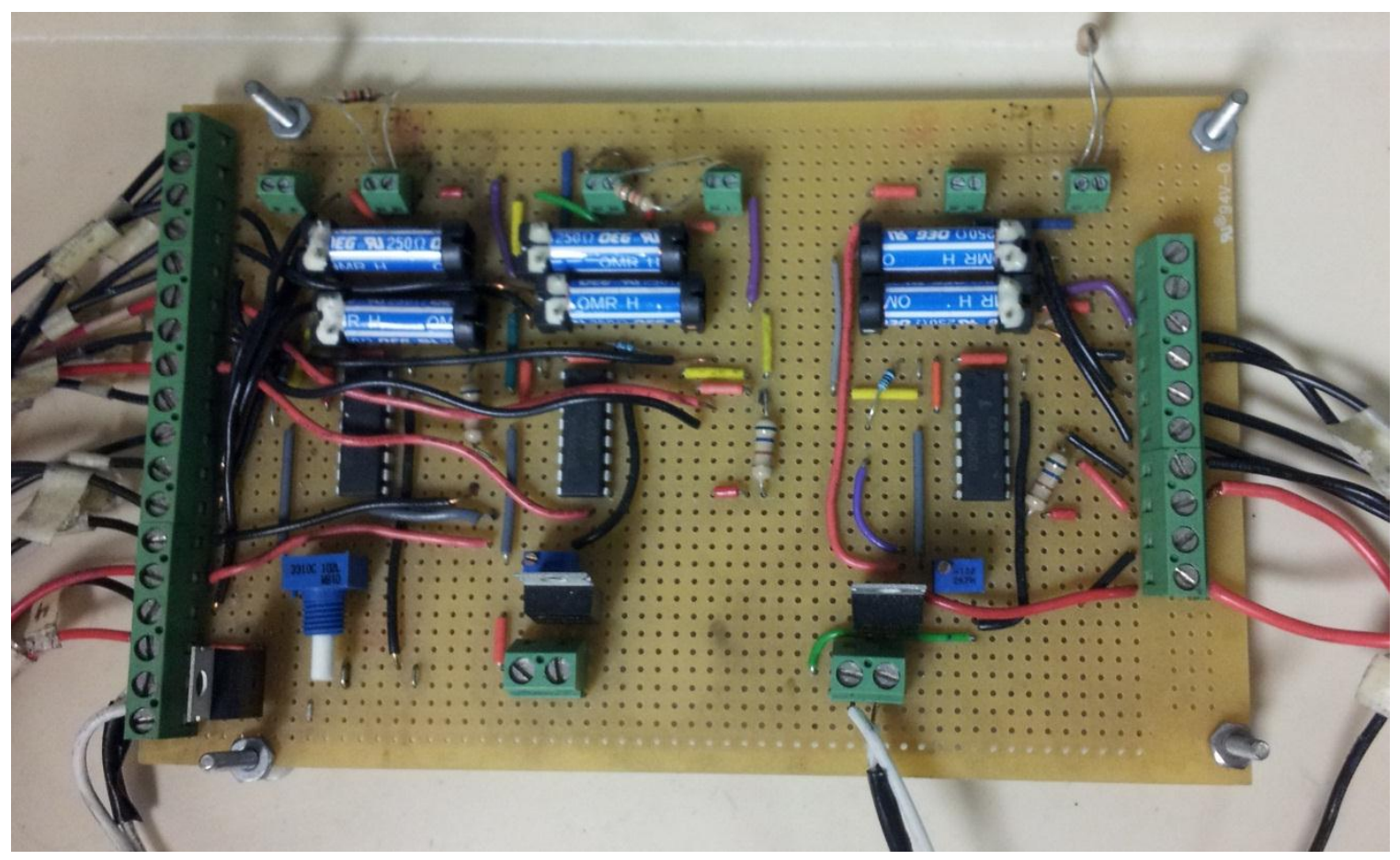

Figure 3.2 A photo of the battery testing system (version two).

\section{Version Two Circuit Design}

The system pictured in Figure 3.2 consists of three separate testing circuits. The diagram, including the connections to the SCB-68, for one of these circuits is shown in Figure 3.3. The battery is in open-circuit mode when both of the relays in the circuit are open. When the discharge relay is closed, the battery is discharged over the discharge resistor, $\mathrm{R}_{\mathrm{D}}$, by applying a $5 \mathrm{~V}$ output signal from LabVIEW across the discharge relay. Similarly, when the charge relay is energized the cell is charged through the lower part of the circuit in Figure 3.3. This part of the circuit is a Widlar current mirror ${ }^{50}$ which 
provides the constant-current charge. The resistor $R_{B}$ (base resistor) and potentiometer $\mathrm{R}_{\mathrm{E}}$ (emitter resistor) are related to the Widlar current mirror and determine the charging current applied to the test cell. The $\mathrm{R}_{\mathrm{E}}$ potentiometer can be varied to adjust the constant current. The voltage drop across the shunt resistor, $\mathrm{R}_{\text {shunt, }}$ is measured by LabVIEW to calculate the charge current. Originally this system was not designed to control the pump, but later pump control was added by making a separate circuit that had an AC outlet for the pump that was switched with a LabVIEW controlled relay.

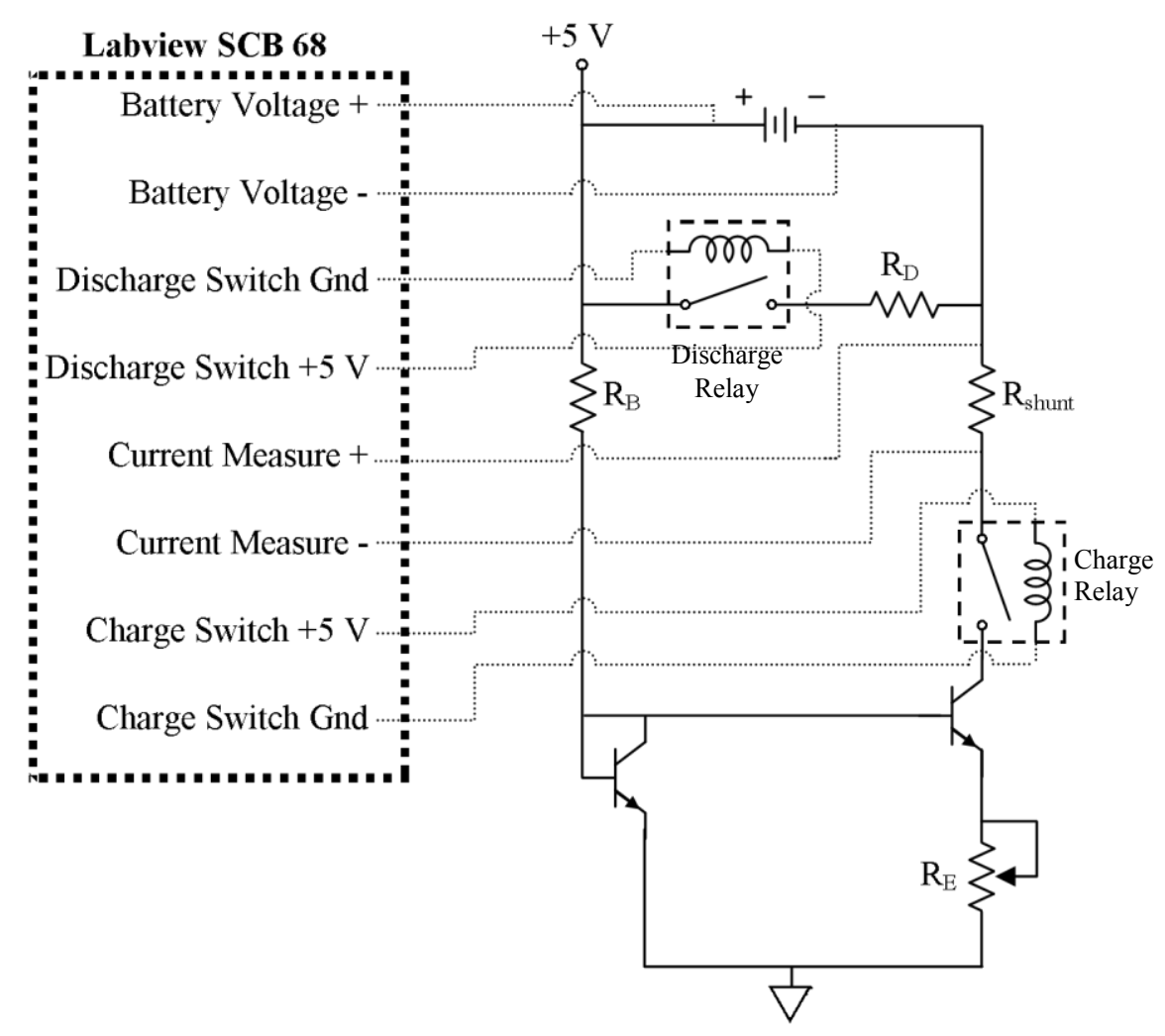

Figure 3.3 A circuit diagram of the version two battery tester.

\section{Version Two LabVIEW Program}

The LabVIEW program used in this system is designed to simultaneously take data from three different cells and write that data to separate files for each cell. Plus, it is 
able to start and stop each cell separately. The program runs the battery at open circuit for a specified time followed by charge and discharge cycles determined by voltage cutoffs. While the cell is running the program records the total time, cycle time, voltage, current, capacity, energy, mode (i.e. charging, discharging, or open circuit), and pump status (i.e. on or off). The capacity and energy are obtained by numerically integrating the current and power (calculated from the voltage and current) using the midpoint method.

The front panel of the program is shown in Figure 3.4. The front panel has three identical tabs - one for each battery. At the top of each tab is a push button, labeled battery 1 , that starts and stops the test of the battery associated with that tab. On the left side of the tab are all of the inputs for the cell. These include open circuit time, discharge time, discharge cutoff voltage, charge cutoff voltage, number of cycles, time-interval between cycles, and discharge resistance. Additionally, there is a switch to choose what mode is used after the open circuit. The two charts output the battery voltage and current. There are also outputs for the file path, total elapsed time, elapsed cycle time, cycles completed, charge/discharge indicator, present voltage, and present current. 


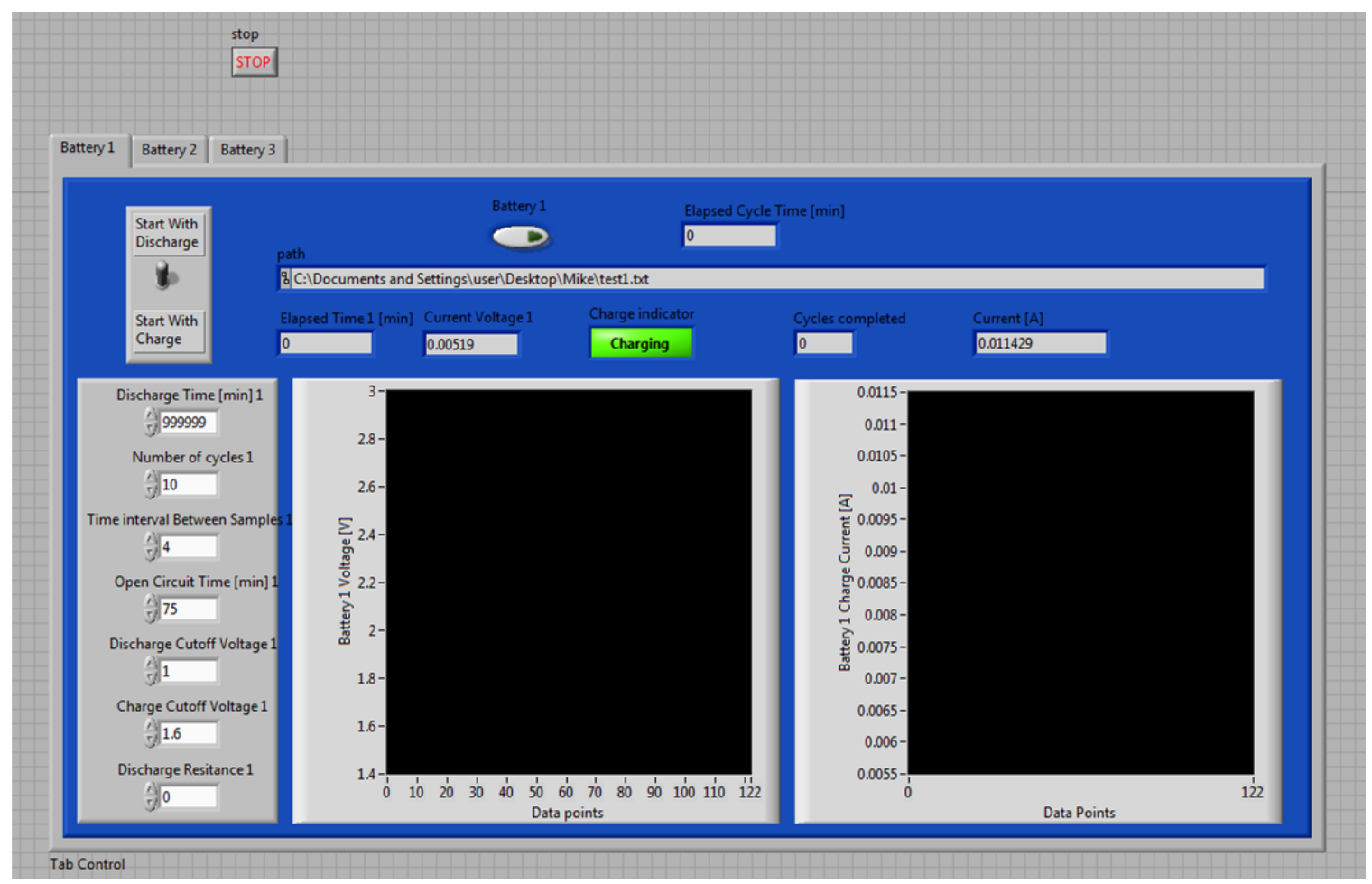

Figure 3.4 The front panel of the LabVIEW program for the version two battery testing system.

When the battery button is engaged, the program asks for the file to write to and then begins testing the battery and recording data. For each measured parameter the program takes 800 samples per second and records the average at the specified intervals. The program starts the cell in open circuit for the time specified in the input. After the open circuit it begins cycling the cell. It begins on either a charge or discharge as indicated by the switch, and then cycles between the two for the specified number of cycles (one cycle includes one charge cycle and one discharge cycle). The charge cycle lasts indefinitely until the charge voltage cutoff is reached, and the discharge last until either the discharge time is reached for the discharge cycle or the discharge cutoff voltage is reached. 


\section{Version Two Drawbacks}

The main drawback of the second version of the battery testing system was that it still used a constant-resistance discharge. While this is a perfectly legitimate method and

all of the necessary cell metrics can still be calculated, a constant-current discharge is desirable for two reasons. First of all, this is the method used by the majority of battery researchers, so using a constant-current discharge would allow easier comparisons to results in literature. Additionally, battery modeling is done with a constant current because it is very difficult to model a constant-resistance discharge. Since modeling is done on the convection cell, constant-current discharge data would be very useful in those efforts.

A second drawback of the second battery tester was that the current range only extended from about $0.05 \mathrm{~mA}$ to $3 \mathrm{~mA}$. While this range is sufficient for slow cycling of small cells, higher currents are needed to get reasonable run-times for the convection cells. The convection cells inherently have more active material than their diffusion cell counterparts, so they take longer to run.

One more issue was that the system was fragile and was not very user friendly. As seen in Figure 3.2, the system had no case and was exposed to the possibility of accidently short-circuiting. Adding to this the circuit was made using a solderable printed circuit breadboard, so it had a high number of solder connections and additional wires that are susceptible to having connection problems. Since all three of the individual testing circuits were on one board, if one test circuit had problems the entire system had to be taken down to fix. Also, the potentiometers used to change charge current were small and sensitive to the slightest movement. To change the discharge 
load, the discharge resistor had to be physical removed and replaced with one of a different value. Sometimes users would misread the color code on the resistors and use the wrong value.

This system also had some complications related to the LabVIEW program. Trying to make a program that could multi-task seamlessly was difficult. While the program did this for the most part, there were some slight bugs with the timing. The main problem though, was that the program was susceptible to human error, like closing out the program accidentally, writing over cell data, or putting in the wrong inputs. Additionally, the cycling sequence of the program was limited to an open circuit followed by subsequent charge and discharge cycles. If other sequences were desired, such as open-circuit rest between charge and discharge cycles, then the program had to be changed manually. Ideally the program would have the cycle sequence as an input parameter.

\section{Version Three}

The third version of the battery testing system uses a constant-current charge and discharge with an expanded current range from about 0.5 to $250 \mathrm{~mA}$ and was used to obtain the data presented in chapter seven. This system addresses many of the deficiencies of the previous system. It is much more robust and simpler to use in terms of the physical equipment and the LabVIEW program. The system contains three independent control boxes that are connected to the SCB-68. One of these control boxes is pictured in Figure 3.5. 


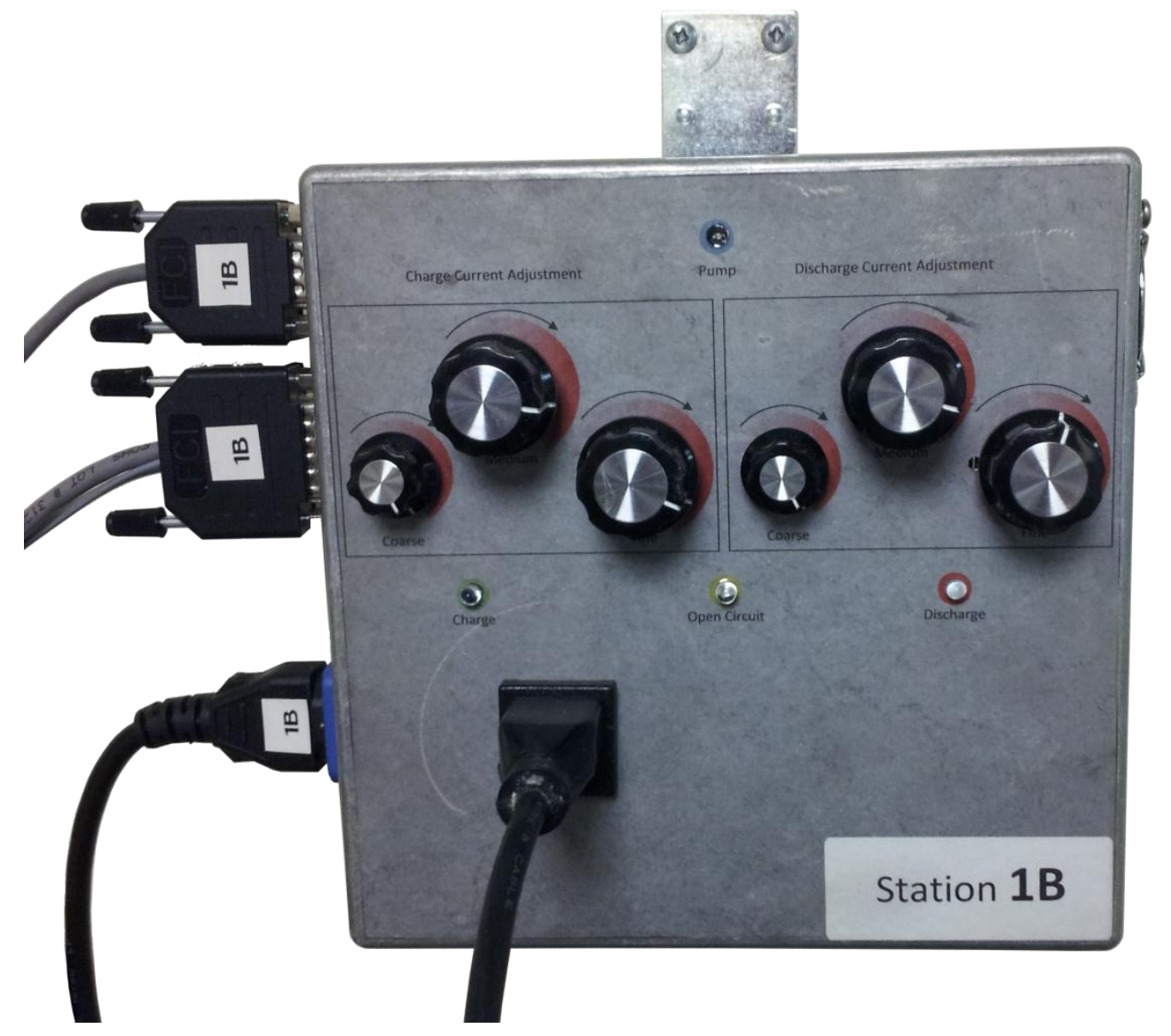

Figure 3.5 A photo of one of three control boxes in the battery testing system (version three).

The control boxes have many nice features. Each control box is used to test one battery independently, so if there is a problem with one box it can be removed from the system without affecting the other two. Also, the control box has an aluminum case that is grounded and uses shielded wires for connections to the SCB-68 and the battery to minimize electromagnetic interference. Plus, D-subminiature connectors with locking screws are used to make connections to the control box. This ensures an easy and reliable connection every time. The AC power cord connected to the box has a locking mechanism also. 
The front of the box features six potentiometer control knobs, indicator control lights, and the AC outlet for the pump. The tree control knobs on the left are used together to finely adjust the discharge current. The provide course, medium, and fine control to accurately dial in the current throughout the entire range from 0.5 to $250 \mathrm{~mA}$. The three knobs on the right perform the same task for the charge current. Dialing the current with these control knobs is much easier than manually changing resistors to adjust the discharge resistance like in the previous system. The indicator LED's indicate the mode of the tester (charge, discharge, open circuit), and whether the pump is on or off. These indicators are also programmed into the LabVIEW software, but the LEDs can be used to double-check the program and ensure that the system is working properly. The pump for the convection cell is plugged into the front of the control box so that it can be controlled via LabVIEW.

The inside of the control box is shown in Figure 3.6. The box contains the circuit board, the DC power supply, the fan, and wires as well as the components mounted on the front of the box. The circuit board is custom printed, as opposed to the breadboard used in the previous system, so there are no excess wires or solder joints. The LM317 and voltage regulator chips generate substantial amounts of heat and can only tolerate certain temperatures. The fan in conjunction with the chip-mounted heat sinks keep the components cool for smooth operation. 


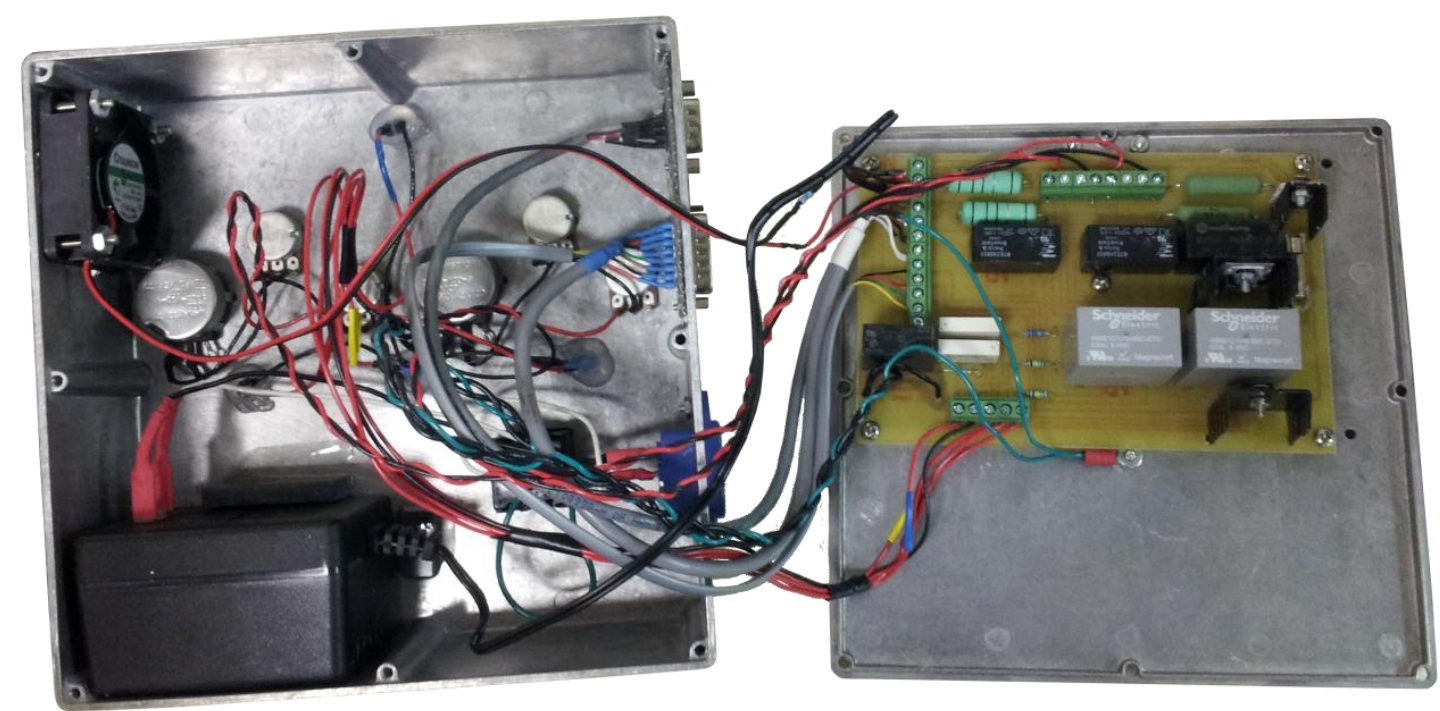

Figure 3.6 The inside of one of the control boxes in the battery testing system (version three).

\section{Version Three Circuit}

The circuit used in the control boxes is shown in Figure 3.7. The main component in this circuit is a LM317 integrated-circuit chip to provide the constant current for charge and discharge. This replaces the Widlar current mirror used in version two of the battery testing system. In the circuit diagram there are four terminal blocks: a 12-pin terminal block to connect to the DC power supply, SCB-68, and test battery; a four-pin terminal block to connect to the current adjusting potentiometers; a five-pin terminal block to connect to the indicating LEDs; and a two-pin terminal block to connect the AC outlet for the pump. The circuit diagram showing the connections for each of these terminals is given in Figure 3.8, Figure 3.9, Figure 3.10, and Figure 3.11 respectively. 


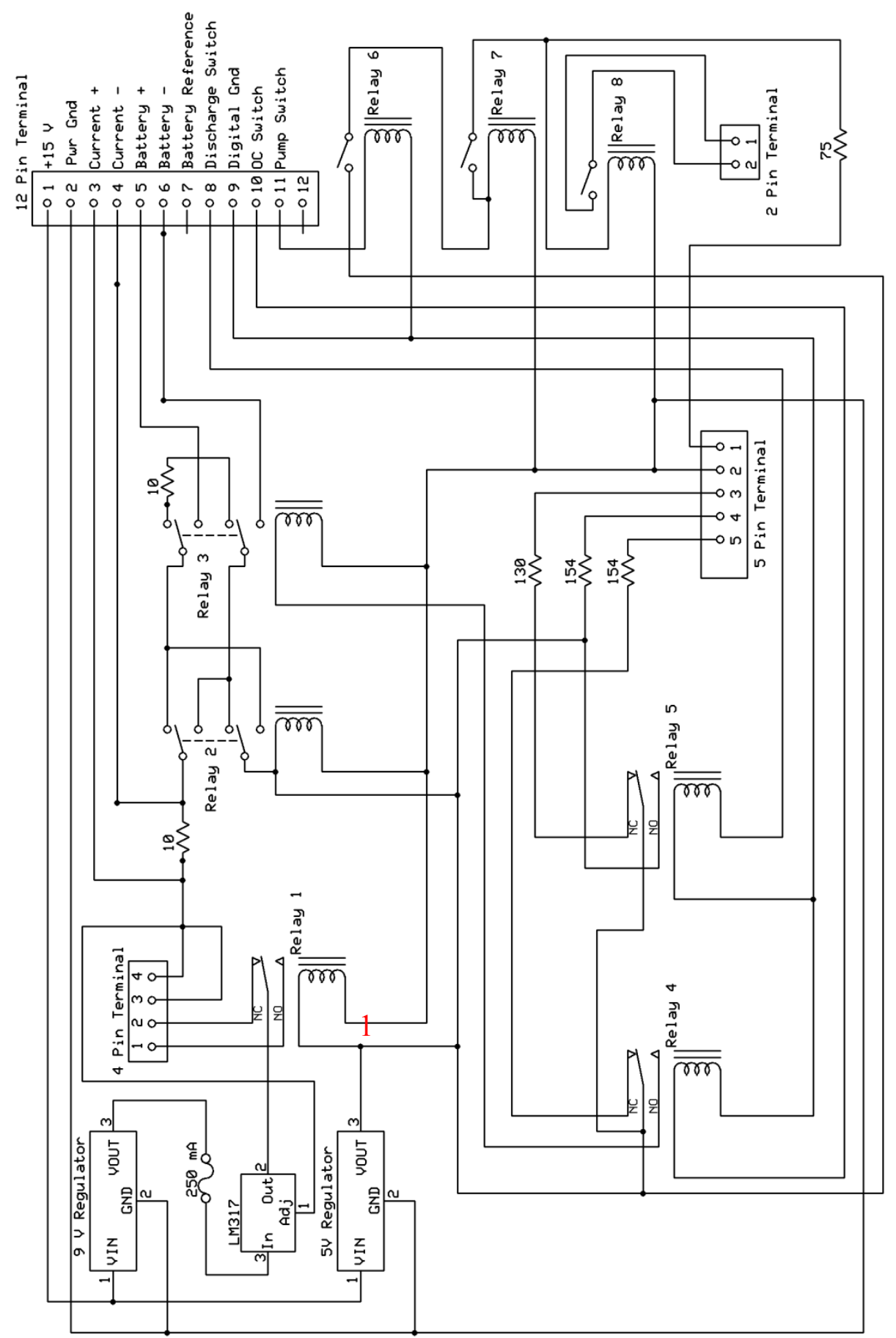

Figure 3.7 The diagram of the circuit board in the control boxes used in the version three battery testing system. All relays are shown in the default open position. 


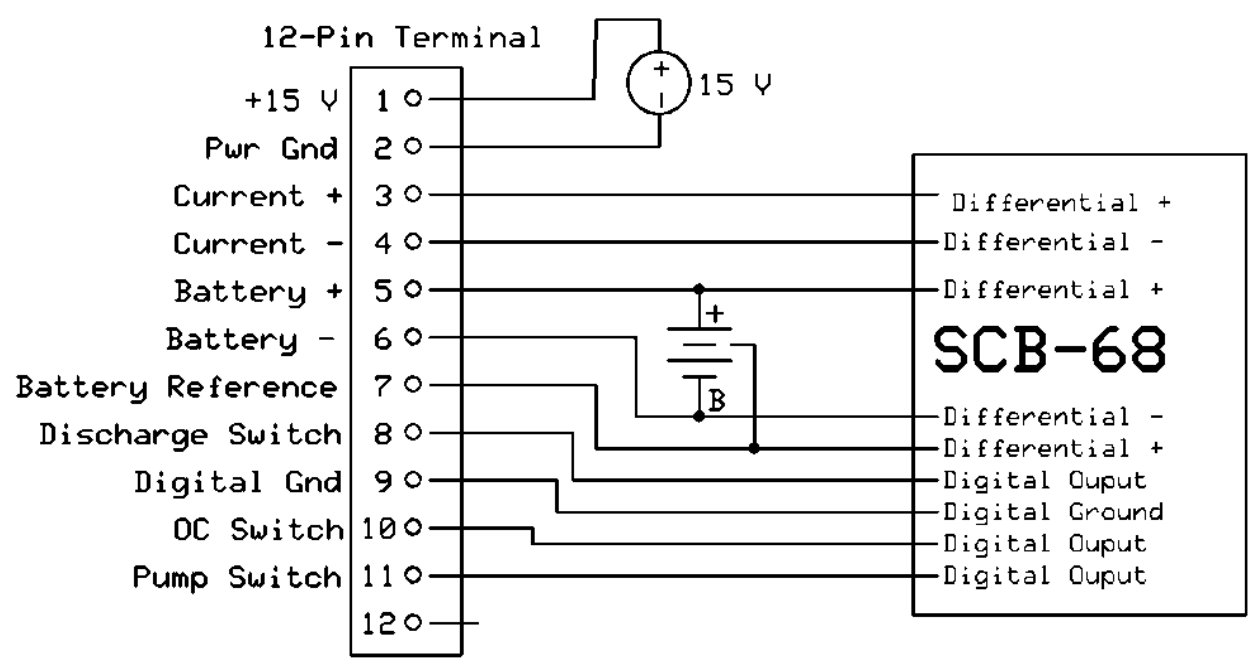

Figure 3.8 Circuit diagram for the 12-pin terminal block connections.

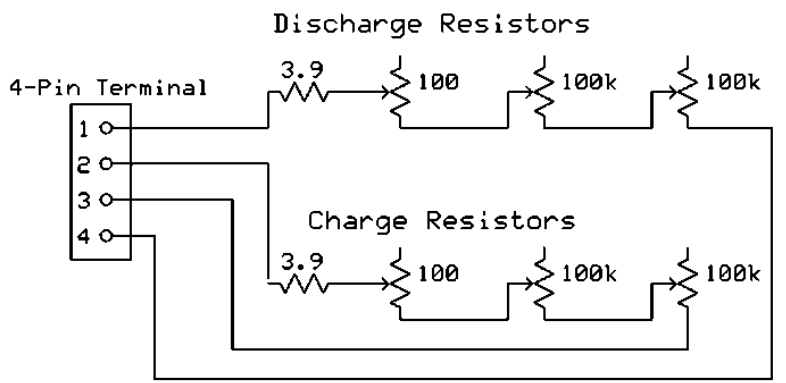

Figure 3.9 Circuit diagram for the four-pin terminal block connections.

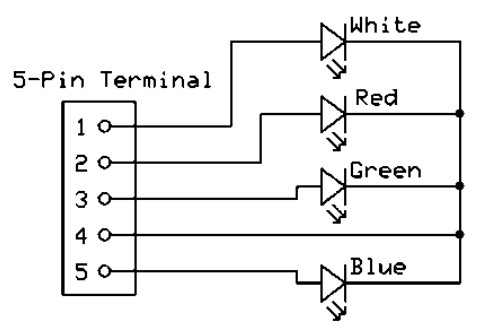

Figure 3.10 Circuit diagram for the five-pin terminal block connections. 


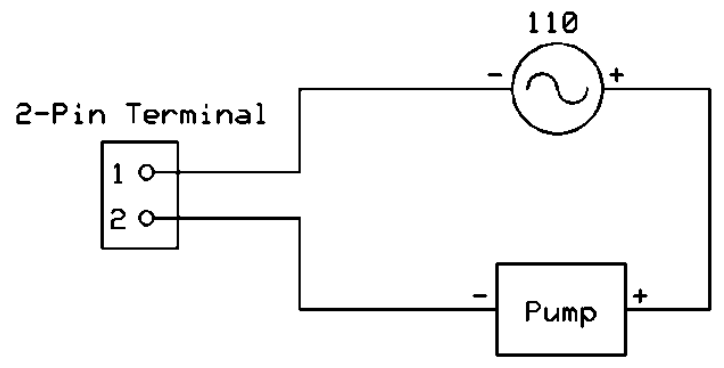

Figure 3.11 Circuit diagram for the two-pin terminal block connections.

The overall operation of the control box circuit can be understood by looking at Figure 3.7 through Figure 3.11 collectively. In Figure 3.7, $15 \mathrm{~V}$ from the 12-pin terminal block provides power to the $9 \mathrm{~V}$ and $5 \mathrm{~V}$ regulators. The $9 \mathrm{~V}$ regulator powers the LM317, and the $5 \mathrm{~V}$ regulator powers the relays and indicator LEDs in the circuit.

The constant current part of the circuit consists of the LM317, some resistors, and some relays to switch between open circuit, charge, and discharge. In Figure 3.7, the output of the LM317 is hooked up to relay one, which is a single-pull-double-throw (SPDT) relay. Depending on the signal to the relay, the relay is connected through the four-pin terminal block to either the charge potentiometers and resistor or the discharge potentiometers and resistor (refer to Figure 3.9). The potentiometers correspond to the potentiometers on the front of the box, and they determine the current output of the LM317. The $3.9 \Omega$ fixed charge and discharge resistors are used to set the maximum current of the circuit, which is limited by the heat removal in the LM317 and the voltage regulators. A $250 \mathrm{~mA}$ fuse also protects the system from exceeding the maximum current. 
The charge and discharge resistors and potentiometers are connected back into the circuit board through the four-pin terminal block and then to a $10 \Omega$ shunt resistor in Figure 3.7. The ends of the shunt resistor are connected to the pins three and four of the 12-pin terminal block, which is connected to the SCB-68 as shown in Figure 3.8. LabVIEW measures the voltage across the shunt resistor to calculate the current.

The shunt resistor is connected to the top pole of relay two, which is a doublepull-double-throw (DPDT) relay. The bottom pole of the relay is connected to the power supply ground through the 12-pin terminal. The four outputs of the relay are connected to the inputs of relay three in a manner that reverses the poles of relay three when a signal is applied to relay two. When relay three, a DPDT relay, is in its default open position, the current from the LM317 to flows through a $10 \Omega$ resistor while the battery is at open circuit. This allows the LM317 current to be measured by LabVIEW and adjusted without affecting the battery potential. When relay three is closed, the LM317 current charges or discharges the battery depending on the position of relay two. When relay two is open and relay three is closed, the LM317 drives a constant charge current into the positive terminal of the battery. When relays two and three are both closed, the LM317 drives a constant discharge current into the negative terminal of the battery. When relay three is open the battery is in open circuit regardless of the position of relay two.

In Figure 3.8, the discharge switch, OC switch, and pump switch terminals from the 12-pin terminal block are all connected to digital output channels in the SCB-68. In Figure 3.7, these digital outputs are used to control the relays in the circuit that source a 5 V signal when turned on. The digital signal from the OC switch terminal controls relay four. When this relay is open, relay three is also open and power is applied to the white 
LED in Figure 3.10 indicating an open circuit. When a $5 \mathrm{~V}$ digital output from LabVIEW is applied to relay four the white LED turns off, relay three is closed to apply current to the battery.

The signal from the discharge switch terminal controls relay five. When this relay is open, power is supplied to the green LED in Figure 3.10 indicating that the current is being controlled with the charge potentiometers. The current may or may not flow through the battery depending on the position of relay four. When a $5 \mathrm{~V}$ digital output from LabVIEW is applied to relay five, the green LED turns off, and the red LED turns on to indicate that the discharge potentiometers are controlling the current. Again, the flow path of the current depends on the position of relay four.

The pump switch signal controls relay six. When this relay is open, the blue LED (Figure 3.10) is off and the pump (in Figure 3.11) is off because relay eight is open. When relay six is closed, relays seven and eight are closed and the pump and blue LED comes on. Relay seven actually does nothing, but it got overlooked when the system was built, so it is still included here to match the circuit board photo in Figure 3.6.

\section{Version Three LabVIEW Program}

The new LabVIEW program for the version three battery testing system has some similarities to the previous version, but it also has some significant improvements. The front panel for the new program is shown in Figure 3.12. This is a similar look to the program for the previous system, but this program has no inputs on the front panel. All of the inputs to the program are read from a text file specified by the user. This way, multiple users can save unique test sequences in a file and reuse them without having to 
reprogram the inputs each time a battery is tested. This saves time and greatly reduces human error. The path of the file is displayed in the front panel along with the content of the file in the cycling information table.

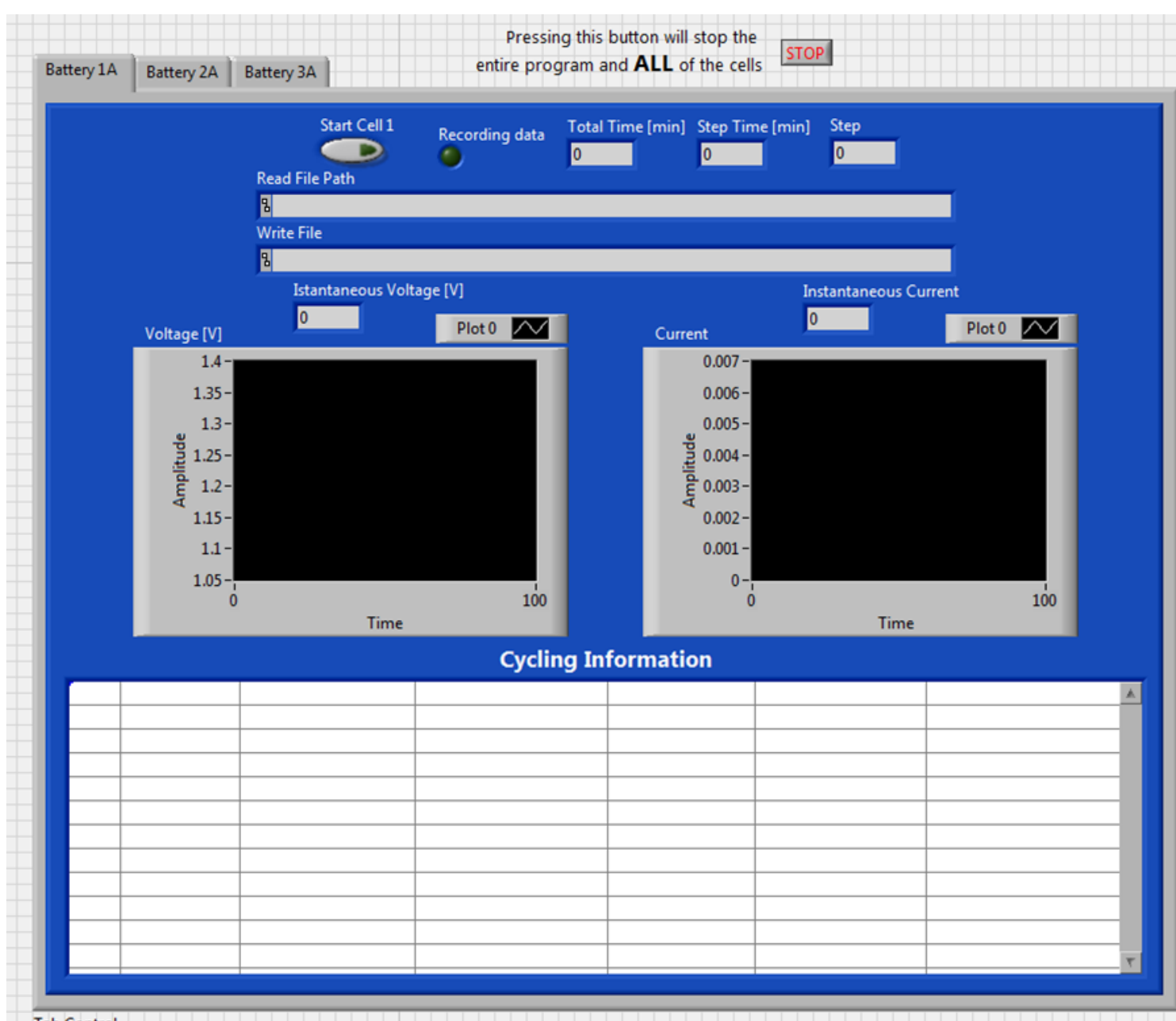

Figure 3.12 The front panel of the LabVIEW program for version three of the battery testing system.

A sample input, or read file, is given in Table 3.1. A huge benefit in this program over the previous version is that the input parameters can be varied for each cycle, and the mode (charge, discharge, or open circuit) of each cycle can be specified. This adds a 
lot of flexibility in the type of experiments that can be used to investigate the convection cell.

Table 3.1 A sample input file for the version three LabVIEW file.

\begin{tabular}{ccccccc}
\hline Step & $\begin{array}{c}\text { Pump } \\
\text { on/off }\end{array}$ & $\begin{array}{c}\text { Charge/ } \\
\text { Discharge/ } \\
\text { OC }\end{array}$ & $\begin{array}{c}\text { Cutoff } \\
\text { Time } \\
{[\mathrm{min}]}\end{array}$ & $\begin{array}{c}\text { Upper } \\
\text { Cutoff } \\
\text { Voltage }\end{array}$ & $\begin{array}{c}\text { Lower } \\
\text { Cutoff } \\
\text { Voltage }\end{array}$ & $\begin{array}{c}\text { Interval } \\
\text { Between } \\
\text { Readings [s] }\end{array}$ \\
\hline 1 & on & o & 30 & 4.5 & -2 & 30 \\
2 & on & c & 9999 & 4 & -2 & 30 \\
3 & on & o & 5 & 4.5 & -2 & 30 \\
4 & on & d & 9999 & 4.5 & 2 & 30 \\
5 & on & o & 5 & 4.5 & -2 & 30 \\
\hline
\end{tabular}

Another difference with this version over the last version is the way the charge and discharge current is set. In version two of the system, a dummy cell has to be cycled by the program to measure and output the charging current while it is being set. This is time consuming and prone to error, so the new LabVIEW program prompts the user to set the current at the beginning of each cycle with the control knobs. As described in the previous section, the charge and discharge current can be set while the battery is in open circuit by leaving the relay three from Figure 3.7 in the open position so that the current is diverted to a resistor. Once the user specifies the write file, read file, charge current, and discharge current, the program cycles the battery per the instructions in the read file.

\section{Summary and Future Improvements}

Version two and three of the LabVIEW based battery testing system have been presented. The second version used a constant-current charge and a constant-current 
discharge. This system suffered significant drawbacks. The third version was a major improvement and addressed many of the problems associated with version two.

The final version of the battery testing system had almost no drawbacks for the tests that it was designed for. However, future improvements could include digital control over the current settings and a constant voltage charge option. This would add more flexibility to the system and allow for new experiments to be performed. 


\section{CHAPTER 4}

\section{INITIAL VALIDATION STUDIES OF CONVECTION CELLS}

The convection cell concept was first initiated in the spring of 2009 by Dr. Galen Suppes. The initial validation studies were conducted by Bryan Sawyer and Michael Gordon under the guidance of Dr. Suppes. ${ }^{38-40}$ This chapter reviews some of those results and puts them in context with the new results presented in this work.

The initial goal was to show that flow improves the cell performance using a simple chemistry like $\mathrm{Zn} / \mathrm{MnO}_{2}$. The studies with the first two generations of convection cells showed some improvement with flow, but as discussed in chapter two it was difficult to interpret these results, and ultimately, the data from these cells was unsuitable for publication. However, with cell improvements, reliable results were obtained with the third and fourth generation flow cells.

\section{Flow versus No-Flow in $\mathrm{Zn} / \mathrm{MnO}_{2}$ Generation 4.1 Convection Cells}

The effects of flow versus no-flow in the convection cell were studied using a generation 4.1 convection cell with an open-reservoir tubing configuration. The $30 \mathrm{~min}$ constant-resistance-discharge profiles for two $\mathrm{Zn} / \mathrm{MnO}_{2}$ convection cells, one with flow and one without flow, are shown in Figure 4.1. This shows that the flow significantly 
reduces the total overpotential in the cell as expected. This was attributed to a lowered concentration overpotential and was a significant advancement in the convection cell research.

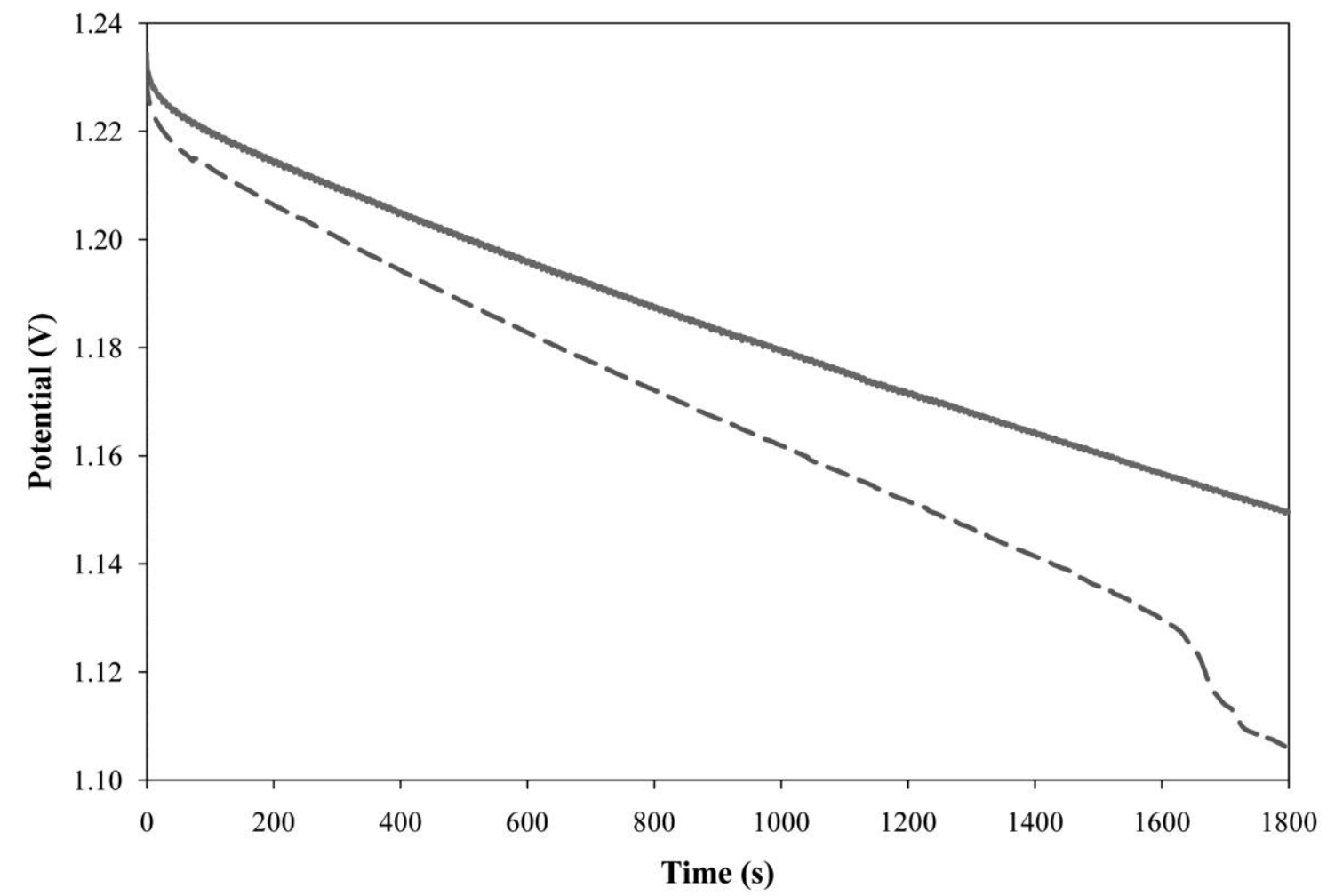

Figure 4.1 Thirty-minute discharge at $550 \Omega$ load with (solid) and without electrolyte flow (dashed) using $2 \mathrm{M} \mathrm{KOH}$ electrolyte. ${ }^{38}$

In the cells for Figure 4.1, the bottom electrode in the cell was packed with granular zinc $(99.8 \%, 110-50$ mesh, ACS reagent grade, Sigma Aldrich). The top electrode was packed with a mixture of $30 \mathrm{wt} . \%$ manganese (IV) oxide, $35 \mathrm{wt} . \%$ graphite (Acros Organics 38503-0010), and 35 wt.\% ALL-CRAFT 4K activated carbon (US Patent Publication 20080207442) mixture was used in the cathode. The $4 \mathrm{k}$ carbon is an activated carbon that is made in house, and the production process is reported 
elsewhere. ${ }^{51}$ A piece of $0.95 \mathrm{~cm}$ diameter filter paper was placed between the base and the bottom electrode and between the top electrode and the piston to prevent the electrode material from flowing out of the cell with the electrolyte. Additionally, three filter papers were used as the separator between the two electrodes.

Another study using identical cells to those used for Figure 4.1 revealed that the effect of flow is greater in cells with lower concentrations of ions. The results given in Figure 4.1 were obtained from three $\mathrm{Zn} / \mathrm{MnO}_{2}$ cells - each with a different concentration of the aqueous $\mathrm{KOH}$ electrolyte. The cells were subjected to an initial 30 min opencircuit rest (not shown) followed by a 60 min discharge. The pump was on for the initial open-circuit period and the first $20 \mathrm{~min}$ of discharge. It was then turned off for a $20 \mathrm{~min}$ period and subsequently turned back on for the remaining 20 min of discharge. 


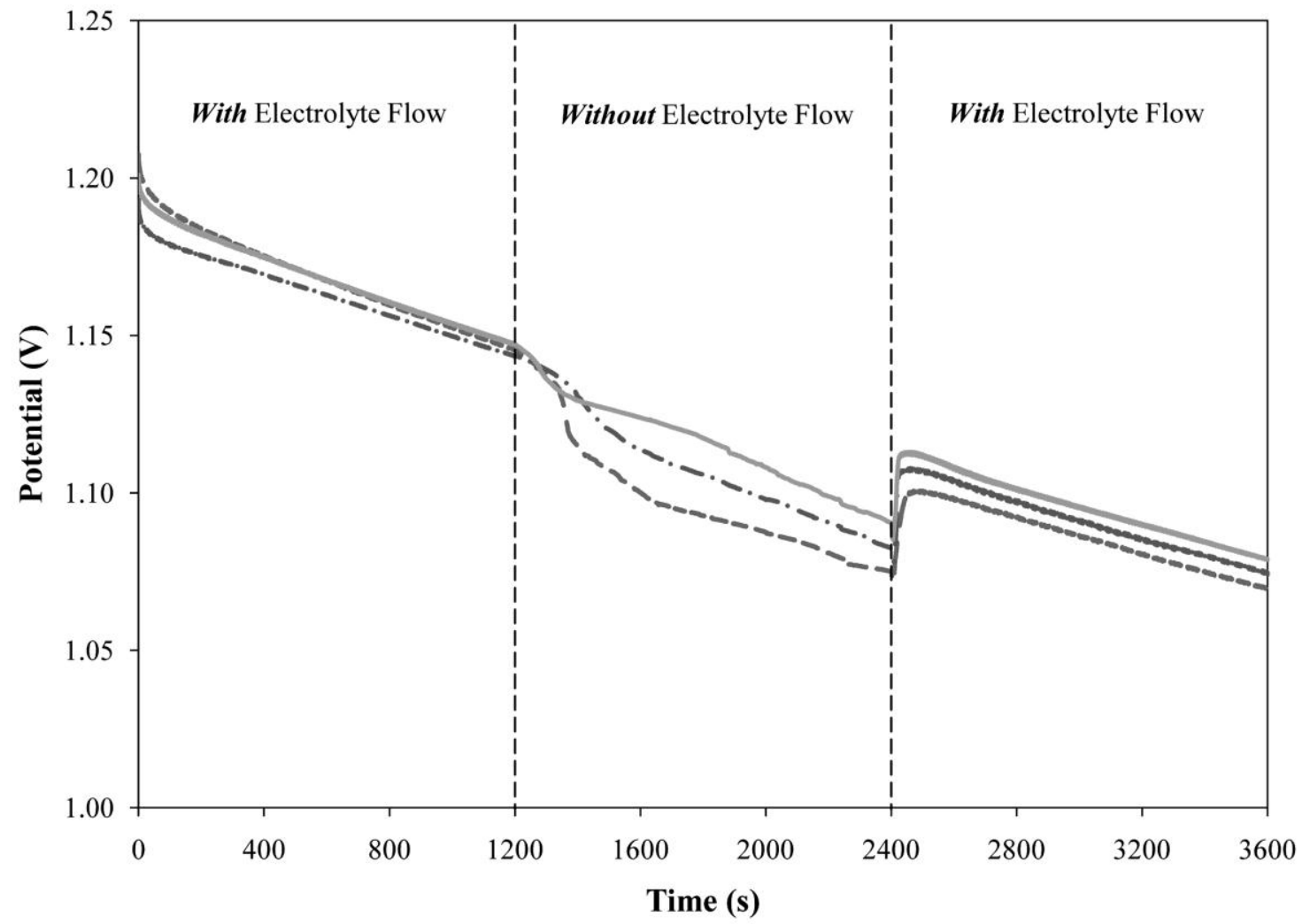

Figure 4.2 Electrolyte flow effects on the 4.1 convection cell potential under a $550 \Omega$ load at three different electrolyte concentrations [4 M KOH (solid line), $3 \mathrm{M} \mathrm{KOH}$ (dash dotted line), and $2 \mathrm{M} \mathrm{KOH} \mathrm{(dashed} \mathrm{line)].}{ }^{38}$

By looking at the discharge profiles in Figure 4.2, it can be seen that when the pump is turned off at the $20 \mathrm{~min}$ mark the voltage slowly tapers off. Then at the $40 \mathrm{~min}$ mark, when the pump is turned back on, the voltage jumps back up to a higher voltage almost immediately. This is consistent with the theory that the flow reduces the concentration overpotential. When the pump is turned off, it takes time for the concentration gradients to form. Since the concentration overpotential is directly related to concentration gradients, it also takes time for the concentration overpotential to increase as seen in the voltage profiles of Figure 4.2 after the pump is turned off. 
Similarly, when the pump is turned back on, the relatively immediate jump in voltage can be correlated to the considerable impact of flow on reducing concentration gradients. In addition, these effects of flow and no-flow would be impacted by the concentration of ions in the electrolyte, which is seen in the figure. The lower concentration electrolytes have higher concentration overpotentials without flow because, due to a lack of ions in solution, larger gradients form in less time than in electrolytes of higher concentrations.

\section{Studies on Separation Materials and Flow Direction}

Further studies were done to look at the effects of using different separator materials using the generation 4.2 convection cell with the open-reservoir tubing configuration. The study compared a generation 4.2 cell with ion-exchange material (IXR) in the separator to a generation 4.1 cell with only filter paper separators. Flow was used in both cells. The generation 4.1 cells were made in the same fashion as the cells used in the flow no-flow experiments in Figure 4.1 and Figure 4.2. The only difference with the generation 4.2 cells was the separator. In the generation 4.1 cell, three piece of $2.5 \mathrm{~cm}$ diameter filter paper was used as the separator. In the generation 4.2 cell, the separator was a $2.5 \mathrm{~cm}$ separator tube filled with Amberlyst A-26(OH) IXR with one piece of $2.5 \mathrm{~cm}$ diameter filter paper on each end.

The comparison results are shown in Figure 4.3. The open circuit for each cell is the same, so if the cells had identical separators, the discharge voltage profiles would be the same. However, they are different. The cell with IXR has a lower overpotential than the cell without, and the decrease in overpotential with the IXR is constant. This means that the decrease is probably not a decrease in concentration overpotential because both 
cells use flow and the concentration overpotential increases over time as concentration gradients rise. One possibility is that the IXR increase the ionic conductivity in the separator and decrease the ohmic overpotential. Assuming a constant current, this would be a constant effect because the ionic current in the separator is the same as the applied current since there are no reactions in that section of the cell. These cells were discharged with a $550 \Omega$ constant-resistance discharge, but by looking at the voltage difference between the beginning and end of discharge $(\sim 80 \mathrm{mV})$ and the average discharge voltage of the smaller cell $(\sim 1.06 \mathrm{~V})$, the percent change in current can be approximated at only a $7 \%$ change in current. Therefore the constant-current approximation may be reasonable.

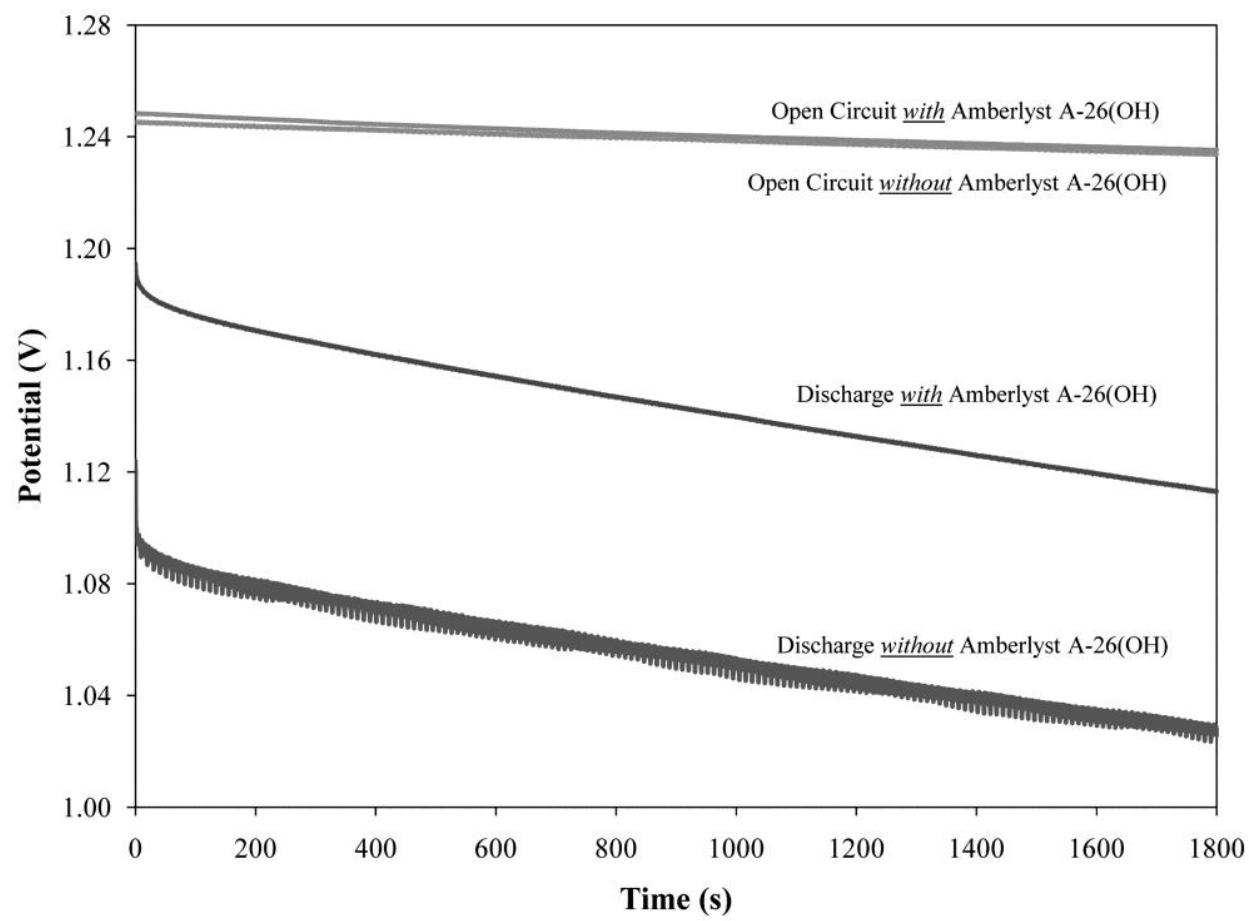

Figure 4.3 Open-circuit and discharge voltage profile comparison between a generation 4.2 Zn/MnO 2 convection cell with IXR and a generation $4.1 \mathrm{Zn} / \mathrm{MnO}_{2}$ convection cell without additional separator material. ${ }^{38}$ 
The effect of flow direction in the convection cell was also investigated. It was hypothesized that the direction of flow would have a significant impact on the cell performance. The two types of cells for this study were the same as the ones built for the generation 4.2 cells used in the previous separation material study, but one with the Amberlyst A-26(OH) IXR and one with Amberlite IR-120H IXR. Two of each type of cell was built - one with flow from an anode-to-cathode flow, and one with cathode-toanode flow. The results are given in Figure 4.4. These results are contrary to the hypothesis, and show that the flow direction does not have a significant effect.

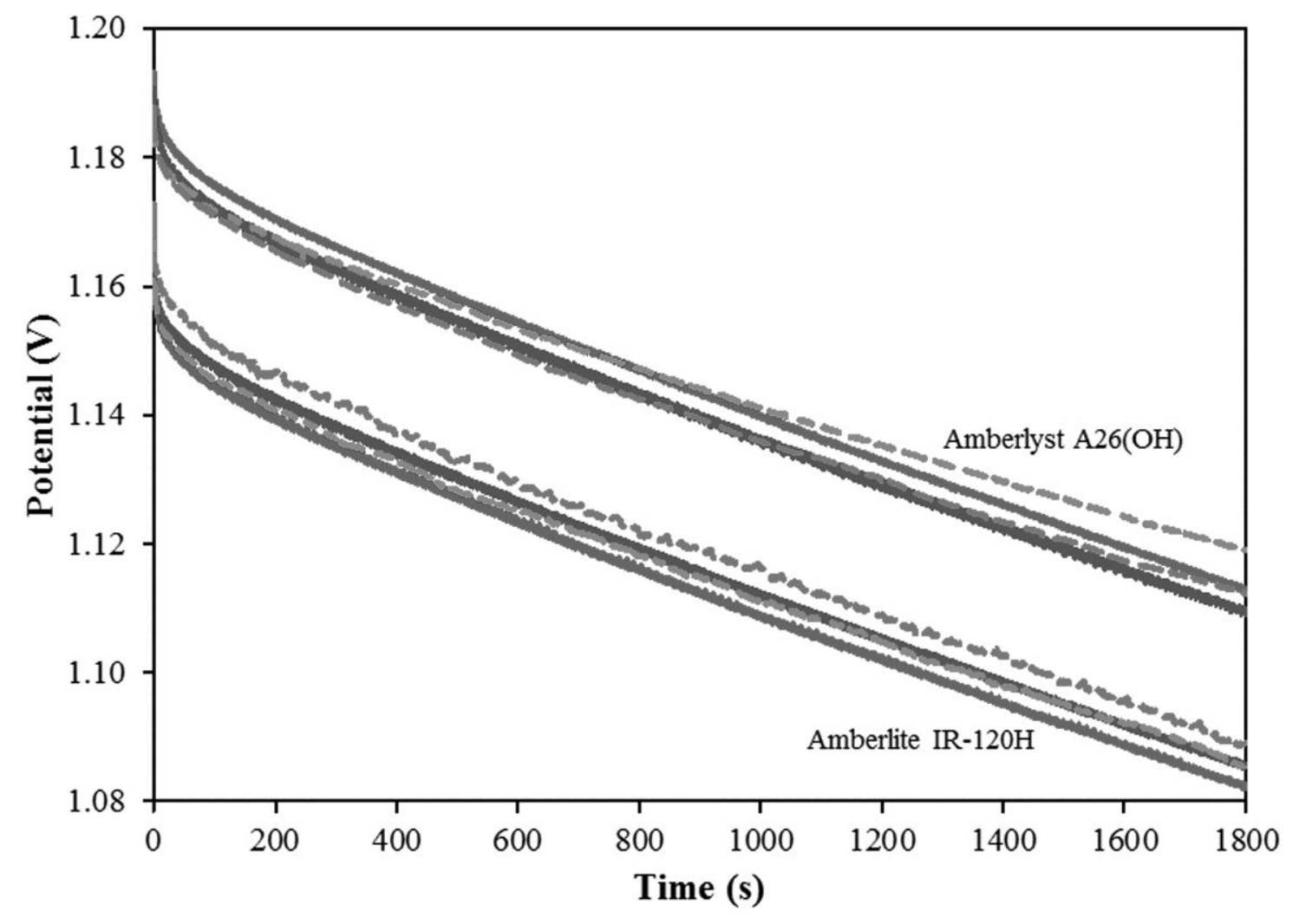

Figure 4.4 Voltage profiles for generation 4.2 convection cells with different IXRs as the separation material. Solid lines were obtained with an anode-to-cathode flow regime and dashed lines were obtained with a cathode-to-anode flow regime. ${ }^{40}$ 


\section{$\mathrm{Li} / \mathrm{MnO}_{2}$ Convection Cell Studies}

After the initial studies that were just discussed, it was becoming clear that the convection cell had a positive impact on the concentration overpotential in the cell. Nevertheless, in order for the convection cell to become viable, a rechargeable and energy dense chemistry would need to be used, such as the lithium-ion chemistry. However, there are more difficulties with the lithium-ion chemistry than the $\mathrm{Zn} / \mathrm{MnO}_{2}$ chemistry because the electrolytes used in lithium-ion cells are highly reactive to the moisture in the air. In addition, cycling the cell comes with its own issues.

It was decided to tackle the hurdles associated with the lithium-ion chemistry and cycling separately. The next studies were done with $\mathrm{Li} / \mathrm{MnO}_{2}$ chemistry to become familiar with handling lithium but not worry about cycling at the same time. A Labconco Controlled Atmosphere glove box filled with argon was used to work with the lithium and its associated electrolytes, both of which are moisture sensitive.

Generation 4.1 convection cells were used with an open-reservoir tubing configuration to look at the effect of flow versus no-flow in cells with the $\mathrm{Li} / \mathrm{MnO}_{2}$ chemistry. The negative electrode of the $\mathrm{Li} / \mathrm{MnO}_{2}$ cells was granular lithium, $99 \%$ trace metals basis, from Sigma Aldrich. The positive electrode was a 90:10 mixture of heattreated-electrolytic manganese dioxide (HEMD) to $4 \mathrm{k}$ carbon ${ }^{51}$ by mass. The HEMD was synthesized by heating electrolytic manganese oxide (EMD) from Erachem Comilog at $375^{\circ} \mathrm{C}$ for $12 \mathrm{~h}$ under a nitrogen purge. The electrolyte consisted of $\mathrm{LiPF}_{6}$ dissolved in a 1:1:1 mixture of ethylene carbonate, dimethyl carbonate, and diethyl carbonate with a vinylene carbonate additive. This was purchased premixed from MTI Corporation. The cell was assembled inside the glove box with the tubing and reservoir attached 
forming a hermetically sealed cell. It was subsequently removed from the glove box and attached to the testing system.

Figure 4.5 represents the constant-resistance discharge voltage profiles of $\mathrm{Li} / \mathrm{MnO}_{2}$ cells at resistances of $2150 \Omega, 986 \Omega, 265 \Omega$, and $98 \Omega$ respectively. The initial voltage, one minute into discharge, ranges from 0.08 to $1.2 \mathrm{~V}$ higher for the convection cells, and the convection cell voltages stay above the cutoff voltage from 9 to 28 hours longer than the corresponding diffusion cell voltages. This is evidence that the convection cell improves the cell performance regardless of chemistry. Moreover, this shows that the cell could successfully be assembled in the glove box with moisturesensitive chemistries and then be removed for testing. 


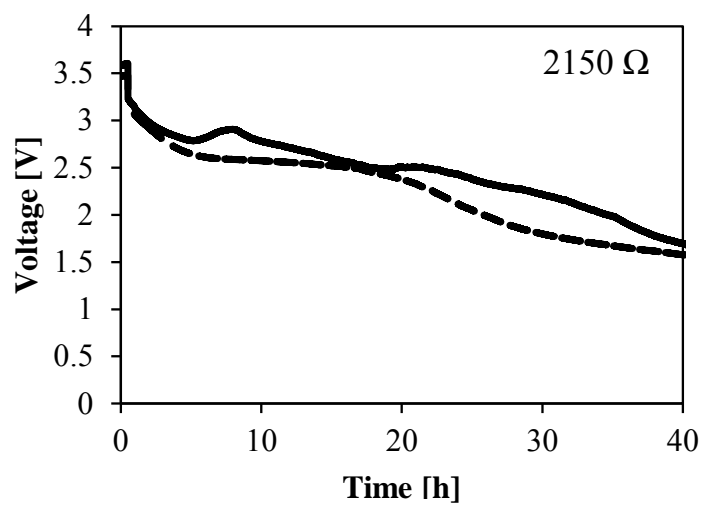

(a)

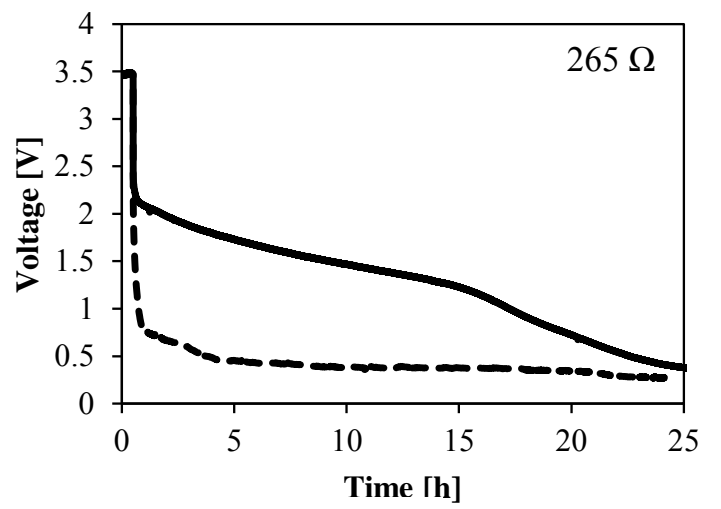

(c)

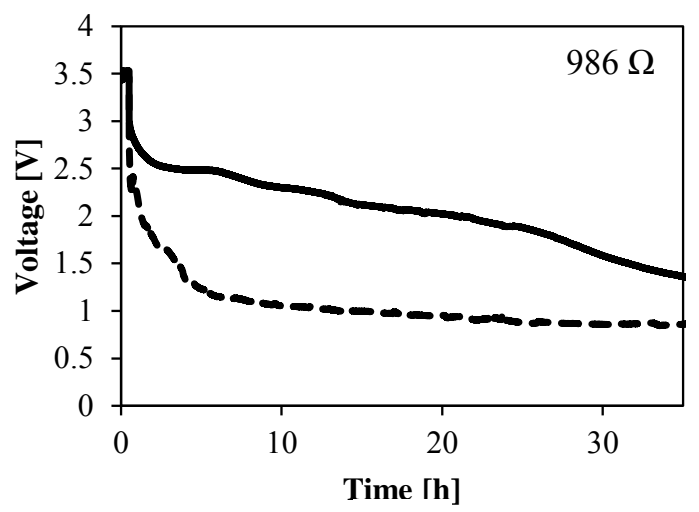

(b)

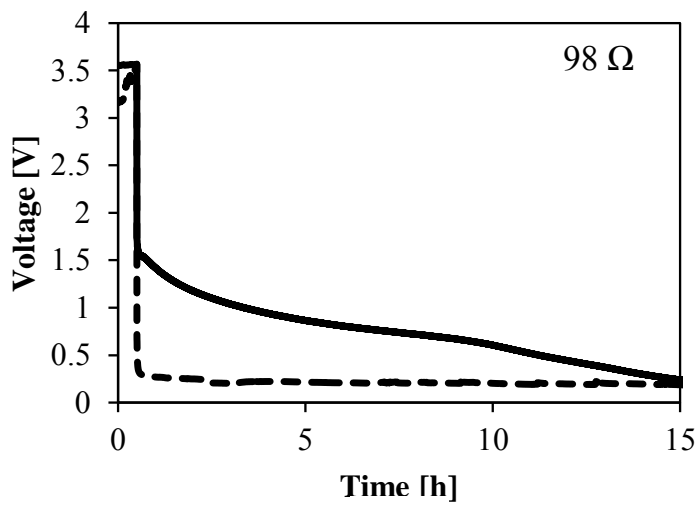

(d)

Figure 4.5 Open circuit and discharge voltage profiles for the $\mathrm{Li} / \mathrm{MnO}_{2}$ convection cells and diffusion cells at $2150 \Omega$ (a), $986 \Omega$ (b), $265 \Omega$ (c), and $98 \Omega$ (d). The convection cells are shown as solid lines and diffusion cells as dashed.

\section{Summary}

In summary the validating studies described in this chapter paved the way for the remaining convection cell research in this work. It was shown that flow in the convection cell decreased the overpotential in the cell regardless of flow direction, and that the performance could be enhanced with the use of additional materials in the separator. In addition lithium was successfully utilized in the convection cell, showing that the convection cell can be applied to a variety of different chemistries. This has laid the 
groundwork for the use of more practical chemistries, specifically lithium-ion chemistries such as $\mathrm{LiFePO}_{4}$. The use of lithium-ion chemistries in the flow cell could help it become viable for the applications discussed in chapter 1. 


\title{
CHAPTER 5
}

\section{LI-ION BATTERY PERFORMANCE IN A CONVECTION CELL CONFIGURATION}

The following paper was published online by the AIChE Journal on Nov 13, 2012:

\section{Li-ion Battery Performance in a Convection Cell Configuration}

Michael Gordon and Galen Suppes

Dept. of Chemical Engineering, University of Missouri, Columbia, MO 65211

\begin{abstract}
The convection battery forces flow of electrolyte through the cathode, anode, and the separator between them, unlike a flow battery where electrolyte cannot cross the separator. The goal is to increase ion fluxes $\left(\mathrm{A} / \mathrm{cm}^{2}\right)$ to realize the benefit of thicker electrodes, lower cost batteries, and reduced charge times. A pump that circulates electrolyte was turned off to create a diffusion control to which the performance of the
\end{abstract}


convection battery was compared. Based on performance at $<1.1 \mathrm{~V}$ overpotential (based on a $3.1 \mathrm{~V}$ open circuit) and similar capacity utilization, the convection battery provided a 5.6 fold increase in ion flux for these initial studies, increasing flux from $1.6 \mathrm{~A} / \mathrm{cm}^{2}$ to 8 $10 \mathrm{~A} / \mathrm{cm}^{2}$. Little capacity fade was observed on the measured discharge cycles (10 cycles). These studies provided an important milestone in the research, development, and validation of a new battery design including cycling studies with lithium iron phosphate chemistry.

\section{Introduction}

Large-scale batteries can be used in conjunction with green energy sources to satisfy rising energy demands in both electric utility and transportation applications in a sustainable manner. Batteries can be used for grid-energy storage to match electricity demand to the output of intermittent energy sources such as wind and solar and constant energy sources like nuclear. Furthermore batteries can provide a mode of emission-free transportation. In order for these applications to come to fruition, large-scale batteries must be made lighter and more cost effective.

A new type of cell, termed a convection cell or convection battery, is being investigated that is aimed at decreasing the cost and mass of large-scale batteries. In the convection cell, electrolyte is pumped through porous electrodes as pictured in Figure 5.1 to decrease diffusion or concentration overpotential losses and make the potential more uniform throughout the electrode. 


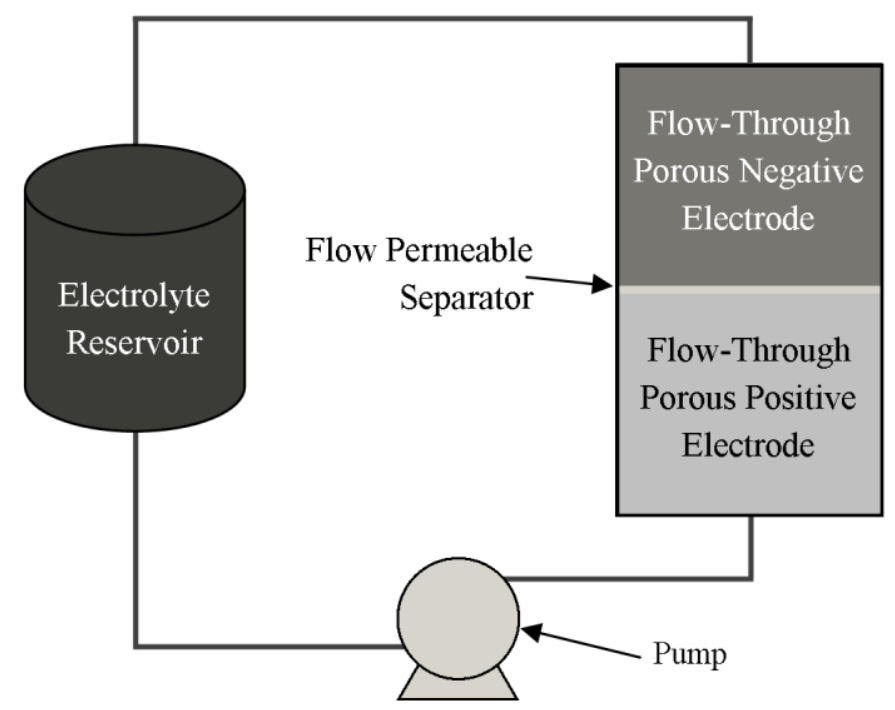

Figure 5.1 A schematic of the convection cell.

In electrochemical reactors, flow-through electrodes can be used for electrowinning, ${ }^{52}$ electro-organic synthesis, ${ }^{53}$ and removal of metals from wastewater streams. ${ }^{54,55}$ For these reactors, flow may be necessary to fully utilize the high surface of porous electrodes; flow-through porous electrodes allow operation at fairly high rates while maintaining selectivity.

Flow-through porous electrodes are frequently used in flow batteries; but with the exception of the convection battery, flow-through separators are not used in commercial or research batteries. In flow batteries either flow-through or flow-by porous electrodes are utilized to distribute active reagents in a liquid electrolyte to the electrodes where reaction occurs. $^{56}$

A key difference between the convection battery and flow batteries (including air batteries) is that the same electrolyte is used in both the anode and cathode in the convection cell. The flow battery requires two separate electrolytes because active species are dissolved in the electrolyte(s) - flow through the separator would mix reactive 
species outside the desired half-cell scheme. ${ }^{29}$ Flow of electrolyte between electrodes in the convection battery is not only allowed, but it can lead to decreased concentration gradients across the separator (at sufficiently high loads). Having one electrolyte also eliminates the need for an ion-selective membrane which is required in the flow batteries to prevent mixing of electrolytes.

Scientific literature describes several different flow cells. Just as with flow reactors, flow patterns and dynamics in flow cells can have a major impact on performance. As described in the previous paragraphs, the convection battery of this paper is unique in design, fluid dynamics, and performance improvements.

A major benefit of the convection battery is compatibility with most commonly used and researched battery chemistries - chemistries that use a single electrolyte. When the convection battery is understood sufficiently, new and improved battery chemistries could be easily incorporated into the convection cell configuration to realize the performance advantages of flow-through separators.

In a convection cell the flow of electrolyte allows the use of thicker electrodes. At sufficiently high currents, in a battery without flow, an inhomogeneous distribution of local current density will develop because of ionic diffusion limitations. ${ }^{22}$ This will lead to a lower overall cell potential and a loss of capacity due to side reactions. Traditional batteries are made with thin electrodes to mitigate these effects. In a convection cell the flow reduces the diffusion limitations, resulting in a higher and more uniform potential throughout the electrode at a given current density. ${ }^{57}$ This allows the use of thicker electrodes which is recognized as a primary means to reduce battery costs. ${ }^{44-46}$ Thicker electrodes result in the use of less separator and current collector materials, which lowers 
material and manufacturing costs while also reducing the mass and volume of the cell. This translates into higher specific capacity and energy density.

The convection battery is pursued due to advantages that could include:

- Better use of thicker electrodes due to a more-uniform distribution of potential in the electrodes.

- Reduced separator and current collector materials which results in lower cost and higher energy density batteries.

- Mitigation of dendrite formation through multiple mechanisms including shear forces from flow which can inhibit single-crystal growth.

- Elimination of drying of electrodes through replenishing of electrolyte.

- Easy temperature management by flow of electrolyte through heat exchangers.

- Ability to routinely drain electrolyte from cells during non-use to increase cell life.

- Ability to increase electrode separation distance due to decreased concentration gradients across the separator.

- Ability to implement measures that will better-allow use of metallic lithium.

- Wide applicability to present and future battery chemistries that use the same electrolyte in both electrodes.

In previous work, the authors have demonstrated the convection battery in primary cell applications with zinc-alkaline chemistry. ${ }^{38,40}$ The purpose of this paper is to present data that validates performance of secondary convection cells using lithium iron phosphate chemistry. $\mathrm{LiFePO}_{4}$, was selected for study because it is a lithium-ion battery 
technology widely regarded as having a good combination of high energy density, good cyclability, safety benefits, and reasonable cost. ${ }^{58}$

The energy and weight required to pump the electrolyte through the convection cell are not addressed at this time because the design parameters to reduce battery system costs are different than those parameters which optimize the performance of the convection battery. As with the vast amount of flow battery research, pumping costs, in both energy and weight, are real; but at the same time, they are not pertinent to the immediate advancement of the science and technology. In addition, pump operation is only needed during high load operation and actual energy costs are a degree of freedom in the overall cell design. As with flow battery technology, pumping costs are a complex function of many variables that are substantially a distraction during fundamental studies

such as those reported in this paper. A recent review on vanadium flow batteries ${ }^{59}$ states that the pump consumes about $8-15 \%$ of the overall energy in standard designs. The energy cost for the convection cell is expected to be lower than this because the convection cell can operate without the pump for extended periods of time when the current density is low. The pump is only necessary at high loads to increase efficiency. With this pumping requirement it is likely that the benefits of the convection battery will outweigh the pump costs in a scaled up cell, but this cannot be determined until the convection battery is more fully understood.

\section{Experimental}

The negative electrode paste used in the cells tested consisted of $62.5 \mathrm{wt} \% 250$ $425 \mu \mathrm{m}$ graphite and $37.5 \mathrm{wt} \%$ binder solution. Acros Organics graphite from Fisher was 
used and sieved to obtain the desired particle size. The binder was a $6 \mathrm{wt} \%$ solution of polyvinylidene fluoride powder (PVDF) in anhydrous n-methyl-2-pyrrolidone (NMP), both from Sigma-Aldrich. The positive electrode paste consisted of $50 \mathrm{wt} \% 250-425 \mu \mathrm{m}$ graphite, $33.3 \mathrm{wt} \%$ binder solution, and $16.7 \% \mathrm{LiFePO}_{4}$ powder obtained from MTI Corporation. The electrolyte was a 1 molar solution of $\mathrm{LiPF}_{6}$ in a 1:1:1 mixture by volume of ethylene carbonate (EC), dimethyl carbonate (DMC), and diethyl carbonate (DEC) with a vinylene carbonate (VC) additive. The premixed electrolyte was also obtained from MTI Corporation.

The convection cell used in these studies is shown in Figure 5.2. This is also the "diffusion" or "control" cell when operated without flow. It consists of two stainless steel pistons fitted with hose barbs to facilitate electrolyte entry/exit, two $1.1 \mathrm{~cm}$ inside diameter stainless steel tubes for the positive and negative electrodes, a high-density polyethylene (HDPE) separation coupling, and two compression plates that are held together with screws and threaded nylon spacers. All work was done in a dry argon-filled glove box until the cell was fully assembled and sealed. 


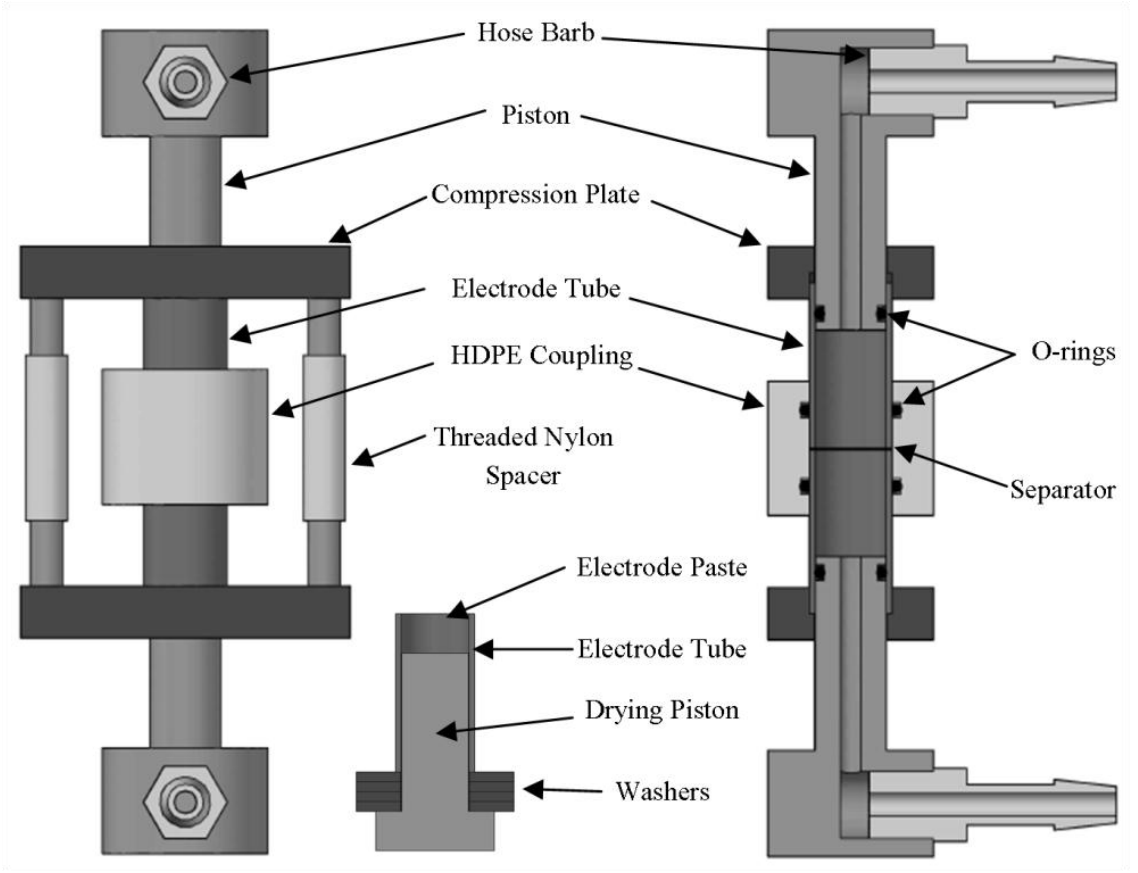

Figure 5.2 Schematic of the test cell for the convection battery and drying piston. Front view (left), rotated cutaway view (right), and cutaway view of the drying piston (center).

The first step in assembling the cell is to dry the electrode pastes in the electrode tubes for the positive and negative electrodes. This is done by using drying pistons (pictured in Figure 5.2 center) that are the same length as the electrode tube. When the piston is inserted into the electrode tubes there is no open volume. Spacers are added between the piston and the bottom of the tube. By doing this the height of the electrode is determined by the height of the spacers. An electrode thickness of $6 \mathrm{~mm}$ was used in these studies. The electrode tubes are then filled with paste and scraped flush with the top of the tubes. The pistons are then placed on a hot plate in the glove box and allowed to fully dry.

After the electrodes are dry, the cell is assembled. The two electrode tubes with the electrodes are inserted into the HDPE coupling and are separated by three pieces of 
$1.27 \mathrm{~cm}$ diameter Fisher P8 filter paper. The sides of the tubes that are flush with the electrode material face the filter paper, so the separation thickness is equal to the thickness of the filter paper. Buna-n O-rings are used to seal between the electrode tubes and the coupling. The two compression plates are then placed on the outsides of the tubes and screwed together with screws from each side with a threaded nylon coupler in the middle to maintain electrical isolation. The pistons are then fitted with O-rings and HDPE hose barbs. They are then inserted into the electrode tubes. Next the tubing is attached to the hose barb in each piston and the electrolyte reservoir. Prior to fully connecting the tubes, $10 \mathrm{~mL}$ of electrolyte is added to saturate the cell and fill the reservoir. A $10 \mathrm{~mL}$ glass volumetric pipette with part of each end cut off was used as a reservoir. A Masterflex L/S high-performance pump head was used with L/S 16HP Norprene tubing to circulate the electrolyte through the convection cells. The flow rate was $0.9 \mathrm{~mL} / \mathrm{min}$ from the positive electrode on the bottom to the negative electrode on top. A pressure of $1200 \mathrm{kPa}$ was applied to the electrodes by adding weights on the top piston.

The test cells were assembled as described above and then connected to an external cycling circuit with switch automation for opening and closing the circuits and controlling the pump. Voltage measurement and automated switch signals were provided by National Instruments LabVIEW software (using custom created virtual instrument files) through a National Instruments PCI-6229 data acquisition card connected to a National Instruments SCB-68 shielded connector block.

For all of the studies of the present work, the cells were operated for 30-minute at open circuit and then cycled. The cells were cycled between 2 and $4 \mathrm{~V}$ using a constant- 
current charge and a constant-resistance discharge. The voltage was recorded over the test so that current and resistance could be calculated for the discharges and charges respectively. For the convection cells the pump was turned on for all of the cycles. For the control cell the pump was turned off for the discharge steps and could be turned on or off for the charging steps depending on the experiment.

The coefficient of permeability was tested for the electrodes and electrode materials using a falling head permeameter according to ASTM test method D5856 95. ${ }^{60}$ A pressure of $1200 \mathrm{kPa}$ was applied to the samples to test the coefficient of permeability. The electrodes were made in the same manner as mentioned above and placed in the permeameter for testing.

\section{Results and Discussion}

The convection battery requires the use of electrodes with good permeabilities to allow flow. As summarized in Table 1, powders such as lithium iron phosphate powder are substantially impermeable to flow. To further exasperate this problem, preliminary studies showed that while packed-bed electrodes worked in primary-cell applications; charging of a depleted cell failed in the absences of a binder like PVDF. This binder tended to further decrease the flow-permeability of the powders. 
Table 5.1 Permeabilities and compositions of dry electrodes and electrode powder materials under a pressure of $1200 \mathrm{kPa}$. The graphite is large-particle graphite with 250$425 \mu \mathrm{m}$ particle sizes.

\begin{tabular}{cccccc}
\hline Description & LiFePO $_{4}$ & Graphite & $\begin{array}{c}\text { PVDF } \\
\text { Binder }\end{array}$ & $\begin{array}{c}\text { Permeability } \\
\text { [Darcy] }\end{array}$ & $\begin{array}{c}\text { Standard } \\
\text { Deviation }\end{array}$ \\
\hline Graphite Powder & N/A & $100 \%$ & N/A & 4 & 2 \\
LiFePO 4 Powder & $100 \%$ & N/A & N/A & $<0.001$ & N/A \\
Negative Electrode & N/A & $97 \%$ & $3 \%$ & 0.8 & 0.4 \\
Positive Electrode & $24.3 \%$ & $72.8 \%$ & $2.9 \%$ & 0.13 & 0.09 \\
\hline
\end{tabular}

A solution to this problem was attained through the use of large-particle graphite, $250-425 \mu \mathrm{m}$, which has an acceptable permeability of 4 Darcy. By mixing lithium iron phosphate powder with $250-425 \mu \mathrm{m}$ graphite and binder, acceptable permeabilities of 0.1 Darcy were attained for the positive electrode. The addition of binder significantly reduces the permeability of the graphite powder, but the negative electrode still has a relatively good permeability of 0.8 Darcy.

Convection cells were assembled using the two electrode compositions summarized in Table 1. Example cycling data for a convection cell, and the diffusion control to which it was compared, are summarized by Figure 5.3. In Figure 5.3, there is a 30 minute open circuit followed by subsequent charge and discharge cycles. For the diffusion control cell, the pump was used during each charging step to assure the same degree of charge as the convection cell; the pump was off during discharge. 

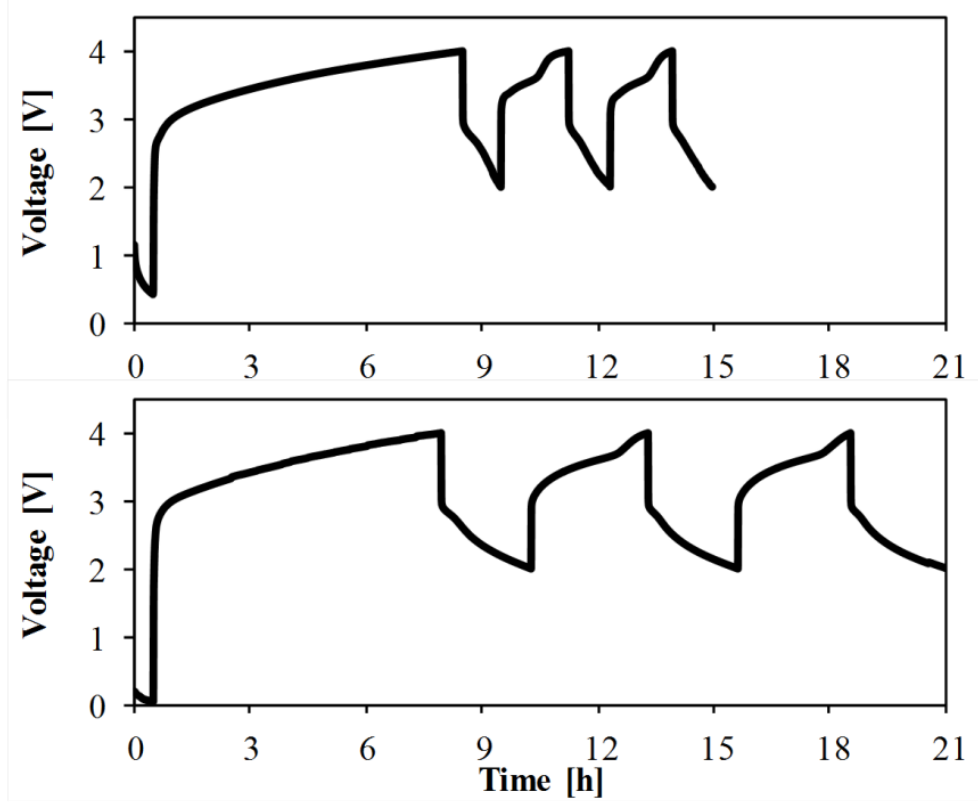

Figure 5.3 Voltage profiles of a convection cell with flow (bottom) and a control cell without flow (top) at a constant discharge resistance of $990 \Omega$. The initial 30 minutes is an open circuit of the discharged cell, followed by subsequent charge and discharge cycles. For the diffusion control studies, the pump was on during charging to ensure that the state of charge at the start of each discharge was the same as the convection cell.

As can be seen by these cycling studies, the convection cell realized a higher discharge time and an associated increased utilization of the electrode reagents. By integrating the voltage divided by the resistance as a function of time (and dividing by the mass of $\mathrm{LiFeO}_{4}$ ) the specific capacities were calculated as summarized by Figure 5.4. 


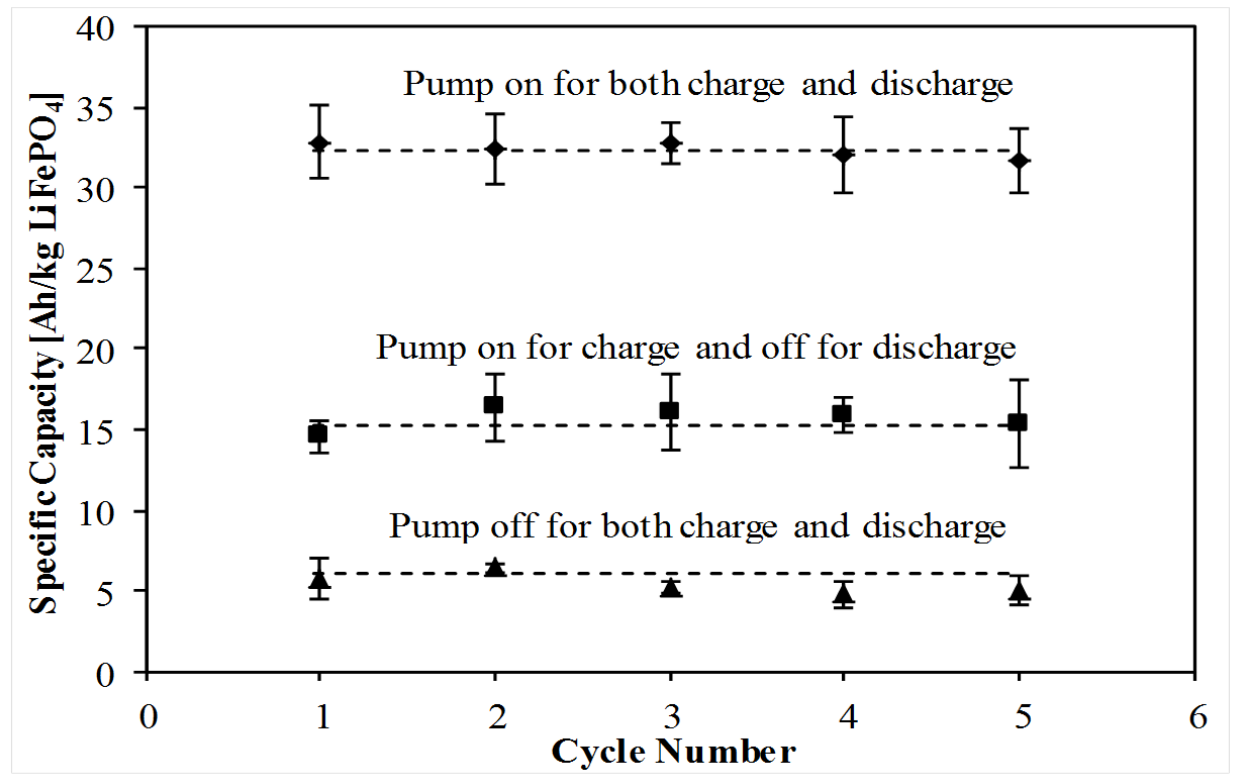

Figure 5.4 Specific capacity upon discharge vs. cycle number at a constant-resistance discharge of $990 \Omega$ for a convection cell and two control cells.

The specific capacities summarized by Figure 5.4 indicate that the convection cell provides consistently higher specific utilization of the active materials. The performances showed little fade with good repeatability. When the pump is turned off during charging as well as discharging, the diffusion control showed even poorer performance.

Performance with the pump on during charging and off during discharging was between the other two performances which is consistent with expectations - it is a further point of validation of benefits of convection. These data show that convection from the cathode (discharge mode) to the anode benefits both charge and discharge; or stated differently, convection assists the transfer of lithium cations to the cathode even when this transfer is against the direction of flow. The author's previous work ${ }^{40}$ summarized a $^{2}$ 
mechanism through which this occurs. This observation has important ramifications in regard to the associated fundamental mechanisms and accurate modeling.

To answer the question of whether the benefits of the convection battery (pumping of electrolyte) are influenced by the history of the cell, studies were conducted with the pump off during discharge for the first five cycles whereafter the pump was on for both charge and discharge (see Figure 5.5). The specific capacities in the convection cell mode of operation (last three cycles of Figure 5.5) were substantially the same as those summarized by Figure 5.4-providing evidence of good reproducibility that is substantially independent of the cell history.

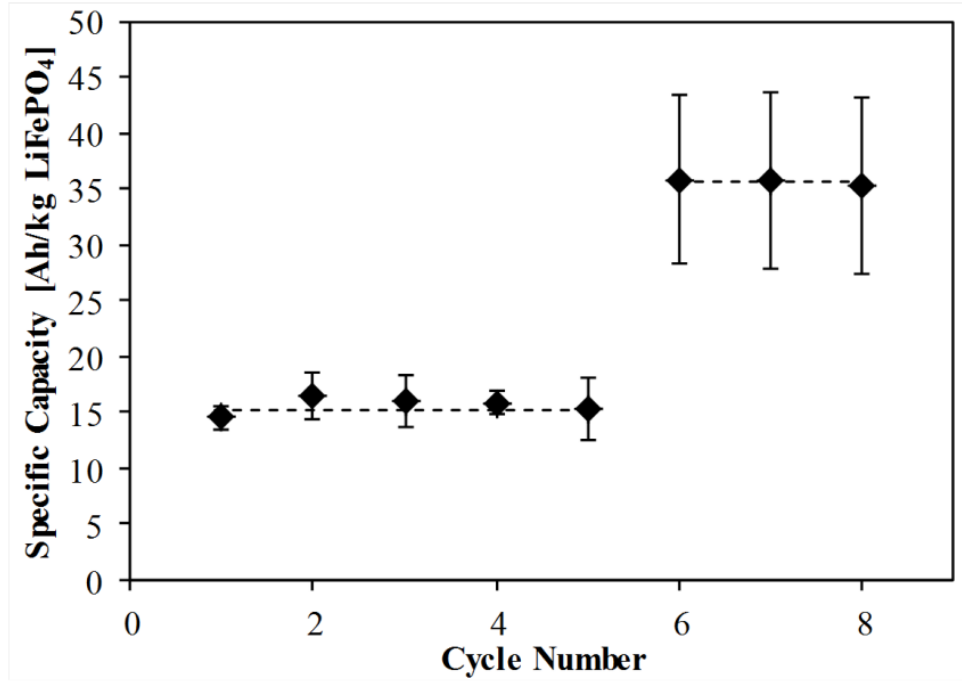

Figure 5.5 Specific discharge capacity vs. cycle number for a cell without convection during the first five discharge cycles and with convection for the last three cycles at a constant-resistance discharge of $990 \Omega$.

Studies were repeated at several resistances to obtain cell performance curves as summarized by Figure 5.6. For the test cell, that had $6 \mathrm{~mm}$ thick electrodes, the utilization of active reagents decreased with increasing load (i.e. lower resistance). The 
convection cell systematically performed better than the diffusion control. It is anticipated that at higher resistances, the gap in performance would diminish, and the two performance curves would asymptotically approach each other. Higher resistances were not studied because the length of time for five cycles would exceed a week.

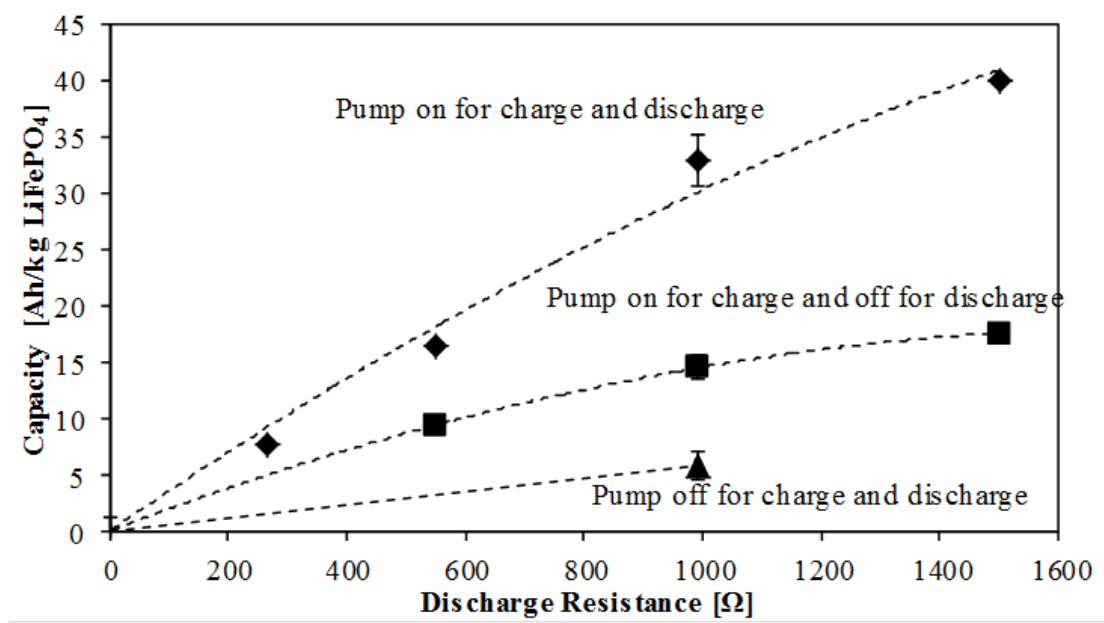

Figure 5.6 Specific discharge capacity vs. discharge resistance for the first cycle of convection cells and control cells.

Comparing the values of the performance curves of Figure 5.6 at similar utilized capacities is substantially equivalent to comparing performance at the same overpotentials since all cells were evaluated until an overpotential of $1.1 \mathrm{~V}$ out of an open-circuit voltage of $3.1 \mathrm{~V}$. The convection battery provided about a 5.6 fold increase in ion flux for these initial studies at the capacity of $5 \mathrm{Ah} / \mathrm{kg}$. For the convection battery, the ion flux was $8-10 \mathrm{~A} / \mathrm{cm}^{2}$ as compared to $1.6 \mathrm{~A} / \mathrm{cm}^{2}$ for the diffusion control.

To further exemplify the difference in performances at different loads and overpotentials seen in Figure 5.6, voltage profiles at several loads are summarized in Figure 5.7. These curves provide more information than the total specific capacity-it 
allows performances to be compared at several different overpotentials. This comparison shows that the convection cells consistently are able to utilize more capacity over a range of loads. The convection cell is able to sustain longer operation due to the improved ion mass transfer from convective flow.
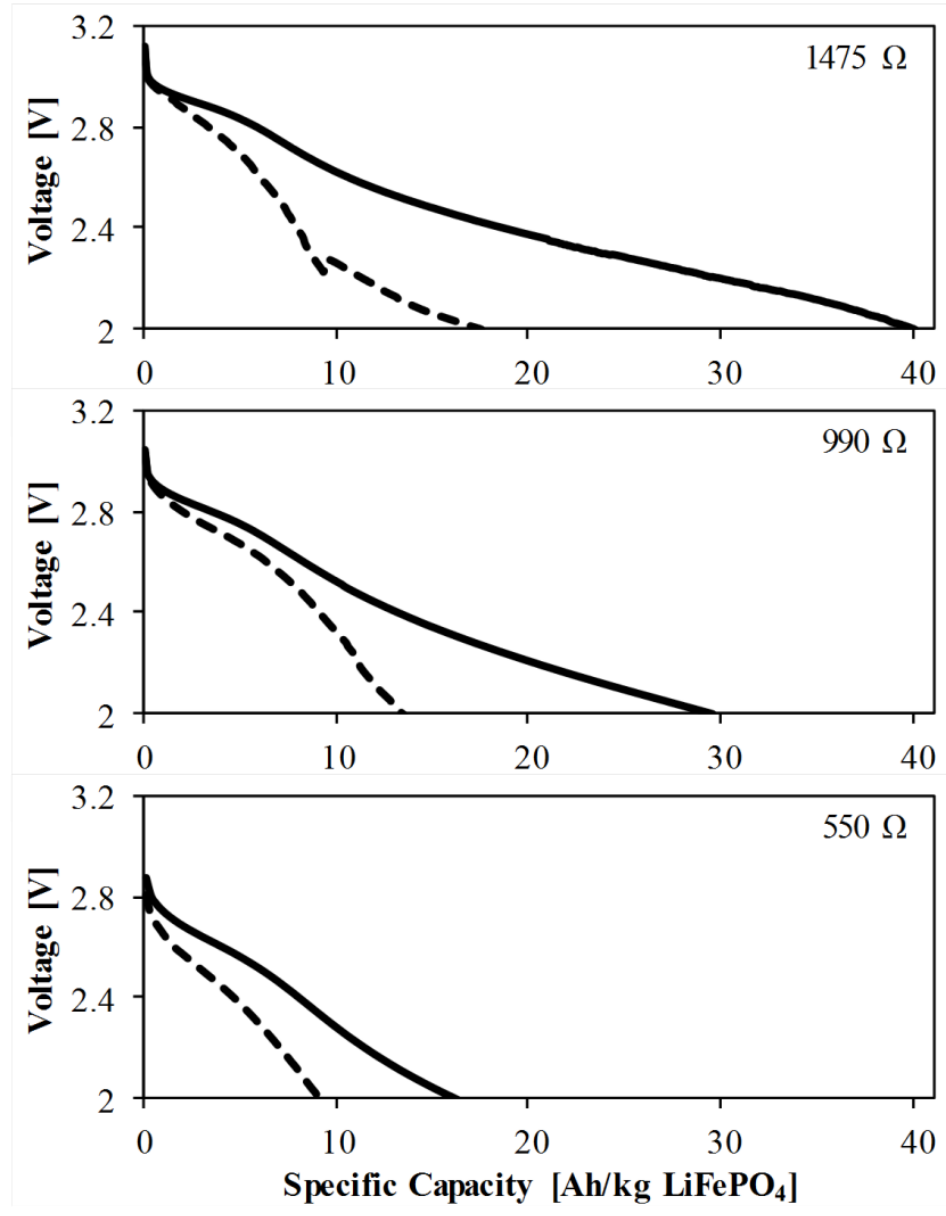

Figure 5.7 Comparison of discharge voltage profiles at several different constant discharge resistances. Solid lines represent convection cells and dashed lines represent the control diffusion cells.

These studies were performed with $6 \mathrm{~mm}$-thick electrodes-these lithium-ion electrodes are 60-200 times thicker than those commercialized with slurry-coating 
technologies. The maximum utilization observed was about $25 \%$ of the theoretical capacity of $170 \mathrm{Ah} / \mathrm{kg}$ based on the loading of lithium-iron-phosphate in the cathode (discharge mode) during cell assembly. While $25 \%$ of theoretical is less than desired, it substantiates an absolute capacity far greater than that of cells with electrode thicknesses of about $0.05 \mathrm{~mm}$, as is typical for commercial lithium-ion batteries. The authors believe that while convection decreases the concentration overpotential, increasing the electrode thickness can increase other overpotentials that affect the cell performance. Therefore there should be optimal thickness between $0.05 \mathrm{~mm}$ and $6 \mathrm{~mm}$ that can provide greater utilization with the use of convection. The optimal thickness can be highly dependent on material properties and other factors specific to design constraints.

The data substantiate a significant improvement in performance of the convection battery versus the diffusion control. The advantages of flow-through versus flow-by separators in batteries remains a topic of further investigation. One advantage of flowthrough membranes is the reduced travel path between electrodes and associated frictional losses from flow. For example, a simple exercise in geometry reveals that the mean travel path over a $1 \mathrm{~m}^{2}$ separator to a single $1 \mathrm{~cm}^{2}$ orifice through the separator is about $0.36 \mathrm{~m}$. For a $1 \mathrm{~m}^{2}$ separator with $40.25 \mathrm{~cm}^{2}$ orifices, the mean travel path can be reduced to $0.18 \mathrm{~m}$; the mean travel path being cut in half each time the number of orifices (with the same cumulative area) is quadrupled. This trend continues until the distance between orifices approaches the thickness of the electrode; hence, the transition from flow-by to flow-through separators is a continuous transition with at least one definitive advantage associated with flow-through separators. 
The improvement in performance due to the convection is attributed to a reduction in the concentration overpotential, $U_{\text {conc }}$, which is approximated by Equation 5.1 in a dilute binary electrolyte, which is derived from the Nernst-Planck equation. ${ }^{61}$

$$
U_{\text {conc }}=\frac{z_{+}-\left(z_{+}-z_{-}\right) t_{+}}{z_{+} z_{-}} \frac{R T}{F} \ln \frac{c_{I}}{c_{I I}}
$$

where $z$ is the charge number of the respective ion, $t_{+}$is the transference number for the positive ion, $F$ is Faraday's constant, $R$ is the universal gas constant, $T$ is the absolute temperature, and $c_{I}$ and $c_{I I}$ are the salt concentrations at two different points within the electrolyte. In a cell without convection large concentration differences can develop in the electrolyte resulting in concentration overpotentials described by the above equation.

It is important to recognize that these are only initial, validating studies. Comparison of the overall convection cell performance, including the costs of pumping, to a standard $\mathrm{Li}$-ion cell is of little value at this point in the research. A host of future studies needs to be performed to increase capacity utilization, identify the best match of materials with the needs of the convection battery, better distinguish between advantages of flow-by versus flow-through separators, and generally optimize performance.

\section{Conclusion}

The convection battery has been demonstrated with an important lithium-ion chemistry with cycling. Benefits of the convection battery include increased utilization of capacity and reduced overpotentials. When considered in combination with previous studies using zinc-alkaline chemistry; the convection battery approach is concluded to be generally applicable to battery chemistries that use the same electrolyte in both electrodes. 
Substantially increased ion fluxes $\left(\mathrm{A} / \mathrm{cm}^{2}\right)$ through the separator and respective increases in current were observed for the convection battery as compared to the diffusion control at similar utilization of the active components. These increased ion fluxes can be used to reduce separator areas in batteries and increase thickness of electrodes; leading to improved combinations of higher power/energy ratios and lower costs.

The $6 \mathrm{~mm}$ thick electrodes were a bit ambitious for these initial studies; however, evidence indicates that there is an optimum electrode thickness between 0.05 and $6 \mathrm{~mm}$ where good utilization is very attainable and a significant increase in performance can be obtained compared to standard cells with electrode thicknesses of about $0.05 \mathrm{~mm}$. As the optimal materials to achieve the advantages of the convection battery remain yet to be identified, increased fluxes and increased electrode thickness are likely attainable.

Mechanistically, these studies showed that convection assists both charge and discharge - independent of direction of flow. Solid-liquid interfaces likely play a key role in promoting counter-ion counter-diffusion and the stabilization of ion concentration gradients which is vital to the performance advantages of the convection battery and the lack of sensitivity to flow direction.

\section{Acknowledgements}

Special thanks are extended to the California Energy Commission and the National Science Foundation for funding aspects of this research. 


\title{
CHAPTER 6
}

\section{CONVECTION BATTERY - MODELING, INSIGHT, AND REVIEW}

The following paper was published online by the AIChE Journal on March 18, 2013:

\section{Convection Battery - Modeling, Insight, and Review}

Michael Gordon and Galen Suppes

Dept. of Chemical Engineering, University of Missouri, Columbia, MO 65211

\begin{abstract}
Porous electrode theory was used to model performance of the convection battery using lithium iron phosphate chemistry. The model results and underlying equations were able to quantify and extend previous interpretations of laboratory validation studies. These analyses substantiated the following conclusions on the performance of the convection battery: a) flow in the convection battery can reduce concentration overpotentials by $99.9 \%$, b) both the ionic and electron conductivities of solid phases can have a major impact on convection battery performance, and c) the solid phase ionic
\end{abstract}


conductivity of a porous separator is an important design parameter and is not considered by porous electrode theory as published to date. In view of the ability of the convection battery to overcome both bulk diffusion and liquid phase effective conductivity limitations; the convection battery has an unprecedented potential to redefine the performance of large batteries.

\section{Introduction}

The convection battery uses a new cell configuration ${ }^{37-41}$ with pumped-electrolyte convection to overcome bulk diffusion limitations. This paper uses the porous electrode theory ${ }^{62-66}$ model to interpret data, provide insight into the physiochemical properties that impact performance, identify performance potential, and identify the materials and configurations needed to attain the performance potential. 
Table 6.1 summarizes potential advantages of batteries using convection battery cells. It is recognized that some of these advantages do not come without a price; however, that price becomes an increasingly small part of the total battery cost for large batteries. It is also important to recognize that these advantages could be applied to most battery chemistries - the exception is that the convection battery is not compatible with flow battery chemistries. 
Table 6.1 Design options for the convection battery architecture.

\begin{tabular}{ll}
\hline $\begin{array}{l}\text { Increased ion flux } \\
\text { through } \\
\text { separator/membrane }\end{array}$ & $\begin{array}{l}\text { This would lower the cost for attaining increased current ratings in } \\
\text { batteries. For larger batteries the goal is a }>10 \mathrm{X} \text { increase in limiting } \\
\text { current (same battery configuration with and without flow). The goal is } \\
\text { for a } 50 \% \text { decrease in the price for convection battery versus diffusion } \\
\text { battery at the same C rating. }\end{array}$ \\
\hline Control of ion flux & $\begin{array}{l}\text { The goal is to be able to increase the current rating of a given convection } \\
\text { battery by turning the pump on. For example a PHEV battery that would } \\
\text { only require that the pump be turned on during acceleration or rapid } \\
\text { battery charging at a station. }\end{array}$ \\
\hline Heat removal & $\begin{array}{l}\text { The goal is for the use of an in-line radiator that will remove heat at } \\
\text { basically any needed rate. }\end{array}$ \\
\hline Safety & $\begin{array}{l}\text { The goal is to reduce battery power by turning off the pump. } \\
\text { Manufacturing / } \\
\text { regeneration } \\
\text { options }\end{array}$ \\
$\begin{array}{l}\text { The goal is to be able to load or recharge an active material into an } \\
\text { electrode of a battery from an exterior canister by flowing electrolyte } \\
\text { through the electrode and controlling voltage to achieve desired electro- } \\
\text { deposition (or other) loading. }\end{array}$ \\
\hline Li-plated anodes & $\begin{array}{l}\text { The goal is to use a combination of flow, thicker separators, and charging } \\
\text { cycles to allow the use of metallic (or plated) lithium in secondary } \\
\text { batteries. }\end{array}$ \\
\hline $\begin{array}{l}\text { Shelf life, fade, and } \\
\text { parasitic reactions }\end{array}$ & $\begin{array}{l}\text { The goal is to be able to routinely drain electrolyte from the battery as part } \\
\text { of normal operation to extend shelf life, reduce fade, and reduce parasitic } \\
\text { losses. }\end{array}$ \\
\hline
\end{tabular}

Both flow batteries and convection batteries use pumps to circulate electrolyte through electrodes as illustrated by Figure 6.1; however, beyond this similarity they are substantially different. The convection battery pumps electrolyte directly from an electrode to its counter-electrode through a flow-permeable separator with the purpose of eliminating concentration overpotentials - the reagents are stored in solid phases as part of the electrodes. The flow battery ${ }^{10,59,67,68}$ stores the reagents in one or both liquid electrolytes and uses flow to deliver the reagent to the electrode(s); the electrolyte of the anode is kept separate from the electrolyte of the cathode to avoid the mixing of reactive reagents. The combinations of reagents and electrolytes compatible with flow batteries versus convection batteries are mutually exclusive. 


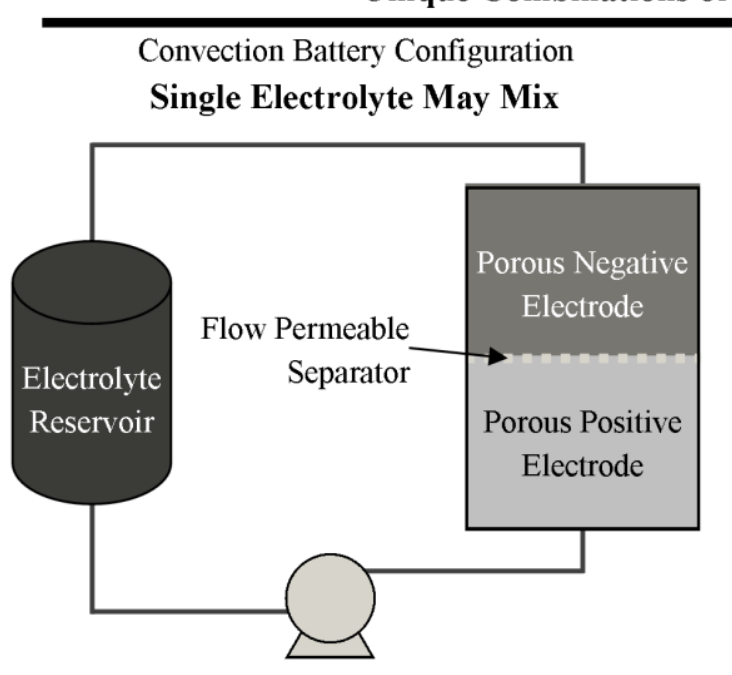

Flow Battery Configuration

\section{Dual Electrolytes May Not Mix}

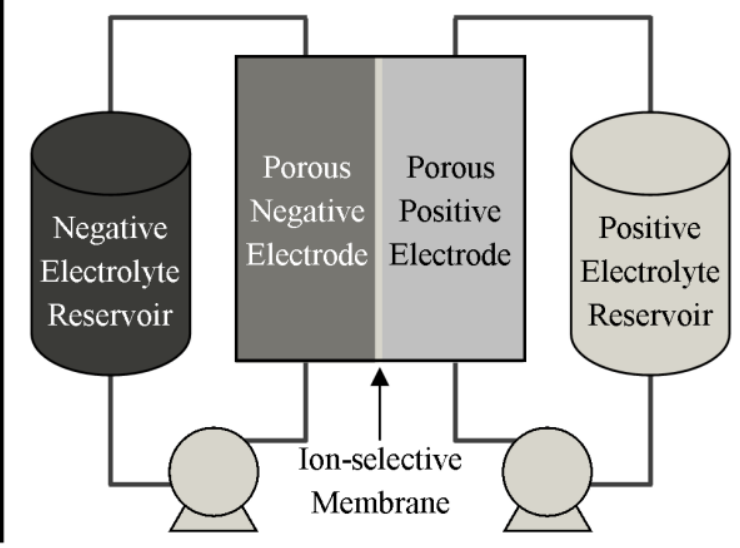

Figure 6.1 Illustration of convection versus flow battery cells emphasizing the null overlap in combinations of reagents and electrolytes compatible with each type of cell.

Both convection and flow batteries have capital and operating costs associated with the pumping of electrolyte. While the determination of pumping costs is an advanced aspect of development and design rather than research; at this research stage on convection batteries certain conclusions can be made about the relative pumping costs of convection versus flow batteries.

As implicit by Figure 6.2, the capital costs associated with pumping in the convection cell are about half those of flow batteries. 


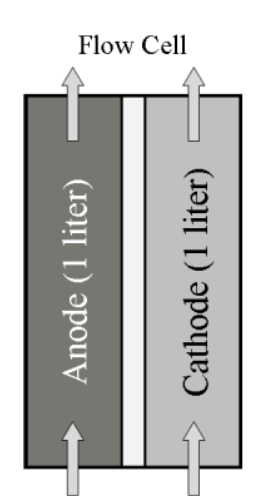

Two pump loops. 1 liter each $(2 \mathrm{~L})$ for full displacement.

1 Watt assumed basis

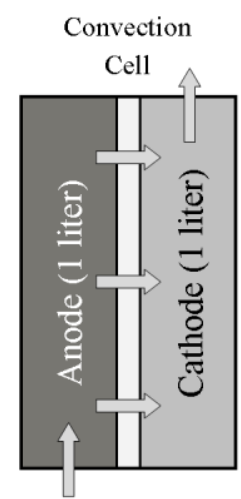

One pump loop. 1 liter for full displacement. $\sim 0.6$ Watt

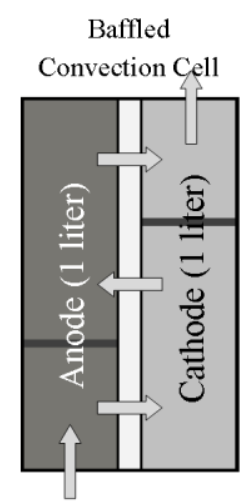

One pump loop.

0.67 liter for full

displacement.

$\sim 0.3$ Watt

Figure 6.2 Comparison of flow patterns for standard flow battery design as compared to standard and baffled convection battery designs. A basis is assumed of 1 liter void volumes in electrodes and a $1 \mathrm{~W}$ basis for the flow battery.

The energy costs are primarily related to the volume that needs to be displacedthis is based on the assumption that pressure drop is less important for low pressure drop designs where the piping and connections tend to normalize pressure drops. Figure 6.2 illustrates the flow pattern for a flow battery and two options for the convection battery. The flow battery requires full displacement of the void volumes of the electrodes for full displacement of electrolyte while the base case convection battery requires displacement of half of the electrode void volumes. This is because the goal of pumping in the convection battery is to displace one electrode volume into the counter-electrode rather than to introduce fresh electrolyte into both electrodes.

An option with the convection battery is to use baffles to direct electrolyte backand-forth between electrodes several times before the electrolyte exits. Figure 6.2 illustrates how two baffles can reduce the volume of displacement relative to the flow 
battery from 2 liters to 0.67 liters. A 9 baffle system would require $10 \%$ of the relative volume displacement. For the case where the pump is only needed $10 \%$ of the time, the convection battery would require about $1 \%$ of the energy of a comparable flow battery based on these assumptions.

The focus of this paper is on modeling of convection battery performance and the conclusions that can be drawn from this modeling. Porous electrolyte theory provides one of the most comprehensive approaches to modeling the phenomena occurring in the convection battery. Previous publications on the convection battery have described experimental systems, presented data, and provided qualitative interpretations of data. The purpose of this paper is to quantify the previously only qualitative insight and to provide additional insight and interpretations of convection battery performance. All model solutions presented in this paper are for the lithium iron phosphate chemistry. ${ }^{69,70}$

\section{Model Development}

The model consists of both a one-dimensional geometry and a two dimensional geometry. The one-dimensional geometry, with the length of the battery along the x-axis, is used to describe the liquid phase material balance, the liquid phase charge balance, and the solid phase material balance and is split into four sections along the axis: the negative electrode (anode during discharge), the separator (sometimes referred to as the membrane), the positive electrode (cathode during discharge), and the circulating tube that directs the electrolyte through the pump and into the counter-electrode. Positive flow is referred to as flow that is in the same direction as the $\mathrm{Li}^{+}$flow in the case of diffusion 
cell operation; more specifically, positive flow is where electrolyte exits the cathode, then enters the pump, and then enters the anode (counter-electrode).

The two-dimensional geometry, with the length of the battery along the x-axis, corresponding to the one-dimensional model, and the particle radius along the y-axis, is used to describe the intercalation of lithium ions in the solid electrodes. This geometry is linked to the one-dimensional geometry at the upper boundary of the y-axis or the maximum particle radius. The values for the solid phase concentration of lithium ions at this boundary are projected onto the corresponding $\mathrm{x}$-axis value in the one dimensional model and are used to calculate the exchange current between the solid electrodes and the electrolyte.

Porous electrode theory reduces to solving Equation 6.1 through Equation 6.4 specific to this pseudo one-dimensional battery configuration where the anions and cations have single charges in a binary electrolyte: the liquid phase material balance which provides concentrations of the cation and anion in the electrolyte:

$$
\epsilon \frac{\partial c_{+}}{\partial t}=D_{2}^{e f f} \frac{\partial^{2} c_{+}}{\partial \mathrm{x}^{2}}-\mathrm{v}^{*} \frac{\partial c_{+}}{\partial \mathrm{x}}+\frac{\left(1-t_{+}^{*}\right)}{F} a i_{n}
$$

Equation 6.1

the liquid phase charge balance which provides a charge continuity via the liquid throughout the cell where,

$$
\kappa_{2}^{e f f} \frac{\partial^{2} \Phi_{2}}{\partial x^{2}}=\frac{2 R T \kappa_{2}^{e f f}}{F}\left(1-t_{+}^{*}\right) \frac{\partial^{2} \ln (\mathrm{c})}{\partial x^{2}}-a i_{n}
$$

the solid phase material balance where,

$$
\frac{\partial c_{s}}{\partial t}=D_{s}\left[\frac{\partial^{2} c_{s}}{\partial r^{2}}+\frac{2}{r} \frac{\partial c_{s}}{\partial r}\right]
$$

and the solid phase charge balance where, 


$$
-\kappa_{1}^{e f f} \frac{\partial^{2} \Phi_{1}}{\partial x^{2}}=-a i_{n}
$$

The Butler-Volmer equation (Equation 6.5) is used to relate the overpotential driving force for the transfer of mass to/from the solid electrode and the electrolyte.

$$
\begin{array}{r}
i_{n}=i_{0}\left[\exp \left(\frac{\alpha_{a} F \eta_{s}}{R T}\right)-\exp \left(-\frac{\alpha_{c} F \eta_{s}}{R T}\right)\right] \quad \text { Equation 6.5 } \\
\mathrm{i}_{\mathrm{n}}=\mathrm{i}_{0}\left[\exp \left(\frac{\alpha_{\mathrm{a} 1} \mathrm{~F} \eta_{\mathrm{s} 1}}{\mathrm{RT}}\right)-\exp \left(-\frac{\alpha_{\mathrm{c} 1} \mathrm{~F} \eta_{\mathrm{s} 1}}{\mathrm{RT}}\right)\right] \text { Equation } 6.6 \text { and Equation } 6.7 \text { express the }
\end{array}
$$

Butler-Volmer terms in terms of parameters related to the materials of the battery.

$$
\begin{aligned}
& \eta_{s}=\Phi_{1}-\Phi_{2}-\mathrm{U}_{1} \\
& i_{0}=F\left(k_{a}\right)^{\alpha_{c}}\left(k_{c}\right)^{\alpha_{a}}\left(c_{s, \max }-c_{s}\right)^{\alpha_{c 1}}\left(c_{s}\right)^{\alpha_{a}}
\end{aligned}
$$

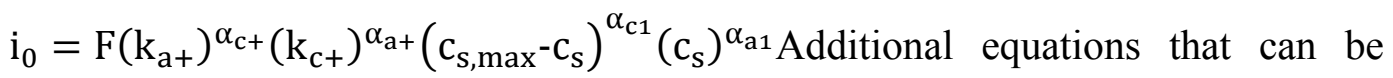

used to provide insight into the performance are the ion flux equations for the anion (Equation 6.8) and the cation (Equation 6.9):

$$
\begin{aligned}
& \boldsymbol{N}_{-}=-D_{2}^{e f f} \frac{d c_{-}}{d x}-\frac{\boldsymbol{i}_{2} t_{-}^{*}}{F}+c_{-} \boldsymbol{v}^{*} \\
& \boldsymbol{N}_{+}=-D_{2}^{e f f} \frac{d c_{+}}{d x}+\frac{\boldsymbol{i}_{2} t_{+}^{*}}{F}+c_{+} \boldsymbol{v}^{*}
\end{aligned}
$$

Figure 6.3 presents a case of the limiting performance of the solution to Equation 6.1 through Equation 6.7 for the limiting case of the diffusion cell with a velocity of zero. In the limit of no flow, the model generates typical concentration profiles for a diffusion cell. With increasing velocities the concentration profiles flatten. This type of limiting behavior is consistent with expectations and serves to validate that the model does not violate known trends in behavior. 


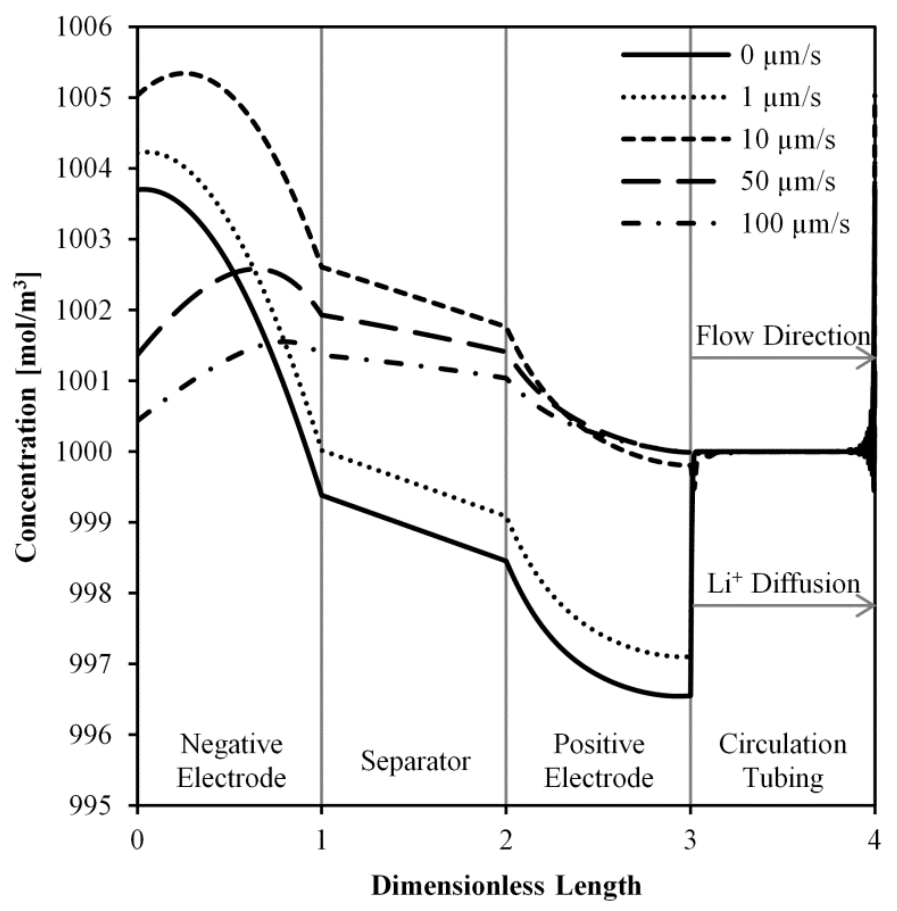

Figure 6.3 Concentration profiles for porous electrode theory model using a combination of parameter values from literature and high diffusivity.

At low velocities the circulation tube shows transient behavior, with the concentration in the middle of the tube not impacted by the flow for the time frame of this simulation. The formation of maxima concentration in the anode is a result of a combination of dilution due to electrolyte flow from the circulating tube and diffusion.

The flat profile of the circulation tube is a result of the volume of electrolyte in the circulation tube being relatively large and the cross-sectional area (for mass transfer) being relatively low. 


\section{Model Solutions}

Model parameters (diffusivity and solid-phase $\mathrm{Li}^{+}$diffusivities) were fit to data for the lithium iron-phosphate cell that were previously published. ${ }^{41}$ Figure 6.4 shows the model lines superimposed over the experimental data. The model fit qualitatively agrees with experimental data. For both the model and the experiment, the performance with flow is considerably better than performance without flow. For initial studies, the convection cell was able to provide currents up to five times greater than the diffusion cell while realizing similar utilization of active materials. Once the parameters were fitted to the model, the performance of the cell was simulated for both positive and negative flow conditions. Figure 6.5 summarizes the voltage drops across the separator vs. time as generated by the simulation at a discharge current density of $2.65 \mathrm{~mA} / \mathrm{cm}^{2}$.

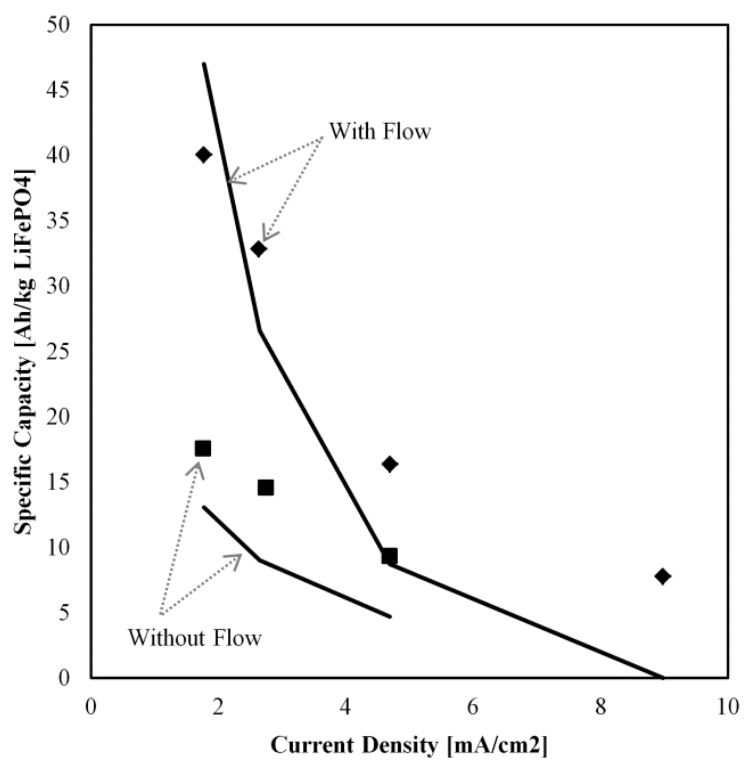

Figure 6.4 Performance curves for the convection versus diffusion battery cell using same loadings and test cell. Flow was turned off on the convection cell to obtain diffusion cell performance. The symbols are for experimental constant-resistance 
discharge with capacity being measured to a cut-off voltage of 2.0 volts from a previous publication. ${ }^{41}$ The lines are model fits using a constant-current discharge.
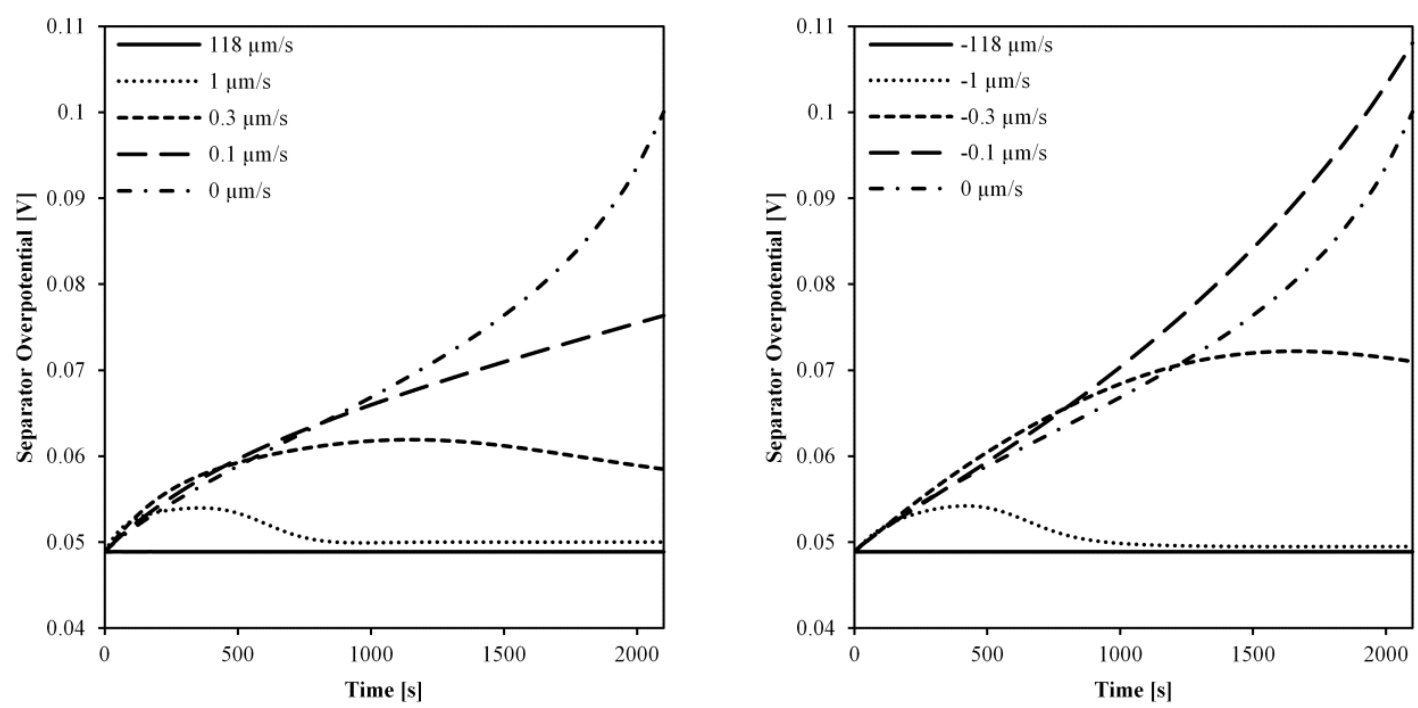

Figure 6.5 Overpotential in the separator as a function of time for different velocities, with positive flow in the left graph and negative flow in the right graph.

Since $\mathrm{Li}^{+}$is the reactive ion that must move from the anode to the cathode during discharge, it is reasonable to hypothesize that the electrolyte should flow from the anode to the cathode during discharge for the best results; this flow direction is referred to as a positive flow direction. These diagrams show voltage drop (overpotential) across the separator for positive versus negative flow as a function of time at the same constant current.

The following are observed: a) for the case of the diffusion cell (velocity $=0$ ), the overpotential increases as the concentration gradients increase in the separator, b) flow substantially reduces the voltage drop (overpotential) relative to the diffusion cell, c) higher velocities result is an essentially constant voltage drop due to the elimination of 
concentration gradients in the convection-dominated cell, and d) the flow direction impacts the transitional behavior between diffusion-dominated mass transport at low velocities and convection-dominated mass transport at high velocities. The hypothesis is valid in the transition from diffusion-dominated to convection-dominated behavior but does not apply at high flow rates (high velocity).

From Figure 6.5, the initial overpotential across the separator is $0.0489 \mathrm{~V}$ for all of the flow rates. Initially the cell is in equilibrium, so there are no concentration gradients, and thus no concentration overpotentials. Therefore this $0.0489 \mathrm{~V}$ is the ohmic overpotential in the separator, which is constant because the model uses a constantcurrent discharge. The total overpotential at $2100 \mathrm{~s}$ into the discharge with no flow is $0.100 \mathrm{~V}$, which translates to a concentration overpotential of $0.051 \mathrm{~V}$ by subtraction of the ohmic overpotential. At $2100 \mathrm{~s}$, for velocities of both $+118 \mu \mathrm{m} / \mathrm{s}$ and $-118 \mu \mathrm{m} / \mathrm{s}$, the concentration overpotential is only $2 \times 10^{-5} \mathrm{~V}$. This is a $99.9 \%$ reduction in the concentration overpotential in the separator with flow in either the positive or the negative direction.

At low velocities such as +0.1 and $-0.1 \mu \mathrm{m} / \mathrm{s}$ the flow direction can have a significant impact on the concentration overpotential as predicted. At $2100 \mathrm{~s}$ into discharge, the concentration overpotential for $+0.1 \mu \mathrm{m} / \mathrm{s}$ is $0.027 \mathrm{~V}$, and it is $0.059 \mathrm{~V}$ for a velocity of $-0.1 \mu \mathrm{m} / \mathrm{s}$. However as the velocity increases the effect of flow direction is diminished as seen at $118 \mu \mathrm{m} / \mathrm{s}$.

Two convection cells were cycled with a $2.19 \mathrm{~mA} / \mathrm{cm}^{2}$ constant-current charge and a $2.65 \mathrm{~mA} / \mathrm{cm}^{2}$ constant-current discharge cycles - one with a velocity of $+118 \mu \mathrm{m} / \mathrm{s}$ and the other with a velocity of $-118 \mu \mathrm{m} / \mathrm{s}$. The assembly of these convection cells has 
been reported previously. ${ }^{41}$ The cells with a positive flow had a capacity of $12 \mathrm{Ah} / \mathrm{kg}$ of $\mathrm{LiFePO}_{4}$, and the cells with a negative flow rate had a capacity of $13 \mathrm{Ah} / \mathrm{kg}$ of $\mathrm{LiFePO}_{4}$. The $<10 \%$ difference between these two cells is within the experimental error and indicates that the direction of flow has little effect at high flow rates. In the model, when flow does make a difference, positive velocities would result in a larger capacity, which is contrary to the minor difference in performance that was detected.

Figure 6.6 summarizes the concentration profiles as modeled for different velocities at $2100 \mathrm{~s}$ into the discharge based on parameters fitted to cell voltage data with a discharge current density of $2.65 \mathrm{~mA} / \mathrm{cm}^{2}$. For positive flow profiles, the concentration in the separator transitions from: a) a gradient that dominated the driving force for $\mathrm{Li}^{+}$ mass transfer, b) to a fairly flat $\mathrm{Li}^{+}$concentration profile at moderate flow rates where ion concentrations are higher in the separator than in the convection tube, and c) to a substantially flat concentration profile at higher flow rates. 

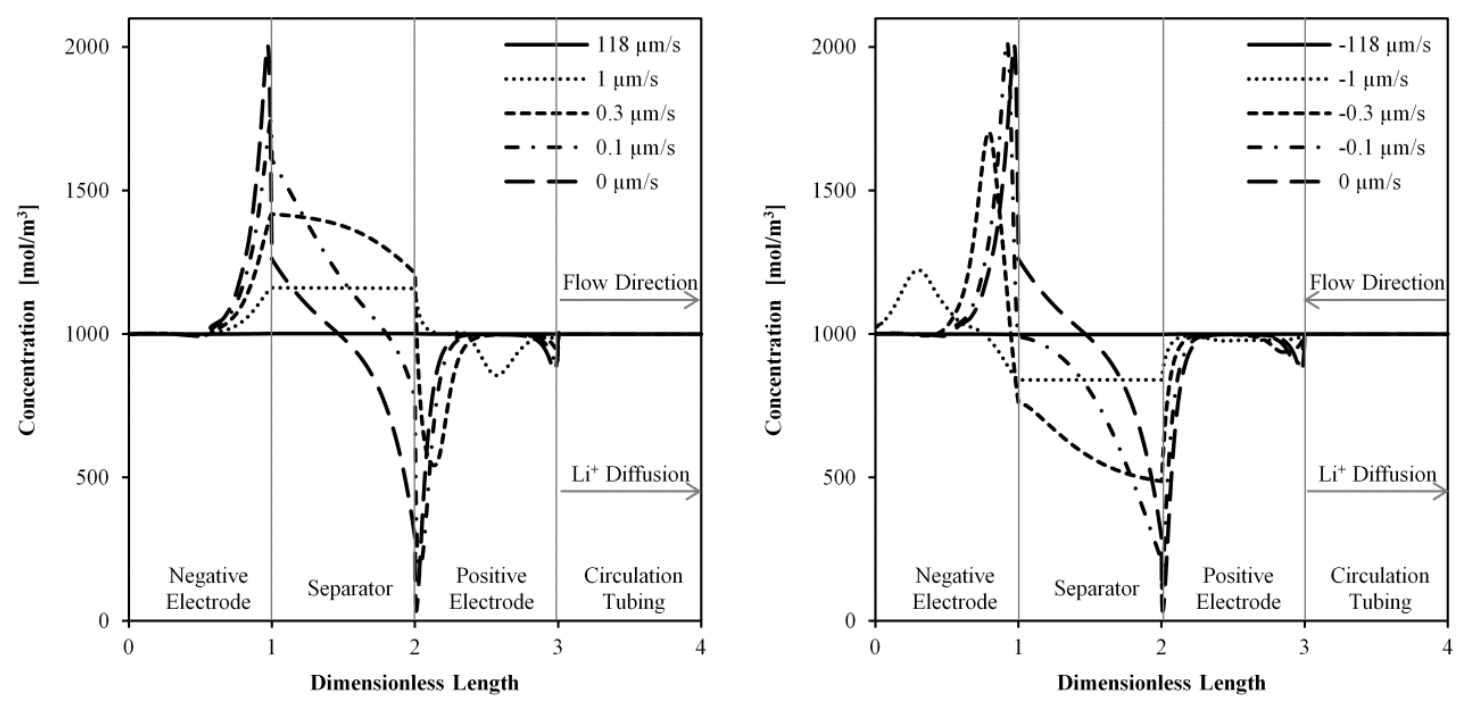

Figure 6.6 Simulated concentration profiles (concentration of $\mathrm{Li}^{+}$which is equal to anion concentration for binary electrolyte) for positive and negative flow.

For negative flow, the convective flow substantially pushes the $\mathrm{Li}^{+}$generated in the anode back into the anode, forming an accumulation in the anode next to the separator. At moderate flow rates the flow of lithium ions in the separator is less than the average bulk concentration which is opposite in trend relative to the positive flow direction. This indicates that $\mathrm{Li}^{+}$is undergoing a net-pumping from the anode to the cathode through the circulating tube rather than through the separator.

For flow in the positive direction, increased concentrations of $\mathrm{Li}^{+}$in the separator translate to a pumping of the active $\mathrm{Li}^{+}$cation from the anode to the cathode through the separator. For negative flow rates, the net pumping of $\mathrm{Li}^{+}$occurs through the circulating tube.

With no flow the maximum deviation in concentration from the equilibrium concentration of $1000 \mathrm{~mol} / \mathrm{m}^{3}$ is $1021 \mathrm{~mol} / \mathrm{m}^{3}$, whereas with a velocity of $+118 \mu \mathrm{m} / \mathrm{s}$ the 
maximum deviation is $1.52 \mathrm{~mol} / \mathrm{m}^{3}$. This is the same maximum deviation for a velocity of $-118 \mu \mathrm{m} / \mathrm{s}$.

The delivered cell voltages of Figure 6.7 reflect overpotential trends in the separator. At $2100 \mathrm{~s}$ into the discharge the cell voltage is $0.283 \mathrm{~V}$ higher with a high flow rate than with no flow regardless of flow direction. The difference in voltage losses (overpotentials) between cells, with flow and without flow, is attributed to the concentration overpotential losses, as quantified in the separator, being extended over the entire battery cell. It should be noted that laboratory experiments were performed at velocities of $118 \mu \mathrm{m} / \mathrm{s}$, and at those conditions the direction of flow had no impact on the cell voltage which is consistent with the simulations summarized by Figure 6.7 .
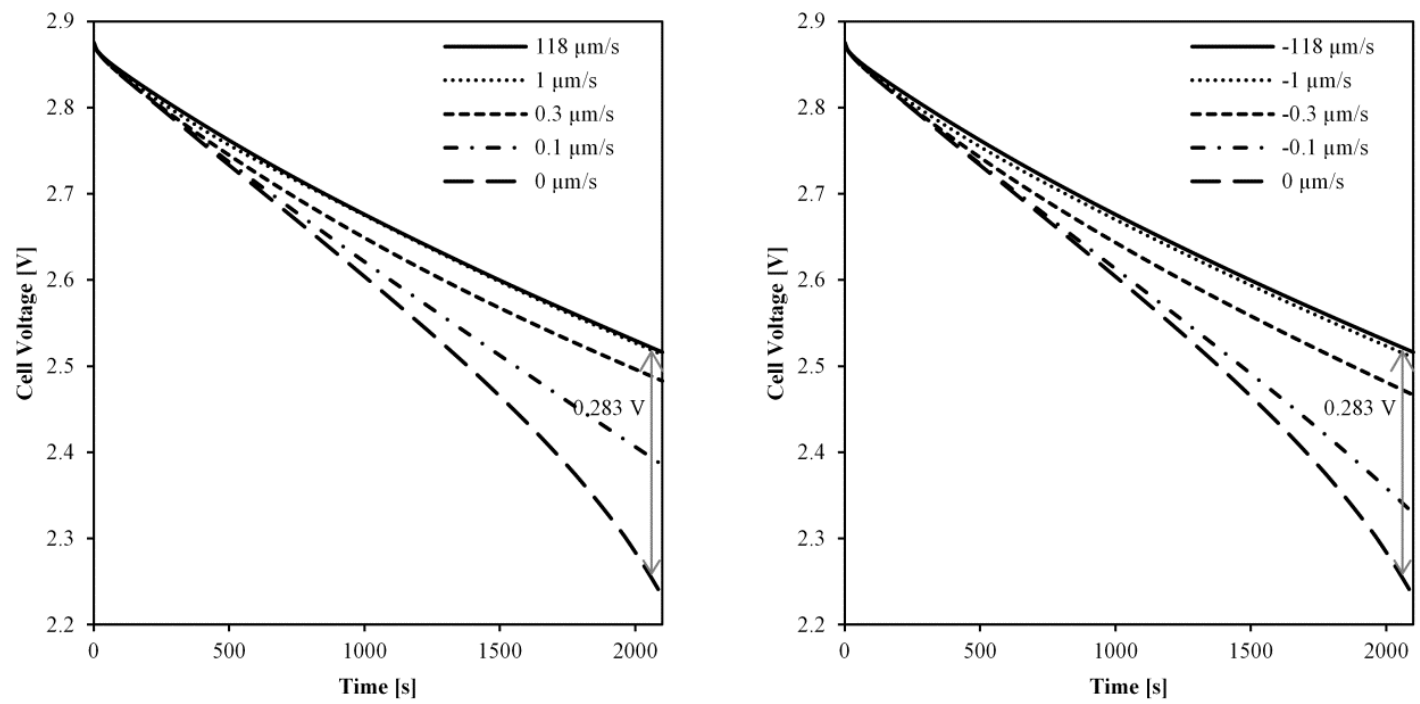

Figure 6.7 Cell voltages as provided by simulation for various positive and negative velocities to emphasize the effect on total overpotential in the cell. 


\section{Diffusion Limit of Performance}

Application of the flux equations (Equation 6.8 and Equation 6.9) across a control volume around the cathode (see Figure 6.8) can be used to quantify the observed phenomena. The flux equations are applied at locations along the axial distance (x dimension). Equation 6.10 and Equation 6.11 are charge balances applied over the cell with positive terms for entering conditions (left) and negative terms for exiting conditions (right) when there is positive flow. The salt concentration $c$ is used in the following equations, which is equal to both the anion and the cation concentrations because of electronuetrality.

$$
\text { Current Flux (constant) }=\Delta N_{-}=-D_{2}^{\text {eff }} \Delta \frac{\mathrm{dc}}{\mathrm{dx}}-\frac{t_{-}^{*}}{F} \Delta i_{2}+v^{*} \Delta c_{-}
$$

Figure 6.8 Illustration of control volume (shaded area) used to interpret performance. 
A pseudo-steady-state (PSS) is assumed as a limiting behavior similar to the diffusion and high flow limits. The PSS condition is the condition defined as the concentration gradient is fully developed across the separator and does not vary much with short increments of time. The PSS condition is approximated by a battery where the solid-phase stored reagents in the electrodes are only partially depleted at all locations and have an activity that is independent of the degree of depletion at the microscopic level in the materials of the electrodes.

When relating the PSS performance to actual cell performance, the primary adjustments to the PSS system are: a) accumulation of ions in the anode and cathode and b) variation in the activity of reagents in the solid phases of the electrodes. Both of these "real battery" variations substantially do not detract from the conclusions made by the PSS analysis since they do not vary the physiochemical properties of the electrolyte and the conclusions made by the following PSS analysis are in terms of the physiochemical properties.

Evaluating the anion flux equation (Equation 6.10) for PSS diffusion (flow at 0 $\mathrm{m} / \mathrm{s}$ ) at the left surface of the control volume, the following are observed: a) there is no net flux of anions and b) the velocity is zero. Therefore, the anion flux equation reduces to two terms: a) the concentration-based diffusion driving force for flow to the cathode and b) the balancing migration term of anions being attracted to the positive lithium generation (minor surplus) on the anode. Taking this into account and the fact that $\boldsymbol{i}_{2}$ is zero at the right surface of the control volume, the following equation can be obtained:

$$
\boldsymbol{i}_{2}=-\frac{F}{t_{-}^{*}} D_{2}^{e f f} \frac{d c}{d x}
$$


The cation flux equation (Equation 6.9) shows the cation flux is driven by complementary diffusion and migration terms. Both diffusion and migration are determined by the physiochemical properties of the fluid electrolyte (and possibly the solid).

The Equation 6.12 diffusion limit of $\boldsymbol{i}_{2}$ can be substituted into Equation 6.9 to provide Equation 6.13. Equation 6.13 indicates that the performance of the diffusion cell (other than accumulation terms) is dominated by the physiochemical parameters: liquid phase diffusivity and the transference number.

$$
\text { Constant current }=\boldsymbol{N}_{+}=-\frac{D_{2}^{e f f}}{t_{-}^{*}} \frac{d c}{d x}
$$

Equation 6.13

\section{High Flow Limit of Performance}

At high flow rates, flat concentration profiles are in both the separator and circulation tube. The anion flux equation (Equation 6.10) simplifies by setting the concentration gradient equal to zero. At high flow rate, this balance equation results in a form where bulk diffusivity drops out of the equation and does not impact performance.

For PSS analysis of the control volume, there is no accumulation (or consumption) of anions in the cathode, and so, $\Delta N_{-}$of Equation 6.10 goes to zero to yield Equation 6.14. The interpretation of this equation is that the amount of $\mathrm{Li}^{+}$that react at the cathode is equal to the amount of anions that migrate from the system in response to electrical potentials.

$$
0=-\frac{t_{-}^{*}}{F} \Delta \boldsymbol{i}_{2}+\boldsymbol{v}^{*} \Delta c_{-}
$$


The same observation of near-zero concentration gradients for convective flow can be applied to Equation 6.11 resulting in Equation 6.15 where a constant current of operation is equal to a term containing the concentration difference and migration currents. A prominent mechanism of cation mass transfer is from flow of the electrolyte where the salt (anion and cation pairs) concentration is different for entering and exiting streams.

$$
\text { Constant Current }=\Delta \boldsymbol{N}_{+}=\frac{t_{+}^{*}}{F} \Delta \boldsymbol{i}_{2}+\boldsymbol{v}^{*} \Delta c
$$

Additional, important observations include: a) bulk diffusivity has minimal impact on performance at high flow rates and b) voltage changes (overpotentials) that occur in the electrolyte must originate from the migration term in the form of ohmic losses.

In a binary electrolyte, the current $i_{2}$ is calculated by Equation 6.16 which relates $\boldsymbol{i}_{2}$ to the overpotentials.

$$
\boldsymbol{i}_{2}=-\kappa_{2}^{e f f} \frac{d \Phi_{2}}{d x}+\frac{2 R T \kappa_{2}^{e f f}}{F}\left(1-t_{+}^{*}\right)\left(1+\frac{d \ln f_{ \pm}}{d \ln c}\right) \frac{d \ln c}{d x} \quad \text { Equation 6.16 }
$$

Recognizing the flat concentration profiles at high flow rates at the entering and exiting conditions, the concentration term goes to zero, and by applying this equation to the control volume, Equation 6.16 can be used to solve for $\Delta \boldsymbol{i}_{2}$ and be used to eliminate this term from Equation 6.15 to arrive at Equation 6.17.

$$
\Delta \boldsymbol{N}_{+}=-\frac{\kappa_{2}^{e f f} t_{+}^{*}}{F} \Delta \frac{d \Phi_{2}}{d x}+v^{*} \Delta c
$$

Hence, at constant current and PSS, the physiochemical properties that have an impact on overpotentials are the transference numbers and effective conductivity. 
Convective flow substantially eliminates bulk liquid diffusivity as a source of overpotential. Hence, overpotential arises from two primary sources in the liquid: a) boundary-layer diffusion between electrode solid phases and the flowing electrolyte and b) migration overpotentials as originating from transference numbers and effective ion conductivity.

\section{Impact of Solid Matrices on Ion Conductivity}

Figure 6.9 summarizes previously-reported voltage profiles for a zinc-alkaline convection battery at a constant high flow rate (out of transition region) and resistance load. ${ }^{40}$ The data illustrate how different solid phases in the separator can result in different overpotential losses associated with these changes in the test cell. The differences between voltages (differences are over potential differences) between the media are relatively constant.

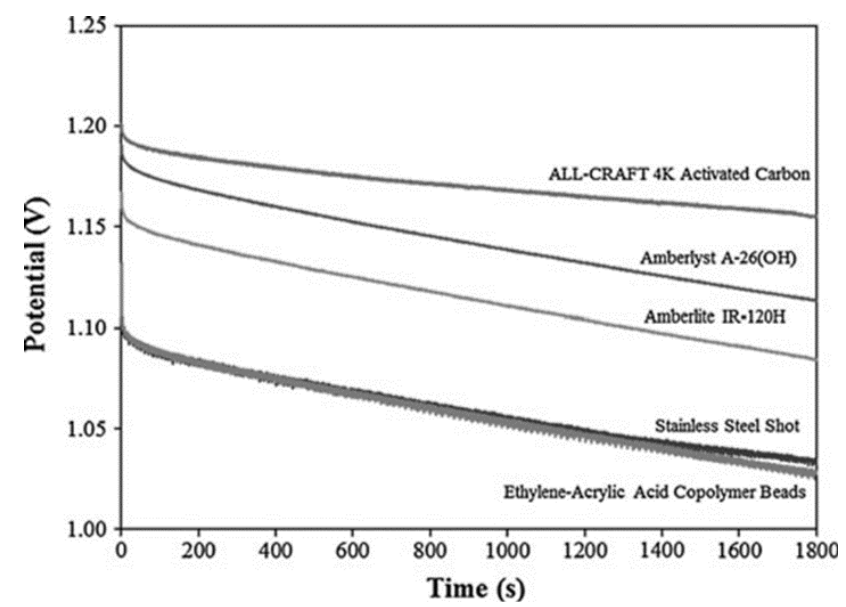

Figure 6.9 Impact of different packing media in the separator on performance of zinc alkaline convection cells. ${ }^{40}$ 
In view of the previous conclusion that the overpotential of the separator at high flow rates is primarily a function of the ion-ohmic losses (specifically, the product $\left.\kappa_{2}^{e f f} t_{+}^{*}\right)$ in the separator, the variations of performances illustrated by Figure 6.9 indicate that transference numbers and effective ion conductivities are functions of the solid material properties in the separator. This implies a surface, boundary layer, and/or solid state transport mechanism for ions in the separator. Figure 6.10 illustrates a separator with ion convection through the pore and cation migration through the membrane ion exchange polymer.

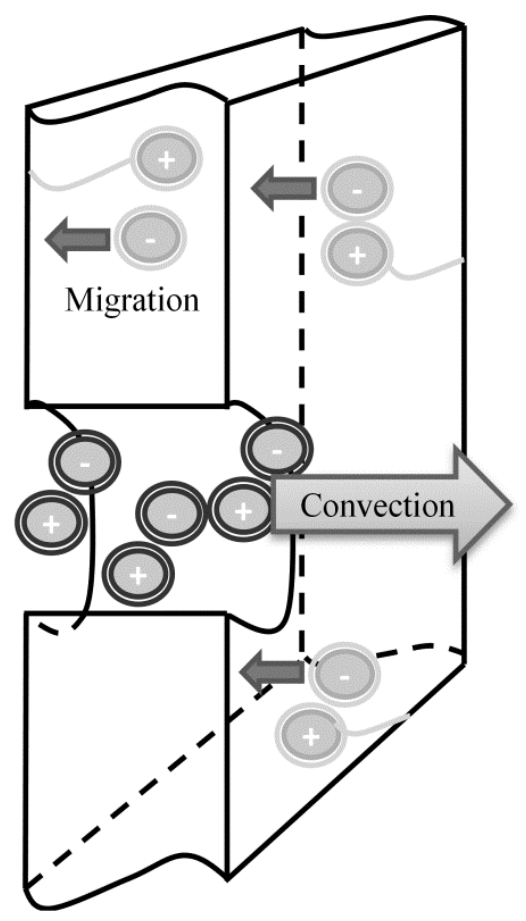

Figure 6.10 Illustration of transport in the separator of a convection battery where convection occurs through pores and anion migration is dominated by a path through the ion membrane material phase. Migration through the polymer phase of the separator is believed to be the most effective migration mechanism. 
Solid-phase-related ion transport mechanisms are most important in liquid chromatography resins (as used for some of the experiments summarized by Figure 6.9). Ion exchange membranes are known to have ion transport properties, ${ }^{71,72}$ and advancement of these membranes is an active area of research. ${ }^{73-75}$

Parallel bulk convection and resin-phase migration transport mechanisms are essential to understanding convection battery performance. At present, porous electrode theory uses one effective conductivity $\kappa_{2}^{e f f}$ to characterize the electrical properties of the separator and electrodes — an adjustment in this theory is needed to simulate the parallel mechanisms of Figure 6.10. For the convection battery, ions may migrate both through the liquid in pores through/on the solid that forms the pores.

This conclusion must extend to the electrode properties. Furthermore, in the convection cell, it is the ion counter to the reacting anion of the electrolyte phase that relies on the solid matrix for transport. The reacting ion relies on convective flow for transport.

The activated carbon of Figure 6.9 is an ultra-high surface area carbon, ${ }^{76}$ the Amberlyte and Amberlyst are liquid chromatography resin beads, and the steel and copolymer are presented as substantially inert solids. Both solid phase surface area and ionic site density benefit the ability of solid materials in the separator to reduce ion-ohmic overpotentials. The Figure 6.4 data are consistent with a solid-phase ion transport mechanism that is robust at higher amperages, and the poor fit of the model could be attributed to the lack of the ability of the model to include supplementary solid phase ion mass transfer. Higher $\kappa_{2}^{e f f}$ diminish the impact of $i_{n}$ on voltage drop in the electrolyte. 


\section{Implications on Convection Battery Performance}

Summarized by Figure 6.11 are qualitative PSS battery performance curves that break out example overpotentials. Bulk diffusion in the electrode and separator will typically increase significantly when the limits of a cell are pushed, eventually producing large overpotentials and a limit to current in that cell $\left(\mathrm{I}_{\text {limit, } 1}\right)$. The figure illustrates the overall performance curve for the diffusion cell (lowest curve on figure) where bulk diffusion overpotentials ultimately and largely determines the limiting current.

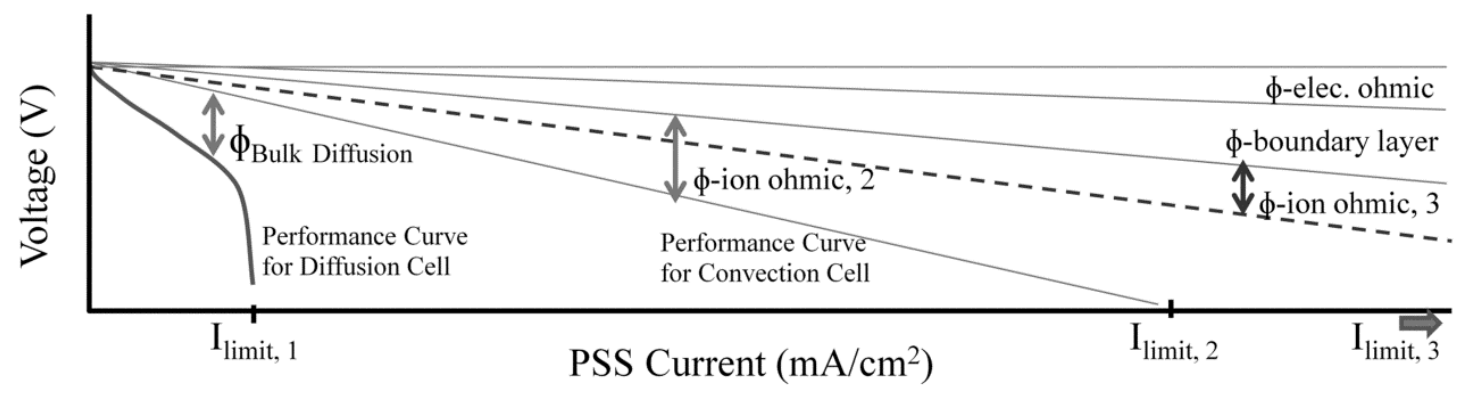

Figure 6.11 Illustrative PSS performance curves. The lowest of the lines represents a diffusion cell performance curve and limiting current with the breakdown of overpotentials as indicted. The lowest straight line is the performance curve for a convection battery that has no bulk diffusion limitation. The dashed like is the performance curve for the convection battery with materials optimized for increased anion diffusivity.

Bulk diffusion limitations are substantially eliminated in the convective battery. The new performance curve for the convective cell tends to be more linear and have a much greater limiting current $\left(\mathrm{I}_{\text {limit, } 2)}\right)$. The ohmic losses tend to be linear with current and liquid phase ionic ohmic overpotentials would tend to dominate the overpotential 
losses for well-engineering solid materials. The illustrated approximate $5 \mathrm{X}$ increase in limiting current was observed in recent studies in the convection cell. ${ }^{41}$

As illustrated by Figure 6.9, the solid matrix of separator materials and electrodes can have a significant impact on the ohmic losses. With improved materials that reduce ion-ohmic overpotentials, further increases in limiting currents can be realized. These could readily be $10 \mathrm{X}$ times the limiting current of the diffusion cell as illustrated by the dashed line; the limiting currents may be considerably more than $10 \mathrm{X}$ that of the diffusion cell.

An extrapolation of Figure 6.11 illustrates a significant performance advantage of the convection battery where power output (or input for charging) can be plotted against limiting current by multiplying the $\mathrm{x}$-axis current times the $\mathrm{y}$-axis voltage. More to the point, elimination of diffusion results in higher limiting currents and much higher maximum power output (or power input during charging). During charging the input power would be from the charging source and significant reductions in charge times would be possible.

Significant reductions in charge times, reduced separator costs (thicker electrodes), and use of electrolyte flow to control power output are all advantages with potentially significant implications. On the topic of safety, thicker electrodes translate to a reduced potential for runaway reactions. And, the optional ability to drain electrolyte from the battery can be used as an ultimate safety control to shut down the battery if an runaway reaction is detected. 


\section{Parallelism of Electrode Overpotentials}

Four sources of overpotential in a battery electrode include: a) ohmic losses for electron transport in the solid, b) ohmic losses for ion transport in the liquid, c) a boundary-layer (including nanopore diffusion) associated with reaction and transport from the solid surface to the bulk liquid, and d) (proposed) ohmic losses for ion transport in/on the solid. Standard porous electrode theory does not account for the solid phase ion transport; however, Equation 6.6 relates the boundary layer overpotential to the solid and liquid voltages.

Figure 6.12 further illustrates how the potential difference between points in the solution (point at $\left.\phi_{\mathrm{A}}\right)$ and at the current collector $\left(\phi_{\mathrm{B}}\right)$ can be calculated via different paths. This indicates that these four sources of overpotentials act in parallel (as well as series) to produce an overall overpotential.

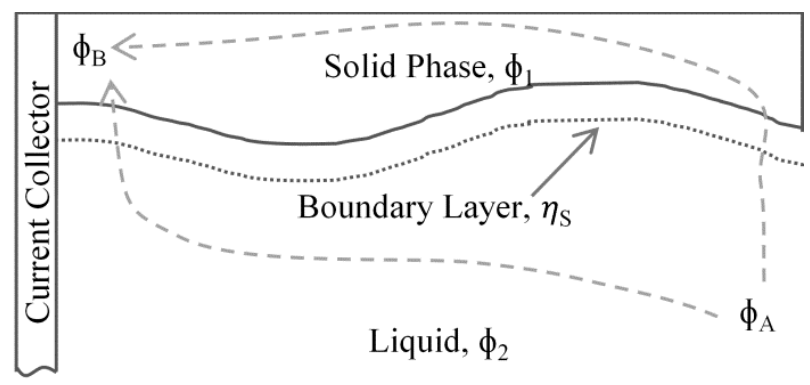

Figure 6.12 Illustration of different paths from the pore of an electrode to the current collector for realization of the potential difference $\phi_{\mathrm{A}}-\phi_{\mathrm{B}}$.

More specifically, the upper path for calculating $\phi_{\mathrm{A}}-\phi_{\mathrm{B}}$ as illustrated by Figure 6.12 proceeds substantially through the solid phase while the lower path proceeds substantially through the liquid. The implication is that the use of a highly conductive 
solid phase (or solid with ion conductivity) can be used to minimize the adverse impacts of a low liquid effective conductivity.

The convection battery substantially eliminates bulk diffusion overpotentials, and so, the implication of being able to reduce the impact of remaining liquid overpotentials substantially increases the upper limits of what is possible with the convection battery.

Another way of considering this parallelism is recognizing that the term $a i_{n}$ can be eliminated between the solid and electrolyte ion balance terms (Equation 6.2 and Equation 6.4) resulting in an equation where the voltage drop in the electrolyte is related to the voltage drop in the solid. The magnitude of this inter-dependence is proportional to $\kappa_{2}^{e f f} / \kappa_{1}^{e f f}$.

\section{Conclusions}

The following conclusions result from the modeling work and associated analysis of the balance equations:

The convective battery is able to use fluid flow to reduce bulk diffusion overpotentials by $99.9 \%$.

As a result, bulk diffusivity has a substantially diminished impact on cell performance.

The primary mechanism of reactive ion transport to and from electrodes in a convection cell is the $\left(v^{*} \Delta c\right)$ term.

Counter-ion (counter to reactive ion) transport emerges as a prominent overpotential that leads to a limiting current in the convective battery. 
This counter-ion ohmic overpotential is highly dependent upon the quantity $\kappa_{2}^{e f f} t_{+}^{*}$.

The solid matrix of separators (and electrodes) can have a significant impact on counter-ion-ohmic overpotential. Both the density of ion sites and surface area impact the ability of the solid matrix to reduce overpotentials.

The electrolyte flow direction has an impact on the performance of the convection battery, but the impact is only moderate and only at the transition from diffusiondominated to convection-dominated performance.

In view of the parallelism of overpotential losses in electrodes, the limitations of low effective conductivities of the liquid phase can be substantially overcome by increasing the electronic (and possibly, the ionic) conductivities of the solid phase of the electrode.

As with the evolution of many chemical processing unit operations, there is a point where engineering design has an ever-increasing impact on scaling up and performance, the convection battery relies on an increasing amount of engineering science, as opposed to basic science, to achieve ever-increasing levels of performance. The convection cell demonstrated a $5 \times$ increase in the current density at the same capacity utilization as a diffusion cell. ${ }^{41}$ Separator materials can limit the performance; improved separator materials have the potential for $>>10 \mathrm{X}$ increases in limiting currents. 


\section{Acknowledgements}

This work was funded by National Science Foundation grant number 1233250.

\section{Support for earlier experimental studies was provided by the California Energy}

Commission. Their support is greatly appreciated.

\section{Notation}

\begin{tabular}{cl}
\hline$\epsilon$ & Volume fraction \\
\hline$c, c_{-}, c_{+}$ & Concentration of salt, anion, or cation in electrolyte \\
\hline$c_{s}$ & Solid phase concentration of reagent \\
\hline$c_{s, \text { max }}$ & Max solid phase concentration \\
\hline$D_{2}^{\text {eff }}$ & Effective salt diffusivity in electrolyte $\left(\kappa_{2}^{\text {eff }}\right)$ \\
\hline$D_{s}$ & Diffusivity of lithium in the solid particles \\
\hline$r$ & Particle radius \\
\hline$F$ & Faraday's constant 96,485 C/mol \\
\hline$v^{*}$ & Molar average velocity \\
\hline$\kappa_{2}^{\text {eff }}$ & Effective conductivity of the liquid ( $\left.\kappa_{2}^{\text {eff }}\right)$ and solid (1 subscript) \\
\hline$i_{n}$ & Interfacial area of electrode solid divided by the volume of the electrode \\
\hline$i_{0}$ & Charge being transferred to/from solid from/to electrolyte in electrode in current per interfacial \\
\hline$i_{2}$ & Exchange current density \\
\hline$\Phi_{1}$ & Net current transported by liquid per cross sectional area (perpendicular to axial dimension) of \\
\hline$\eta_{s}$ & Potential of the liquid (1) and solid (2) phases \\
\hline$U_{1}$ & Surface overpotential \\
\hline$R$ & Equilibrium voltage of the electrode \\
\hline$T$ & Ideal gas constant \\
\hline$N_{-}, N_{+}$ & Absolute temperature \\
\hline$t_{+}^{*}, t_{-}^{*}$ & Time \\
\hline$\alpha_{a}, \alpha_{c}$ & Flux of anions (-) and cations (+) \\
\hline$k_{a}, k_{c}$ & Apparent transfer coefficient for the anodic and cathodic reaction respectively \\
\hline$f_{ \pm}$ & Reaction rate coefficient for the anodic and cathodic reaction respectively on the positive electrode \\
\hline & Distance along the length of the cell \\
\hline
\end{tabular}




\section{CHAPTER 7}

\section{A COMPARISON OF MODELED AN EXPERIMENTALLY MEASURED OVERPOTENTIALS IN A MULTIPLE-REFERENCE ELECTRODE CONVECTION CELL}

\section{Introduction}

The convection cell is a new cell architecture that uses flow to reduce concentration overpotentials in the electrodes and the separator. ${ }^{37-40,42}$ The $\mathrm{LiFePO}_{4}$ convection cell was modeled in a previous paper. ${ }^{42}$ The model was fitted using constantresistance-discharge data, and it was then used to show that the overpotentials in the separator could be substantially eliminated using electrolyte flow. One of the limitations of that study is that the experimental data used to fit the model only contained the total cell potential, so the internal overpotentials within the cell were not verified. The objective of this paper is to compare the model overpotentials with data obtained by probing the convection cell with reference electrodes to spatially resolve the cell overpotentials.

Previous studies have measured overpotentials in lithium-ion cells ${ }^{77,78}$ and in fuel cells. $^{79-82}$ Harris et al. built an optical lithium half-cell to visually observe changes in the lithiation of the negative electrode over time. $\mathrm{Ng}$ et al. used multiple working electrodes 
in a stacked configuration with Celgard separators inbetween to measure the currentdensity and overpotentials in graphite current electrodes, and Hess et al. used reference electrodes that were in ionic contact with the electrolyte of a fuel cell at specific distances in the electrode to measure the concentration overpotentials. The method used by Hess is similar to the method that will be implemented here to measure the overpotentials in the electrolyte of a convection cell. No previous studies have measured electrode overpotentials in a convection cell.

To directly measure the concentrations within a $\mathrm{LiFePO}_{4}$ convection cell, lithium reference electrodes can be place throughout the length of the cell and measured with respect to the positive electrode current collector. The voltage difference between to reference electrodes in the electrolyte, $\nabla \Phi_{2}$, is related to both the concentration overpotentials and the ohmic overpotentials in the electrolyte by the following equation for a binary electrolyte: ${ }^{83}$

$$
\nabla \Phi_{2}=-\frac{\mathbf{i}_{2}}{\kappa_{2}^{e f f}}+\frac{2 R T}{F}\left(1-t_{+}^{*}\right)\left(1+\frac{d \ln f_{ \pm}}{d \ln c}\right) \nabla \ln c \quad \text { Equation 7.1 }
$$

This equation is used in the convection cell model and is used to predict the potential in the electrolyte in relation to the electrodes of the cell. The potential difference between the positive electrode current collector and the reference electrodes in the convection cell can be directly calculated by the model, and then compared to the measured values. This will either validate, or be used to improve the model.

One limitation of the model described in the previous paper, is that the model was fitted to constant-resistance discharge data. To increase the accuracy of the model, the 
model is fitted to new convection cell data that is obtained using a constant-current discharge.

\section{Multiple-Reference Electrode Convection Cell}

A new multiple-reference electrode convection electrode cell was designed to accommodate eight different reference electrodes as shown in Figure 7.1. This generation 5.2 cell is similar to the generation 5.1 convection cell. The difference is that the electrode tubes and separator coupling have ports for the eight different electrodes and are made from Teflon. The compression plates also had to be widened to accommodate the bigger separator coupling and allow connection to the reference electrodes. Eight threaded holes are spaced $1 \mathrm{~mm}$ apart along the length of the separator coupling in a spiral configuration at $45^{\circ}$ increments beginning at the center. The stepped holes have a smaller $0.34 \mathrm{~mm}$ hole that goes through to the inside of the electrode tube to allow contact between the reference electrode and the electrolyte. One of the electrode tubes has corresponding stepped holes that line up with the holes in the separator coupling. A cutaway view showing how tube and coupling line up is illustrated in the enlargement in Figure 7.1. Notice that the reference electrode ports are only in one of the electrodes. 

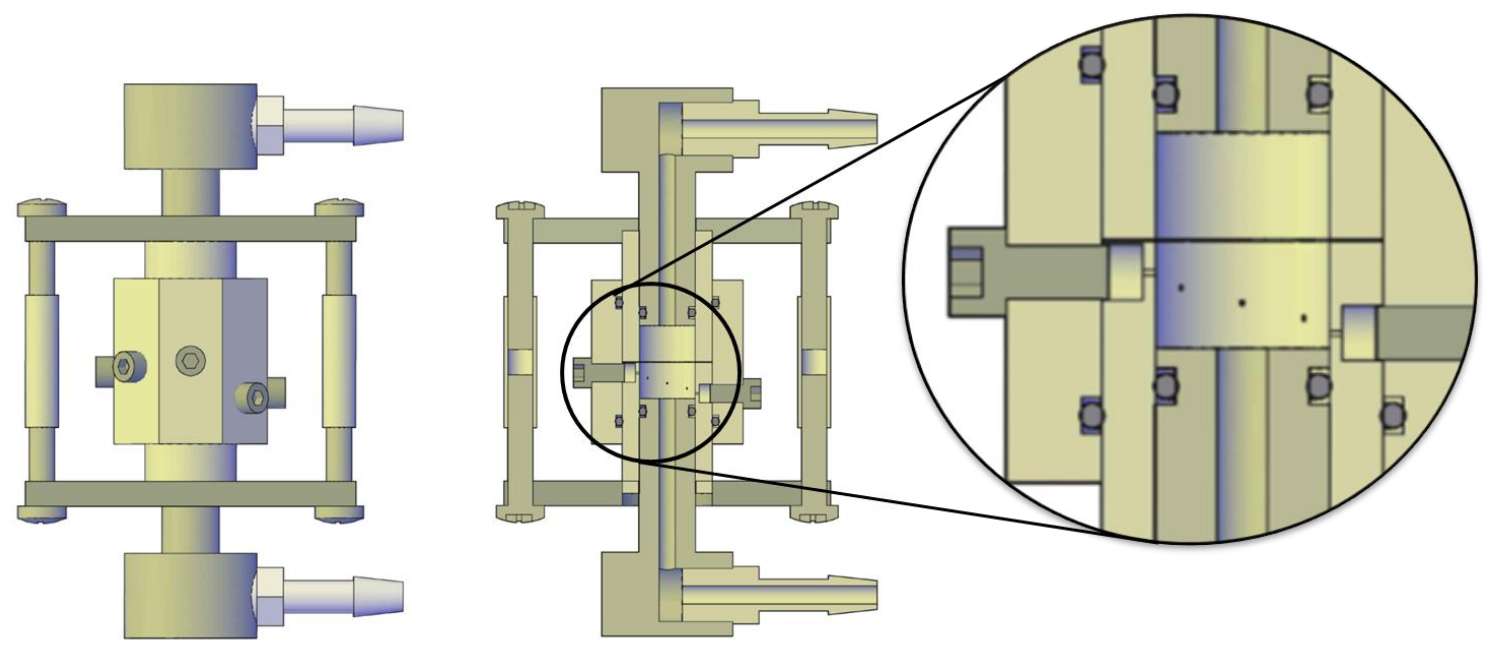

Figure 7.1 The multiple-reference electrode convection cell design.

To assemble this cell, electrode paste is cast into the electrode tubes using the same electrode tube assembly and method used for the generation 5.1 convection cell (described in chapter two). The separator is sandwiched between the electrode tubes in the separator coupling, and the holes in the coupling and electrode tubes are lined up. Then the compression plates are secured over the electrode tubes to apply compression between the electrode tubes and the separator. At this point, one piece of $3 \mathrm{~mm}$ filter paper and two lithium pellets are placed in each reference electrode hole. The filter paper sits flush with the bottom of the stepped hole in the electrode tube with the pellets on top. The lithium pellets extend slightly into the threaded hole of the coupling. O-ring sealing screws are then tightened in the threaded hole of the separator coupling. When tightened all the way, the end of the screws extend just beyond the separator coupling and into the stepped hole of the electrode tube. This pushes on the lithium and causes it to deform against the pressure of the screw, which guarantees good electrical contact. Once all the lithium pellets and screws are in the cell, the pistons are inserted into the electrode tubes 
and attached to the tubing and reservoir. Before closing the cell, electrolyte is added and saturates the cell. Electrolyte contacts the lithium reference electrodes through the 0.34 $\mathrm{mm}$ holes in the electrode tubes. This can be verified with a multimeter to check for conductivity.

\section{Experimental}

Positive and negative electrode pastes were made using the formulas listed in Table 1.1. The 250-425 $\mu \mathrm{m}$ graphite was Acros Organics graphite from Fisher Scientific (AC38503-0010) that was sieved to the desired size. This product has been discontinued, and Alfa Aesar 40769 graphite has been shown to be a suitable replacement. The PVDF (182702) and NMP (328634) were from Sigma Aldrich, and the $\mathrm{LiFePO}_{4}$ powder was from MTI (EQ-Lib-LFPO).

Table 7.1 Electrode paste compositions (percentages are by mass).

\begin{tabular}{cccc}
\hline & $\begin{array}{c}\text { 6\% PVDF } \\
\text { in NMP }\end{array}$ & $\begin{array}{c}\mathbf{2 5 0 - 4 2 5} \boldsymbol{\mu m} \\
\text { Graphite }\end{array}$ & LiFePO4 \\
\hline $\begin{array}{c}\text { Negative } \\
\text { Electrode Paste } \\
\begin{array}{c}\text { Positive } \\
\text { Electrode Paste }\end{array}\end{array}$ & $37 \%$ & $63 \%$ & N/A \\
\hline
\end{tabular}

Generation 5.1 cells, described in chapter two, were used with $7 \mathrm{~mm}$ electrodes to obtain fitting data for the model. The positive and negative electrode pastes from Table 7.1 were cast into the electrode tubes, and dried in a vacuum oven at $50^{\circ} \mathrm{C}$ for $24 \mathrm{~h}$. The cells were assembled with three filter papers for the separator. $10 \mathrm{~mL}$ of LiPF6 electrolyte from MTI (EQ-LBC3015B) was added to the cells and the tubing was 
attached in a closed-reservoir configuration (also described in chapter two). These cells were cycled with version three of the battery testing system (described in chapter three). The assembly of the cell, after the electrodes were made, was done in an argon filled Vacuum Atmospheres glove box with a dew point below $-70^{\circ} \mathrm{C}$.

The new cell was used for the reference electrode measurements and was assembled as described in the previous section using $7 \mathrm{~mm}$ electrodes. The same pastes, electrolyte, and tubing configuration as the generation 5.1 cells were used. The lithium pellets for the reference electrodes were obtained from Sigma Aldrich (499811). These cells were also assembled in the same glove box and cycled with the version three battery testing system, but eight additional differential channels were used in the SCB-68 to measure the reference electrode voltages. This did not result in modifying the control box, but the LabVIEW program had to be modified slightly to record the additional measurements. The reference electrodes were measured with respect to the positive terminal of the battery.

\section{Results and Discussion}

The generation 5.1 convection cells were discharged at constant current densities of $1.8,2.7$, and $4.6 \mathrm{~mA} / \mathrm{cm}^{2}$ for fifteen cycles. The pump was set to a flow rate of 0.9 $\mathrm{mL} / \mathrm{min}$ for the first and last five discharge cycles and turned off for the middle five discharge cycles. The pump was on for all the charge cycles so that the convection cell was at the same state-of-charge for every discharge cycle. In this way, comparisons can be made between the cycles with flow and without flow. 
After the cycling tests, the convection cell model was fitted to the data as shown in Figure 7.2. The model fit is very accurate at $2.6 \mathrm{~mA} / \mathrm{cm}^{2}$, but begins to deviate as the current changes up or down. This is similar to what was seen in when the model was fitted to constant-resistance discharge data. Because the model is most accurate at 2.6 $\mathrm{mA} / \mathrm{cm}^{2}$, this is the current density used to obtain reference electrode measurements in the convection cell.
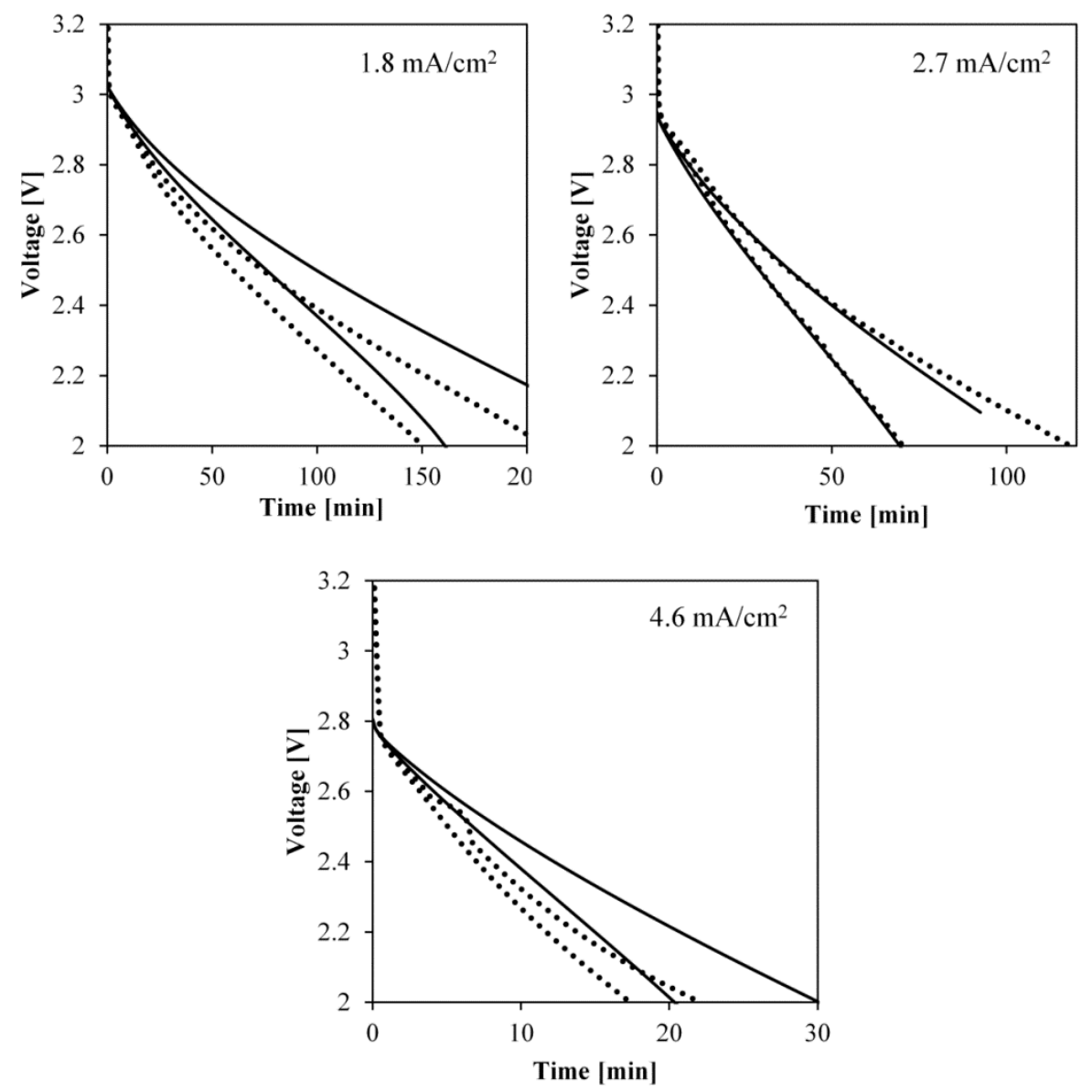

Figure 7.2 Constant-current discharge voltage profiles for the convection cell at various currents with flow and without flow. Modeled data are shown by solid lines and experimental data are shown as dotted lines. The top solid line and the top dotted line in each graph were obtained with flow. The bottom lines were obtained without flow. 
Since the multiple-reference electrode cell only allows reference measurements on one of the electrodes, two cells were tested - one with reference electrodes on positive end of the cell (cell one), and one with reference electrodes on the negative end (cell two). In cell one there was one reference electrode at the separator, and seven more each along the $7 \mathrm{~mm}$ positive electrode spaced $1 \mathrm{~mm}$ apart. In contrast, cell two had one reference electrode at the separator and seven more spaced equally along the $7 \mathrm{~mm}$ electrode. The combination of both cells will provide information about the electrolyte potential along the entire length of the cell.

The total cell and reference electrode voltages are given in Figure 7.3 for cell one. The cell was subjected to a $30 \mathrm{~min}$ open-circuit rest, followed by five charge and discharge cycles with a $5 \mathrm{~min}$ rest between each. The electrolyte flow rate was 0.9 $\mathrm{mL} / \mathrm{min}$ for the entire test. The interesting observation is that the eight different reference-electrode measurements are almost indistinguishable in this graph. This would imply that there is little overpotential in the electrolyte and that most of the overpotential is in the solid phase as ohmic overpotentials or at the solid-electrolyte interface as reaction overpotentials. The data from cell two were similar. 


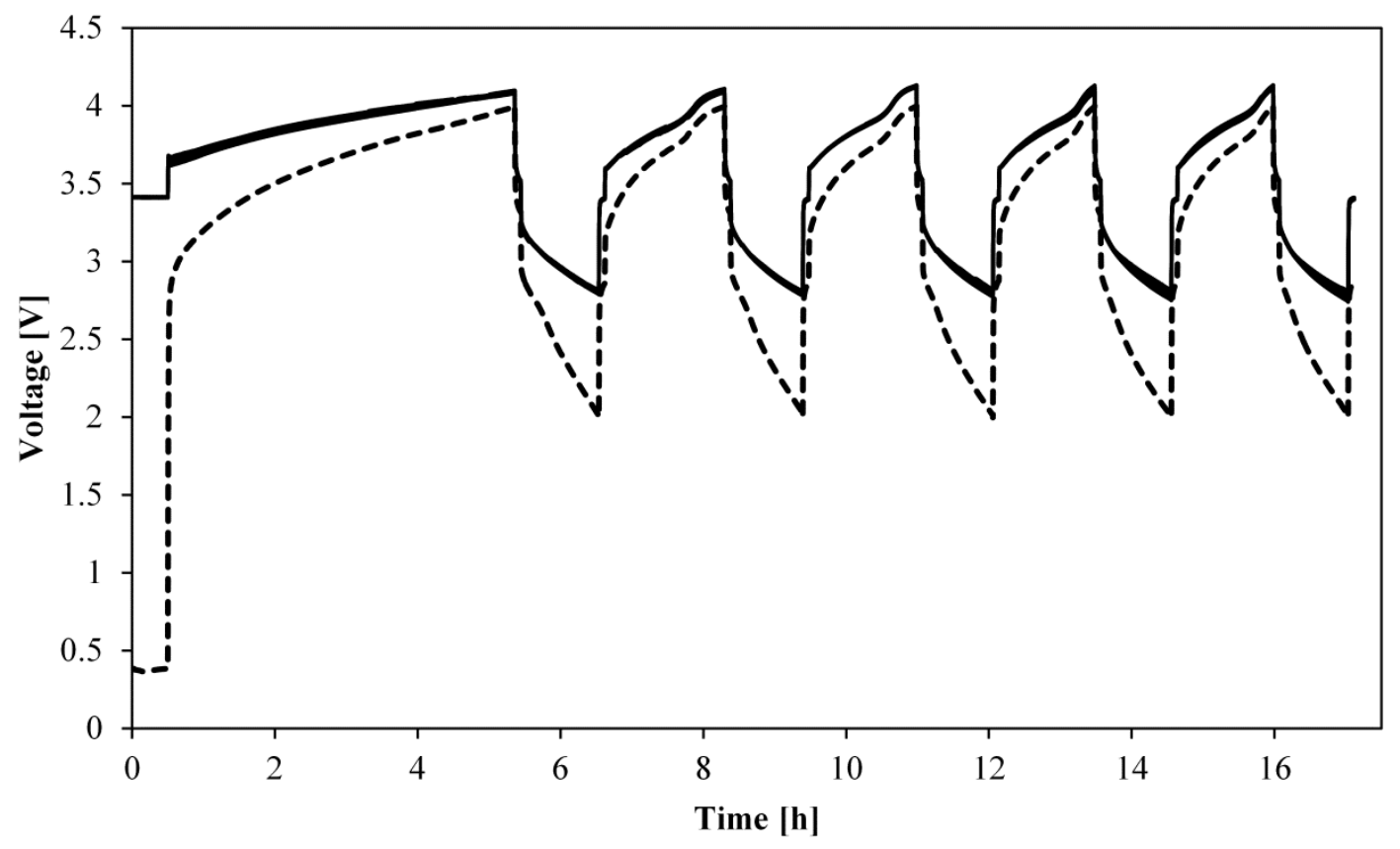

Figure 7.3 Cycling data from the multi-reference electrode convection cell 2. There are eight reference electrode measurements represented by the solid lines that are too close to differentiate. The overall cell voltage is represented by the dashed line.

The reference electrode voltage measurements for a short interval of the fifth discharge cycle of both cells one and two are given in Figure 7.4. The measurements for the two cells are grouped together. This is due to slight differences in the discharge profiles that are amplified because this is the fifth discharge cycle. However, both cells have a reference electrode at the center of the separator, so the data from both cells can still be compared. If the difference between the separator measurements from each cell is subtracted, the voltage difference in electrolyte over the entire length of the cell is only about $100 \mathrm{mV}$. This is less than would be expected for a cell with such thick electrodes as this one. 


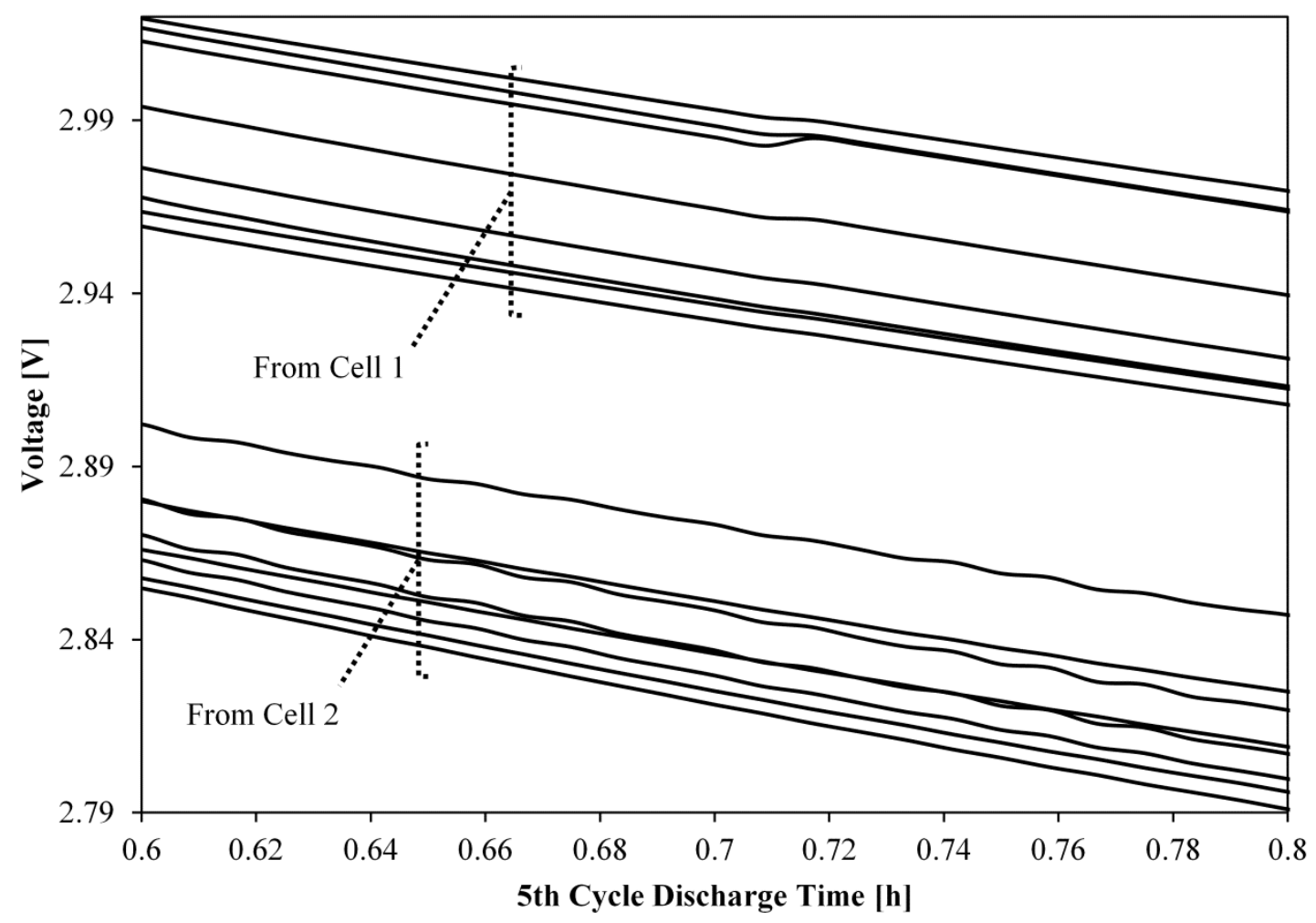

Figure 7.4 A close-up view of the voltage of the eight reference electrodes in cell one and the eight in cell two.

This is reiterated in Figure 7.5, which is the voltage at each reference electrode from both cells $0.7 \mathrm{~h}$ into the fifth discharge. The left of the Figure 7.5 corresponds to the positive terminal of the cell and the right side corresponds to the negative terminal at $14.5 \mathrm{~mm}$. That is $7 \mathrm{~mm}$ for each electrode and $0.5 \mathrm{~mm}$ for the separator. The difference in the separator measurements is indicated by the dashed line between them. In theory the reference electrode voltage with respect to the positive terminal of the cell should be at a maximum directly next to the current collector and decrease as the reference moves farther away. This trend is observed for the most part in Figure 7.5, but is not followed strictly, particularly at the separator of cell one and the negative end of the cell. This 
small variation could be due to non-ideal conditions in the cell or it could be a repeatable phenomenon, but more testing would be required to determine which one is the case.

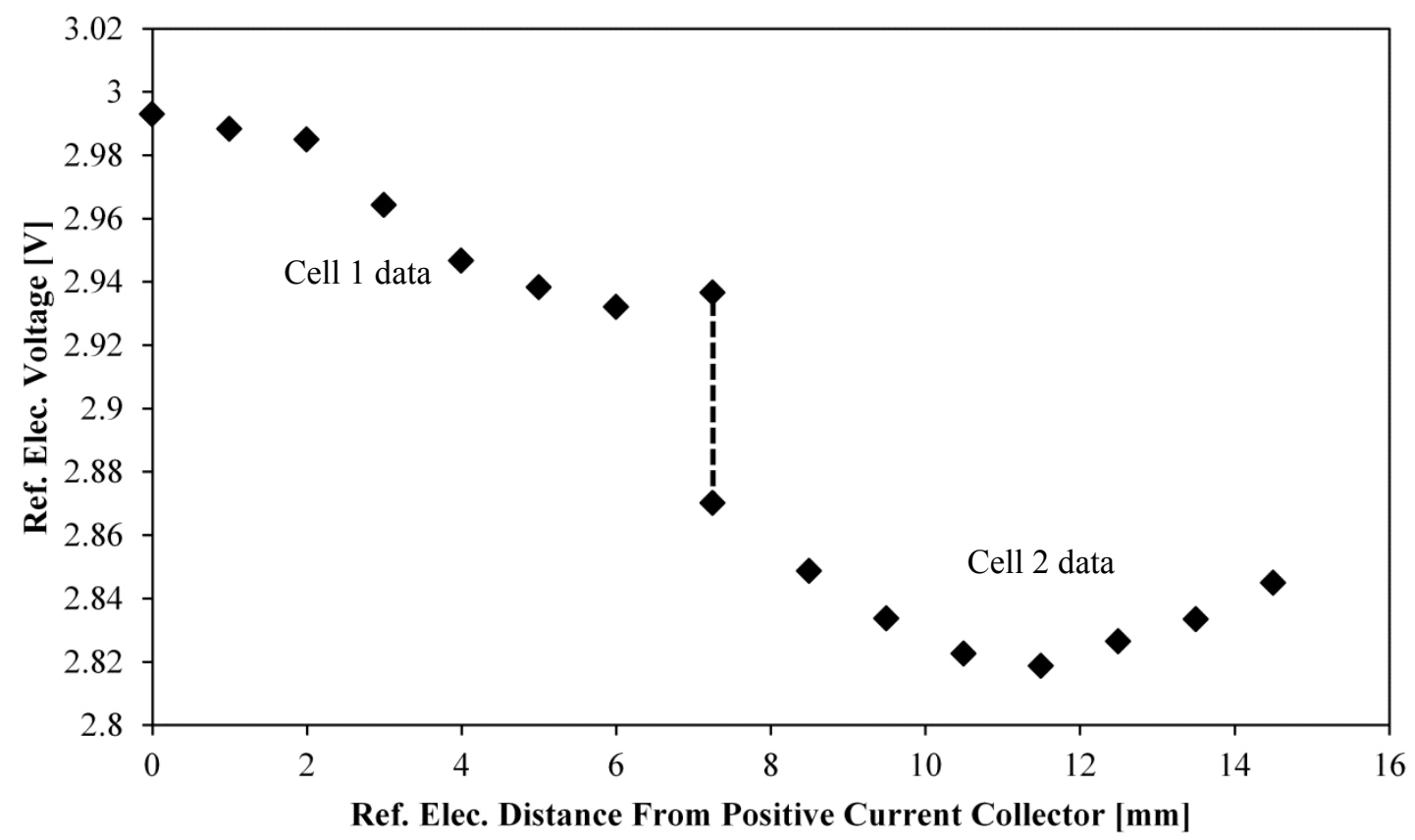

Figure 7.5 Experimental reference electrode voltage versus electrode distance at $0.7 \mathrm{~h}$ into the convection cell discharge. The data above and left of the dashed line are from cell one. The data below and to the right are from cell two.

The modeling output corresponding to the reference electrode measurements in cells one and two is shown in Figure 7.6. The model predicts much greater overpotentials within the electrolyte of the cell. Over the course of the entire $1.5 \mathrm{~h}$ discharge, the total overpotential in the electrolyte, i.e. the difference between the reference electrodes at each end of the cell, varies between $270 \mathrm{mV}$ to $1.1 \mathrm{~V}$. This is much higher than what was observed for the experimental data. 


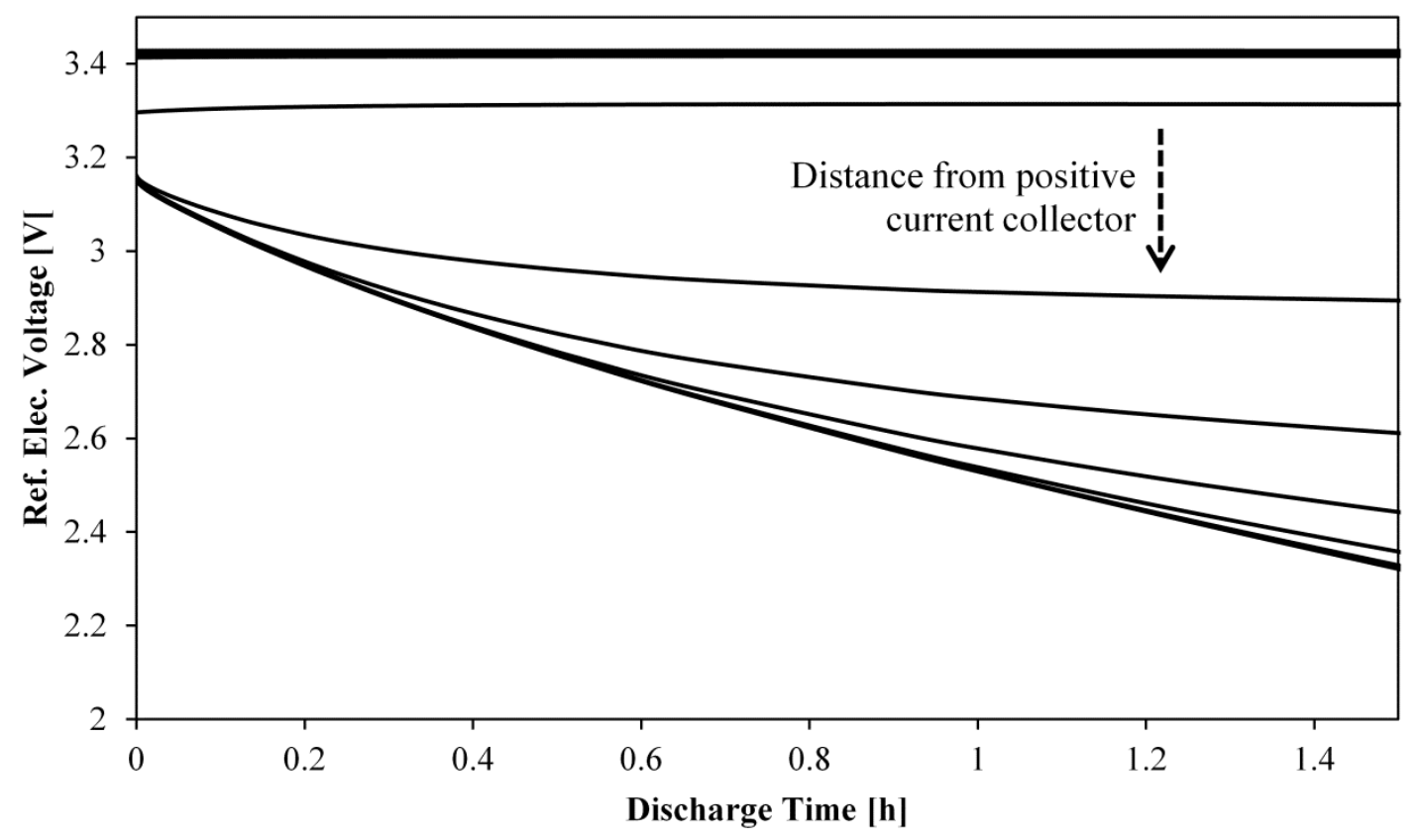

Figure 7.6 Reference electrode voltage over time at 15 different positions within the convection cell. The voltage profiles decrease with distance from the positive current collector.

To further investigate the reference electrode voltages calculated by the model, the modeled reference cell voltages as a function of distance from the positive current collector are plotted in Figure 7.7 for three different times into the discharge. At $0.7 \mathrm{~h}$ into the discharge the potential drop is about $700 \mathrm{mV}$ compared to the measured $100 \mathrm{mV}$ in Figure 7.4. The graph in Figure 7.7 also shows that the majority of potential drop in the electrolyte is between the separator and the negative electrode, in contrast to the experimental data in Figure 7.5 when comparing at the same time. 


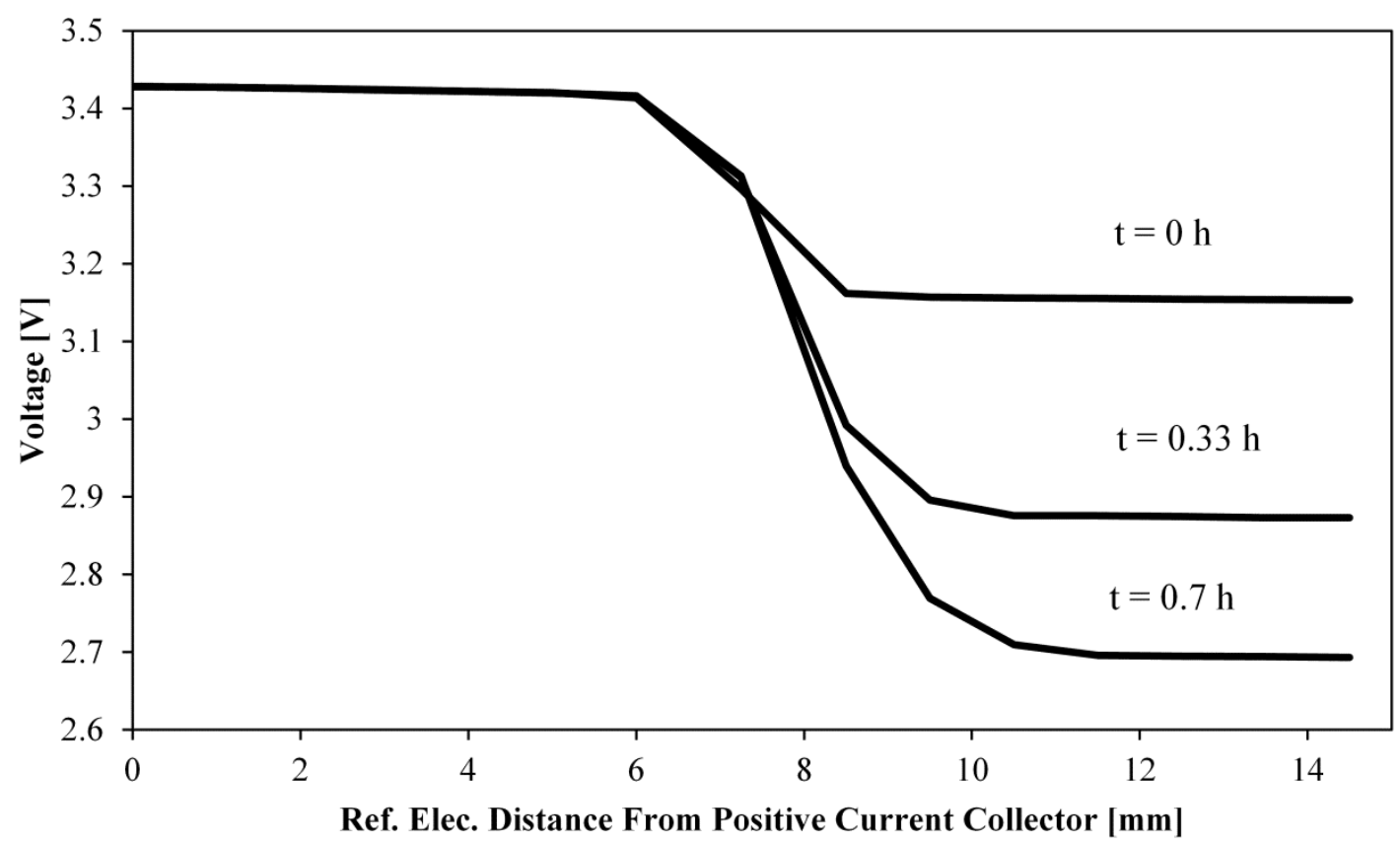

Figure 7.7 The modeled reference electrode voltages versus distance from the positive current collector at three different times into the discharge. The dashed lines indicate the separator boundary.

In the chapter 6, it was shown that the concentration overpotential in the cell was virtually eliminated in the model, so this would imply that the increased overpotential in is strictly ohmic in nature. This increase in ohmic overpotential in the model is caused by the low electrolyte conductivity and nonhomogeneous current distribution. At the beginning of discharge, the redox reactions are concentrated at the separator end of the electrodes because of the disparate conductivities of the electrolyte and the solid electrode. This causes the concentration of $\mathrm{LiFePO}_{4}$ in the positive electrode to drop and intercalated lithium to increase in the negative electrode close to the separator. As the concentration of the intercalated lithium increases in the negative graphite electrode, the 
equilibrium voltage of the electrode vs. Li decreases. ${ }^{84}$ This causes the interfacial current distribution to move away from the separator so more current is passing through the electrolyte. This results in the increased ohmic overpotential seen in Figure 7.6. In contrast, this increase in ohmic overpotential is not seen in the positive electrode because the equilibrium voltage $\mathrm{LiFePO}_{4}$ does not change much with concentration $\mathrm{LiFePO}_{4}$ or state of charge. ${ }^{69}$

The effect of the increase in modeled ohmic overpotential in the context of the total cell overpotential can be seen in Figure 7.8. The negative overpotential dominates the other overpotentials to determine the cell performance. However, this is not in agreement with the experimental measurements. One explanation for lack of model accuracy in predicting the overpotentials is that the electrolyte conductivity is too low and/or the solid phase conductivities are too high in the model. If the difference between the conductivities of the solid and the electrolyte are too large, then the current density distribution in the electrolyte will be concentrated close to the separator and cause the large increase in ohmic overpotential in the negative electrode. In the convection cell model these parameters were taken from literature values, so measuring these values directly would potential improve the model considerably. 


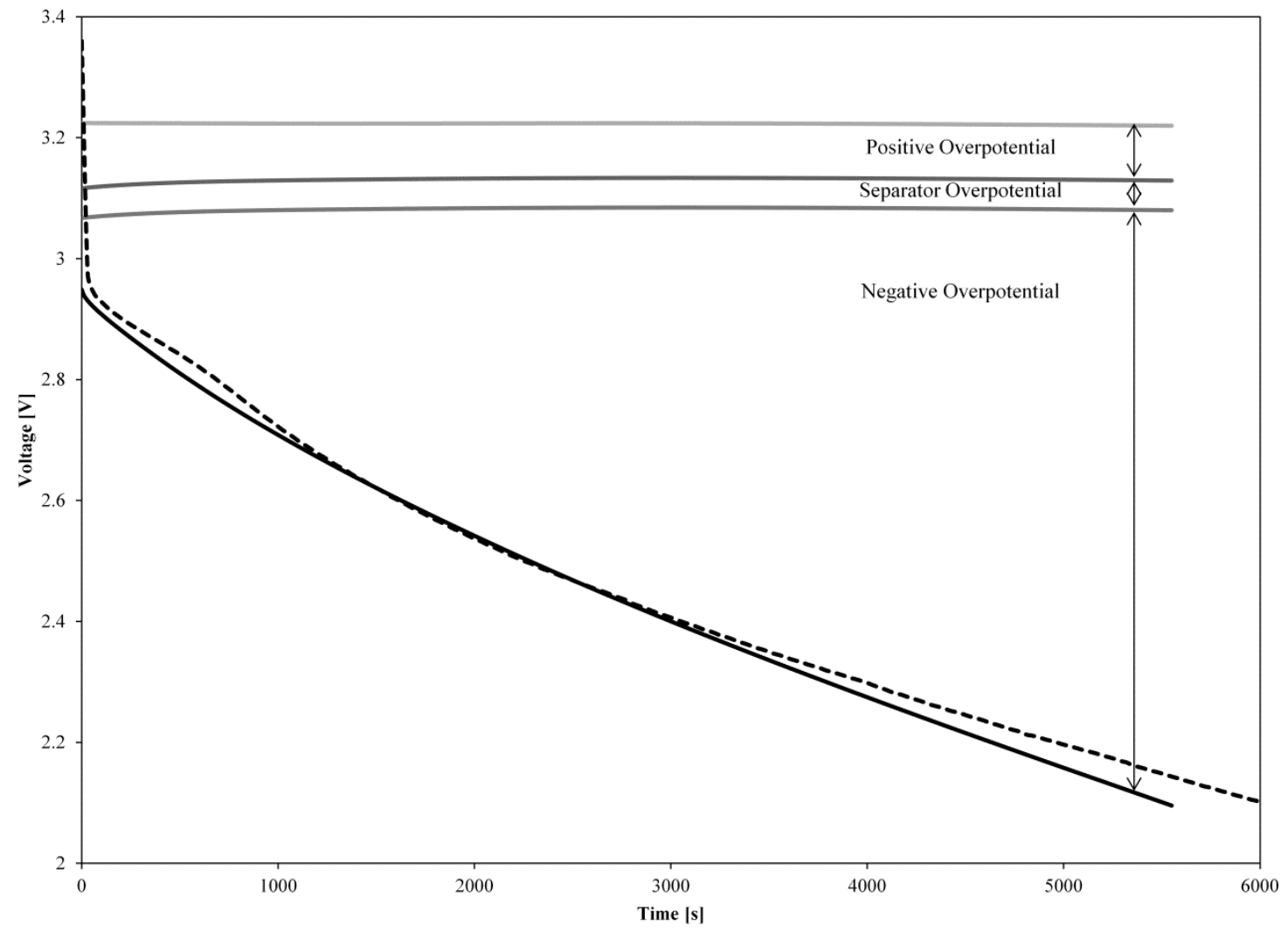

Figure 7.8 Modeled overpotentials compared to experimental cell voltage (dashed line) at a discharge current of $2.7 \mathrm{~mA} / \mathrm{cm}^{2}$ in a convection cell with flow.

\section{Conclusion}

A new multi-reference electrode convection cell has been developed that can accommodate up to eight reference electrodes. This cell is a powerful tool that can be used to experimentally investigate overpotentials in the electrolyte and provide insight to improve the convection battery.

A convection cell model that was presented previously was refitted to constantcurrent discharge data and then used to calculate values for the reference electrode measurements. The calculated values predicted an overpotential in the electrolyte across the entire cell that was seven times greater than the measured value. One explanation for 
this was that the difference in conductivities of the electrolyte and the solid electrodes in the model is too high. To improve the model, these parameters should be measured directly. Despite the differences in model and experimental data, this study provided insight into the mechanisms that affect the overall performance of the convection cell.

In the future, more insight could be obtained from the multiple-reference electrode cell by looking at electrolyte potentials in a convection cell without flow. The flow in the convection cell eliminates most of the concentration overpotentials, so there was little difference in the reference electrode measurements in this study, but without flow the differences should be much greater. This would provide even further insight into the transport phenomena that occur in the convection cell. 


\section{CHAPTER 8}

\section{CONCLUSIONS AND FUTURE WORK}

This dissertation gives a comprehensive view of the convection cell. It looks at the progression in convection cell design and the parallel development of the custombuilt test equipment needed to advance the convection cell research. This work also reviews the initial experimental work that validated the convection cell concept, and presents new experimental and model data that has provided insight into the phenomena that shape the convection cell performance.

In chapter two, eight different design iterations of the convection cell were presented including details of construction. The applications, benefits, and limitations of each design were discussed. This knowledge of convection cell design can be used in the future to make improvements and hopefully prevent design mistakes from being made.

A new LabVIEW-based battery testing system was presented. The final version allowed for flexible and simultaneous testing of three different batteries. The design was robust and user friendly. Because of its ability to control a pump and its relatively lowcost, this system is better suited for convection cell research than many of the commercial systems available. 
A review of the initial validating studies of the convection cell showed that flow in $\mathrm{Zn} / \mathrm{MnO}_{2}$ convection cells decreased concentration overpotentials and improved cell performance. Furthermore, it was shown that separator materials could be selected to decrease ohmic losses in the cell and that the improvement in performance caused by flow is not dependent on the direction of flow.

Studies on $\mathrm{LiFePO}_{4}$ convection cells revealed that the flow enhanced performance in the convection cell is applicable to a variety of different chemistries. It was also found that flow increased performance for both charge and discharge, increasing the amount of active material utilized.

In chapter six, a comprehensive model of the convection cell based on porous electrode theory was presented. The modeling results indicated that the concentration overpotentials in the separator were substantially eliminated.

The latest convection cell studies utilized a new multiple-reference electrode cell to measure electrolyte potentials along the length of the convection cell. Experimental data were compared to calculated model values and revealed that while the model may accurately describe the total cell voltage, improved model parameters still need to be obtained to accurately predict the internal overpotentials within the cell.

\section{Future Work}

The end goal of the convection cell research is to develop the understanding of the convection cell to a level at which the cell can be optimized and made into a practical battery. Future studies should focus on building upon the work presented here to achieve that goal. Some of the tools to do this, such as the multiple-reference cell and the 
convection cell model, have already been developed to an extent, but need to be utilized appropriately and/or improved to advance the research.

Specifically, the battery model is very useful to the research, but as demonstrated in chapter seven, the model parameters need to be improved. Some of the parameters that could be measured include the conductivity of the electrodes and the electrolyte, electrode porosity, electrode surface areas, separator surface areas, and electrode equilibrium potentials. These can all be measured fairly easily and would cut down on the uncertainty in the model.

More work can also be done with the multiple-reference electrode cell. Reference electrode measurements in the convection cell without flow could yield some very interesting results that could be used to help improve the model and the design of the convection cell itself.

In summary, the convection cell has room for significant advancements in the future. If the convection cell can be scaled up practically and economically, then the potential impact on the world's use of fossil fuels in the transportation and power generation sectors could be significant. 


\section{Appendix A}

\section{CONVECTION CELL DESIGN DIMENSIONAL SPECIFICATIONS}

In this appendix detailed dimensional drawings for custom-machined parts in the generation $3,4.1,4.2,5.1$, and 5.2 convection cells are provided. Some of the parts are the same for multiple cells as noted.

\section{Generation 3 Parts}
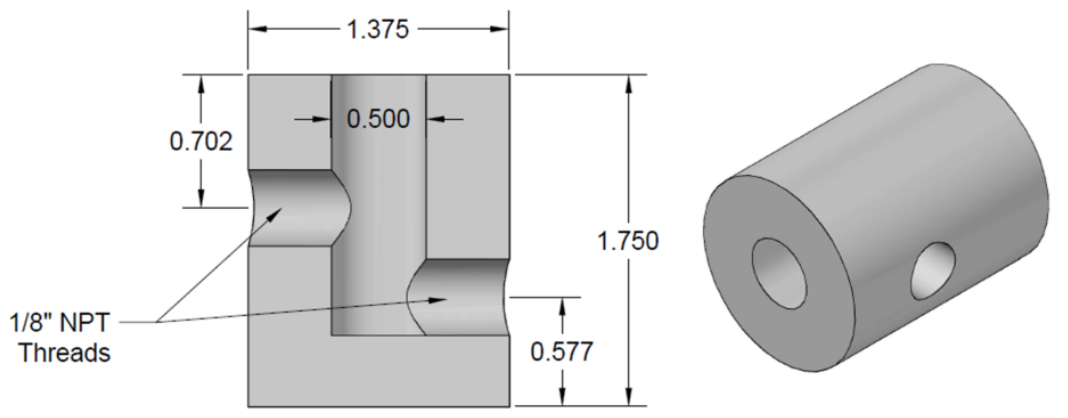

Figure A.1 Dimensional drawings for the 316 SS electrode body of the generation 3 convection cell. Dimensions are in inches.
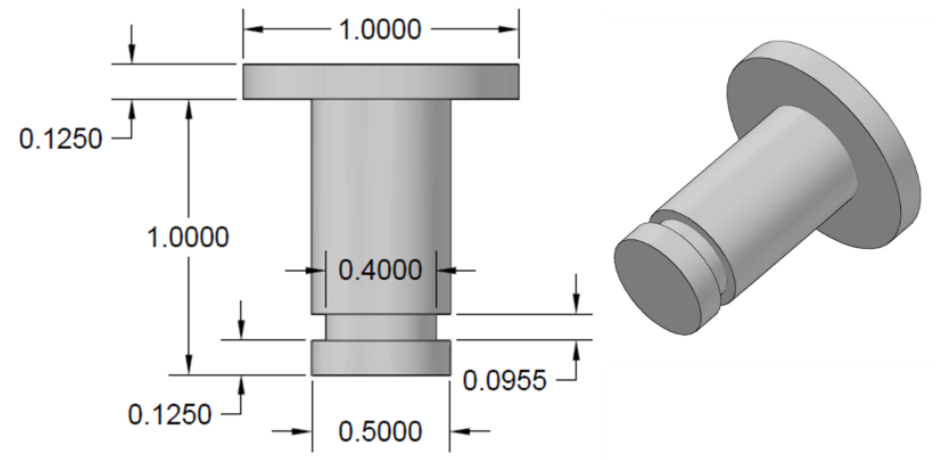

Figure A.2 Dimensional drawings for the 316 SS piston of the generation 3 convection cell. Dimensions are in inches. 


\section{Generation 4.1 and 4.2 Parts}

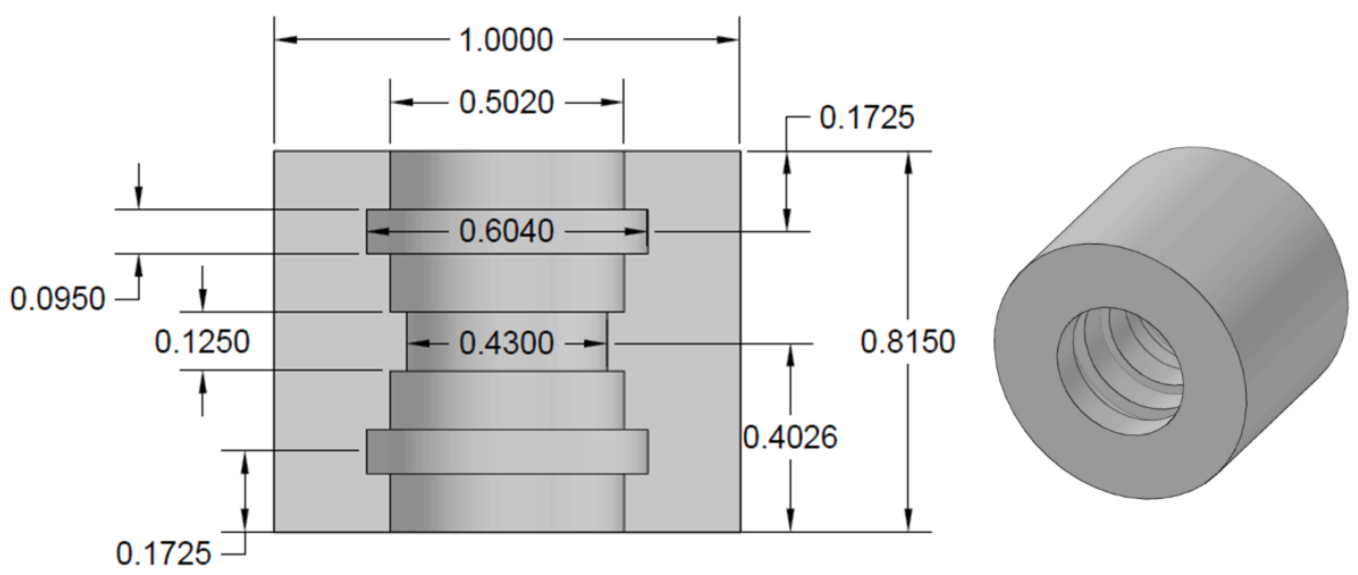

Figure A.3 Dimensional drawings for the HDPE coupling of the generation 4.1 and 4.2 cells. Dimensions are in inches.
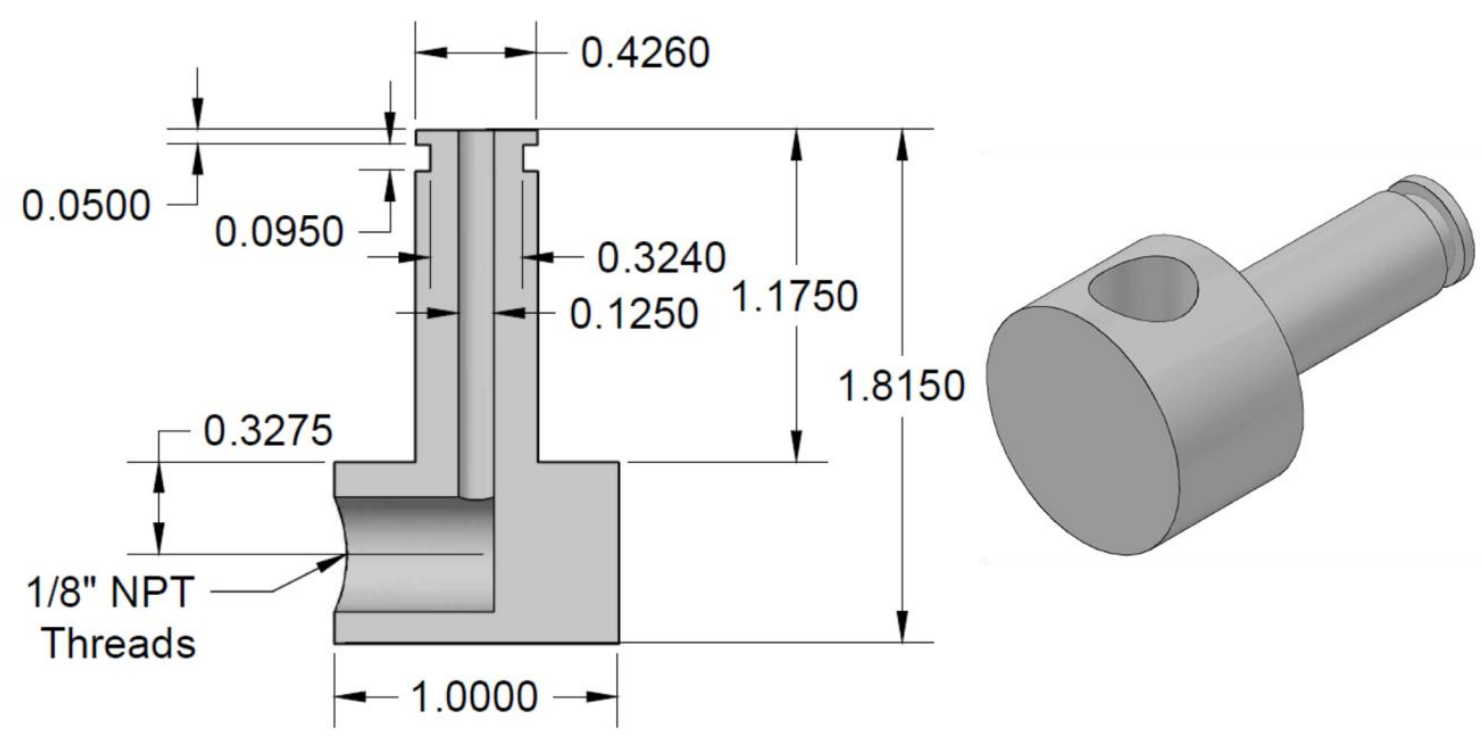

Figure A.4 Dimensional drawings for the 316 SS piston of the generation 4.1 and 4.2 cells. This part is also used in both of the generation 5 cells. Dimensions are in inches. 


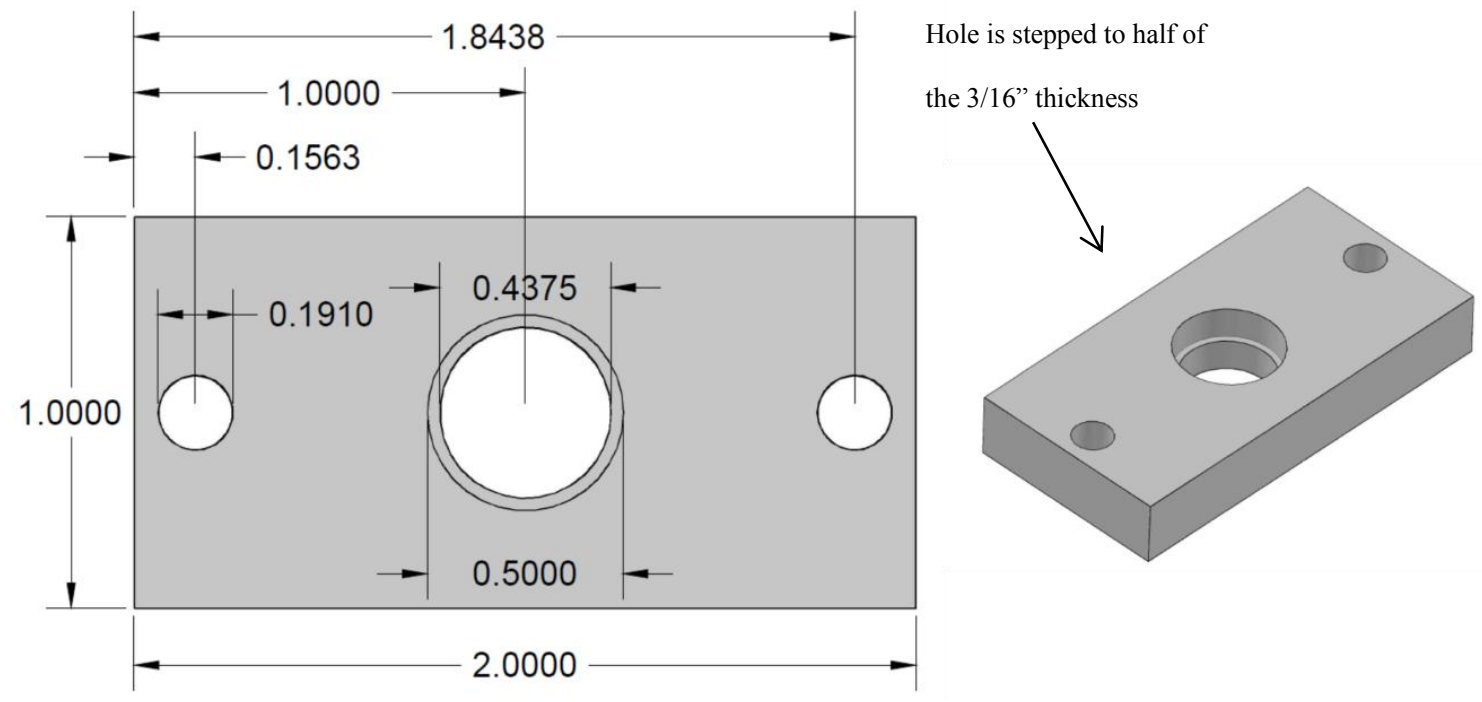

Figure A.5 Dimensional drawings for the 316 SS compression plate of the generation 4.1 and 4.2 cells. This part is also used in both of the generation 5 cells. Dimensions are in inches.
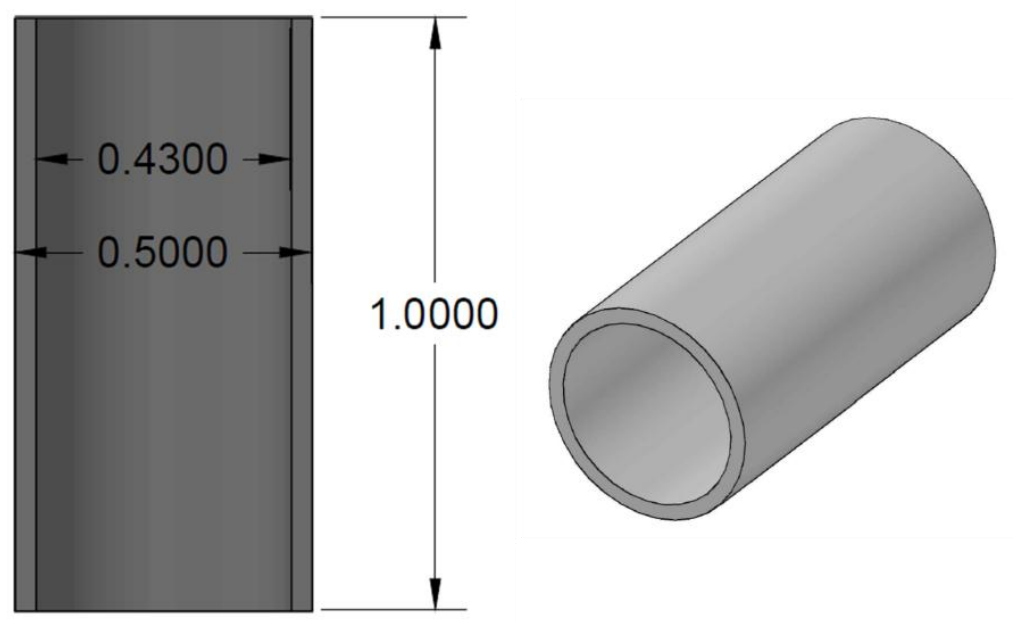

Figure A.6 Dimensional drawings for the 316 SS electrode tubes of the generation 4.1 and 4.2 cells. This part is also used in both of the generation 5 cells. Dimensions are in inches. 


\section{Generation 5.1 Parts}
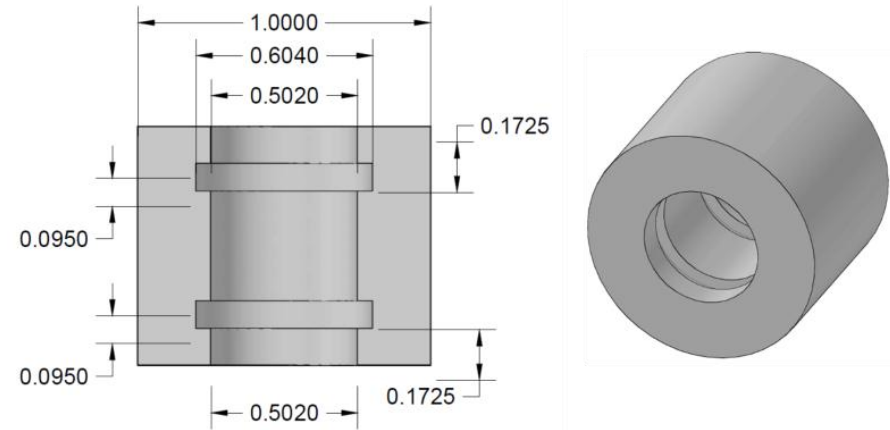

Figure A.7 Dimensional drawings and measurements for the HDPE coupling of the generation 5.1 convection cell. Dimensions are in inches.

\section{Generation 5.2 Parts}

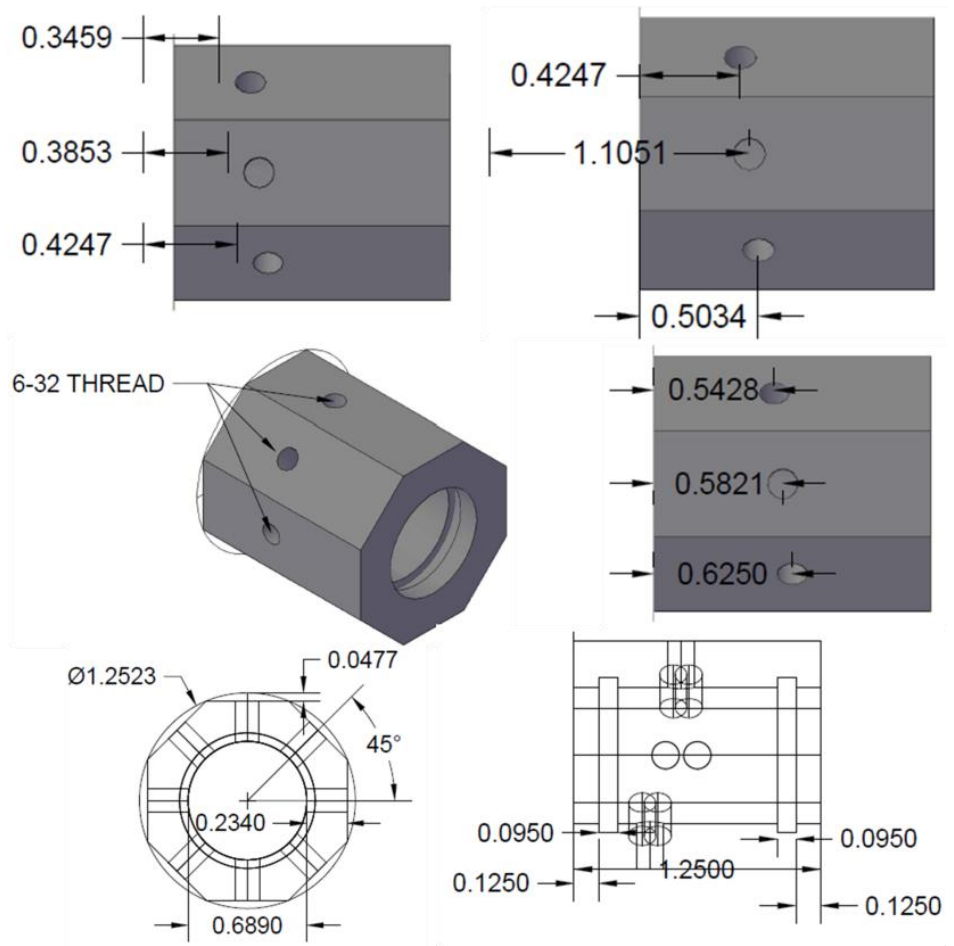

Figure A.8 Dimensional drawings for the Teflon coupler of the generation 5.2 cell.

Dimensions are in inches. 

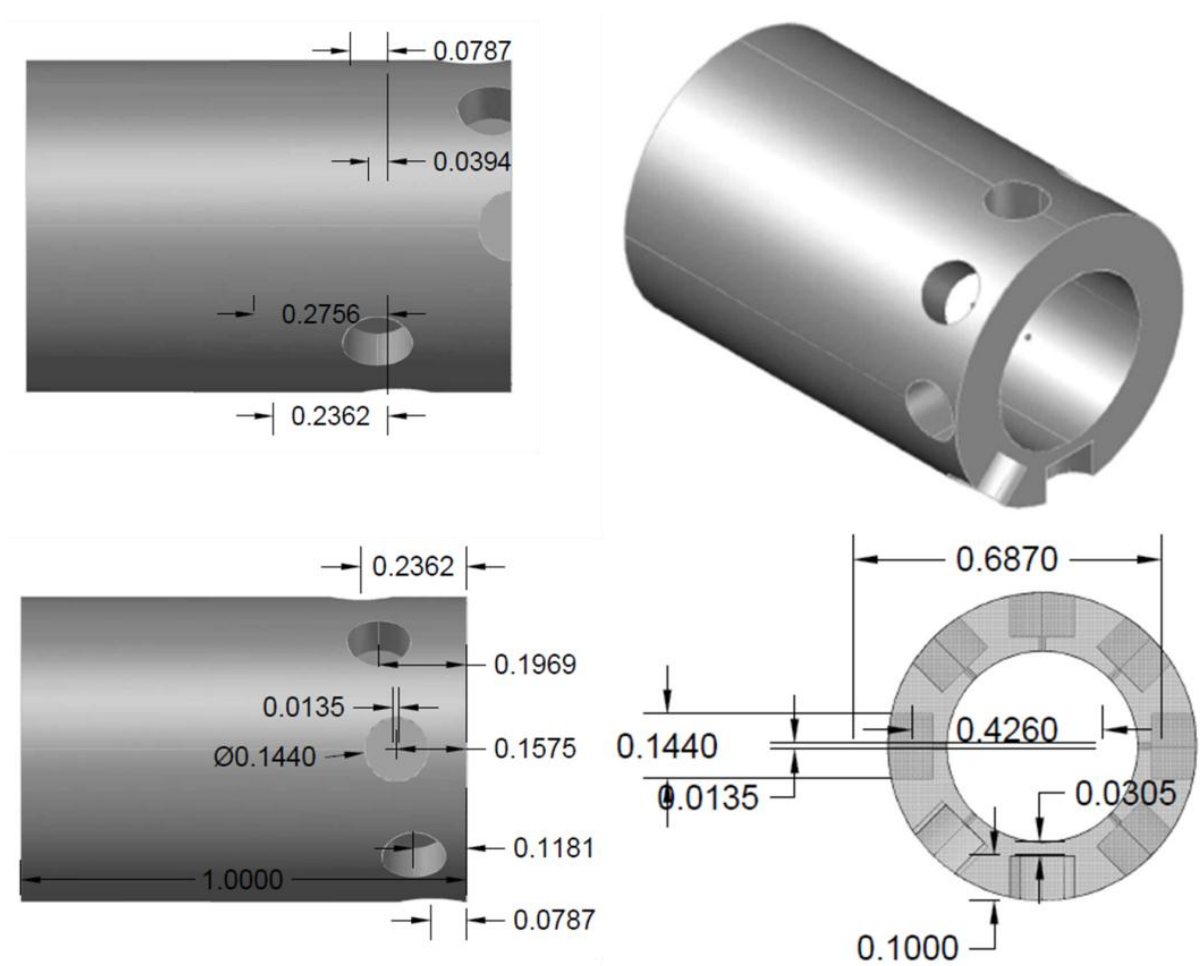

Figure A.9 Dimensional drawings for the Teflon electrode tube 1 of the generation 5.2 cell. Dimensions are in inches.

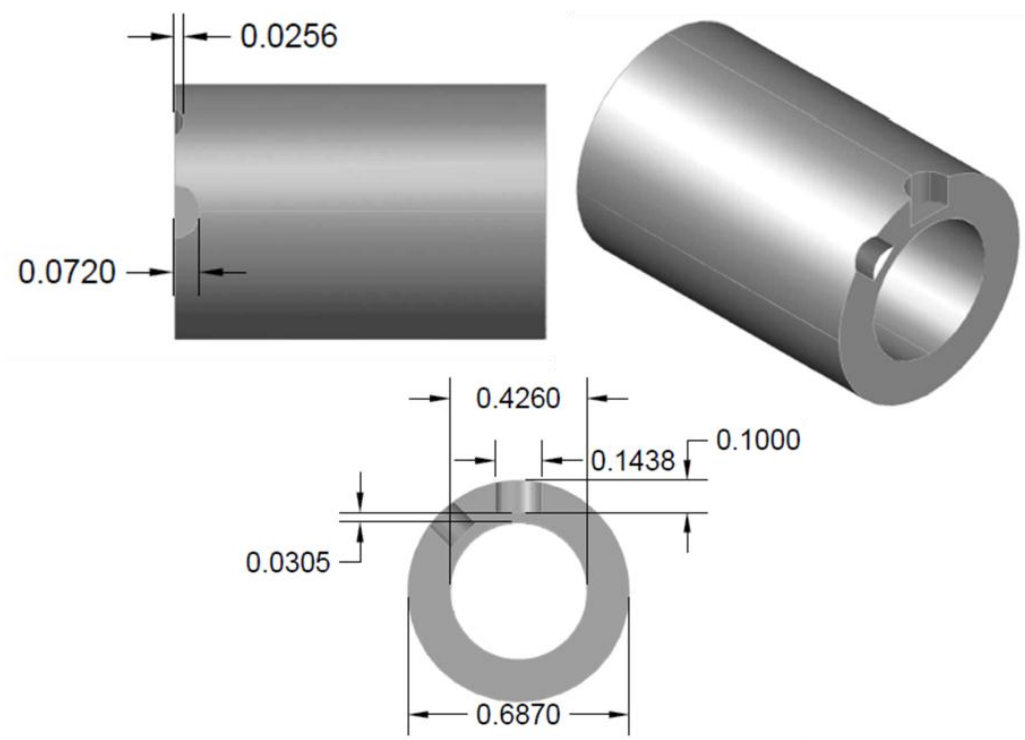

Figure A.10 Dimensional drawings for the Teflon electrode tube 2 of the generation 5.2 cell. Dimensions are in inches. 


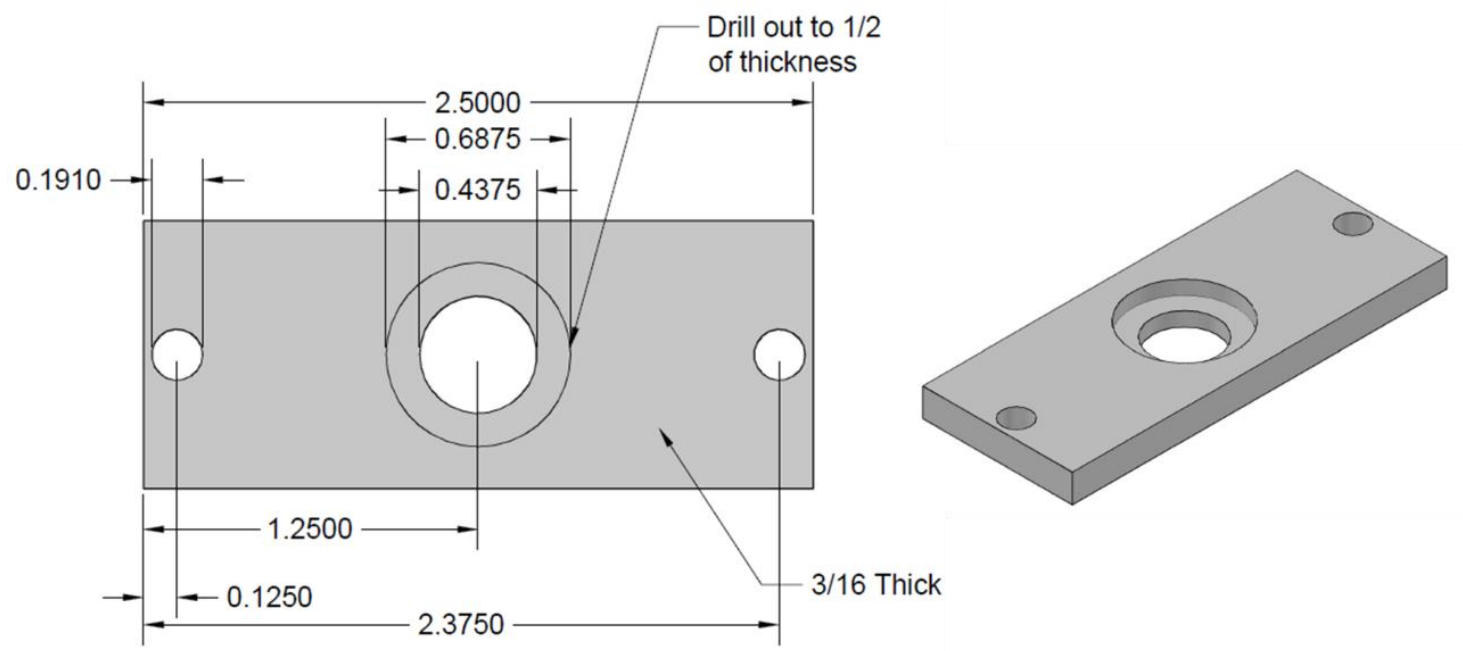

Figure A.11 Dimensional drawings for the 316 SS compression plate of the generation 5.2 cell. Dimensions are in inches. 


\section{BIBLIOGRAPHY}

1. Tesla N. Our Future Motive Power. Everyday Science and Mechanics. 1931;12:230237.

2. US Energy Information Administration. Annual Energy Review. DOE/EIA0384(2011). http://www.eia.gov/totalenergy/data/annual/pdf/aer.pdf. Released September 27, 2012. Accessed April 5, 2013.

3. Schneider D. Plug-ins proliferate. IEEE Spectrum. 2012;49(1):36-37.

4. US Department of Energy. EV Everywhere Grand Challenge Blueprint. http://wwwl.eere.energy.gov/vehiclesandfuels/electric_vehicles/pdfs/eveverywhe re_blueprint.pdf. Released January 31, 2013. Accessed April 9, 2013.

5. Chevorlet. http://www.chevrolet.com/volt-electric-car.html. Accessed April 6, 2013.

6. Nissan. http://www.nissanusa.com/electric-cars/leaf/versions-specs/version.s.html. Accessed April 6, 2013.

7. Aguirre K, Eisenhardt L, Lim C, et al. Lifecycle Analysis Comparison of a Battery Electric Vehicle and a Conventional Gasoline Vehicle. http://www.environment.ucla.edu/media_IOE/files/BatteryElectricVehicleLCA20 12-rh-ptd.pdf. Accessed April 6, 2013.

8. US Energy Information Administration. International Energy Outlook 2011. DOE/EIA-0484(2011). http://www.eia.gov/forecasts/ieo/pdf/0484(2011).pdf. Released September 2011; Accessed April 6, 2013.

9. Rahman F, Rehman S, Abdul-Majeed MA. Overview of energy storage systems for storing electricity from renewable energy sources in Saudi Arabia. Renew Sust Energ Rev. 2012;16(1):274-283. 
10. Dunn B, Kamath H, Tarascon J-M. Electrical Energy Storage for the Grid: A Battery of Choices. Science. 2011;334(6058):928-935.

11. Yang Z, Zhang J, Kintner-Meyer MC, et al. Electrochemical energy storage for green grid. Chem Rev. 2011;111(5):3577.

12. Soloveichik GL. Battery Technologies for Large-Scale Stationary Energy Storage. Annu Rev Chem Biomol. 2011;2(1):503-527.

13. Smith SC, Sen PK, Kroposki B. Advancement of energy storage devices and applications in electrical power system. Paper presented at: Power and Energy Society General Meeting - Conversion and Delivery of Electrical Energy in the 21st Century, 2008 IEEE; July 20-24, 2008; Pittsburgh, PA.

14. Yüksel I. Hydroelectric power in developing countries. Energ Source Part B. 2009;4(4):377-386.

15. Paish O. Small hydro power: technology and current status. Renew Sust Energ Rev. 2002;6(6):537-556.

16. Bathurst GN, Strbac G. Value of combining energy storage and wind in short-term energy and balancing markets. Electr Pow Syst Res. 2003;67(1):1-8.

17. Culver WJ. High-Value Energy Storage for the Grid: A Multi-Dimensional Look. Elec J. 2010;23(10):59-71.

18. Yuri V. Makarov JM, S. Lu, and T.B. Nguyen. Assessing the Value of Regulation Resources Based on Their Time Response Characteristics. PNNL - 17632. http://www.pnl.gov/main/publications/external/technical_reports/PNNL17632.pdf. Released June 2008. Accessed April 9, 2013.

19. Petkov V, Timmons A, Camardese J, Ren Y. Li insertion in ball-milled graphitic carbon studied by total x-ray diffraction. J Phys-Condens Mat. 2011;23(43):435003.

20. Reddy TB. Handbook of Batteries. 4th Ed. New York, NY: McGraw-Hill; 2011.

21. Daniel C. Materials and processing for lithium-ion batteries. JOM-US. 2008;60(9):4348.

22. Newman JS, Tobias CW. Theoretical Analysis of Current Distribution in Porous Electrodes. J Electrochem Soc. 1962;109(12):1183-1191.

23. Zhang SS. A review on the separators of liquid electrolyte Li-ion batteries. $J$ Power Sources. 2007;164(1):351-364. 
24. Pinnangudi BN, Dalal SB, Medora NK, Arora A, Swart J. Thermal shutdown characteristics of insulating materials used in lithium ion batteries. Paper presented at: 2010 IEEE Symposium on Product Compliance Engineering (ISPCE); October 18-20, 2010.

25. Huang X. Separator technologies for lithium-ion batteries. J Solid State Electr. 2011;15(4):649-662.

26. Bartolozzi M. Development of redox flow batteries. A historical bibliography. $J$ Power Sources. 1989;27(3):219-234.

27. Rychcik M, Skyllas-Kazacos M. Characteristics of a new all-vanadium redox flow battery. J Power Sources. 1988;22(1):59-67.

28. Shibata A, Sato K. Development of vanadium redox flow battery for electricity storage. Power Eng J. 1999;13(3):130-135.

29. Ponce de León C, Frías-Ferrer A, González-García J, Szánto DA, Walsh FC. Redox flow cells for energy conversion. J Power Sources. 2006;160(1):716-732.

30. Skyllas-Kazacos M, Kazacos G, Poon G, Verseema H. Recent advances with UNSW vanadium-based redox flow batteries. Int J Energ Res. 2010;34(2):182-189.

31. Skyllas-Kazacos M. Novel vanadium chloride/polyhalide redox flow battery. J Power Sources. 2003;124(1):299-302.

32. Fedkiw PS, Watts RW. A Mathematical Model for the Iron/Chromium Redox Battery. J Electrochem Soc. 1984;131(4):701-709.

33. Price A, Bartley S, Male S, Cooley G. A novel approach to utility scale energy storage [regenerative fuel cells]. Power Eng J. 1999;13(3):122-129.

34. Wills R, Collins J, Stratton-Campbell D, Low C, Pletcher D, Walsh F. Developments in the soluble lead-acid flow battery. $J$ Appl Electrochem. 2010;40(5):955-965.

35. Prudent Energy. VRB Technology in Japan. http://www.pdenergy.com/pdfs/casestudy_japan.pdf. Accessed April 2, 2013.

36. Mohamed MR, Sharkh SM, Walsh FC. Redox flow batteries for hybrid electric vehicles: Progress and challenges. Paper presented at: IEEE Vehicle Power and Propulsion Conference, 2009; September 7-10, 2009.

37. Suppes GJ, Inventor; University of Missouri, USA . assignee. Convection battery configuration for connective carbon matrix electrode. US patent WO2010051540A12010. 
38. Suppes GJ, Sawyer BD, Gordon MJ. High-energy density flow battery validation. AIChE J. 2011;57(7):1961-1967.

39. Sawyer BD. Validation and insight into a novel packed-bed electrode flow battery architecture [dissertation]. Columbia: University of Missouri; 2010.

40. Sawyer B, Suppes G, Gordon M, Heidlage M. Impact of electrode separator on performance of a zinc/alkaline/manganese dioxide packed-bed electrode flow battery. J Appl Electrochem. 2011;41(5):543-550.

41. Gordon MS, Galen. Li-Ion Battery Performacne in Convection Cell Configuration. AIChE J. 2012;59(5):1774-1779.

42. Gordon M, Suppes G. Convection battery — modeling, insight, and review. AIChE J. In Press.

43. Remick RJ, Ang PG. Electrically rechargeable anionically active reduction-oxidation electrical storage-supply system. US Patent US4485154 A.

44. Barnett B, et al. PHEV and LEESS Battery Cost Assessment. http://www1.eere.energy.gov/vehiclesandfuels/pdfs/merit_review_2011/electroch emical_storage/es001_barnett_2011_o.pdf. May 10, 2011. Accessed March 1, 2012.

45. Gallagher K, et al. PHEV Battery Cost Assessment. http://www1.eere.energy.gov/vehiclesandfuels/pdfs/merit_review_2011/electroch emical_storage/es111_gallagher_2011_o.pdf. May 2011. Accessed March 1, 2012.

46. Markel T, et al. PHEV Energy Storage Performance/Life/Cost Trade-off Analysis. http://www.nrel.gov/docs/fy08osti/43159.pdf. May 15, 2008. Accessed March 1, 2012.

47. Wang Y, He P, Zhou H. Li-Redox Flow Batteries Based on Hybrid Electrolytes: At the Cross Road between Li-ion and Redox Flow Batteries. Adv Energy Mater. 2012;2(7):770-779.

48. Lu Y, Goodenough JB. Rechargeable alkali-ion cathode-flow battery. J Mater Chem. 2011;21(27):10113-10117.

49. Huang Q, Li H, Gratzel M, Wang Q. Reversible chemical delithiation/lithiation of LiFePO4: towards a redox flow lithium-ion battery. Phys Chem Chem Phys. 2013;15(6):1793-1797.

50. Hart B. Designing the Widlar current mirror. Int J Elec Eng Educ. 2003;40(4):285298. 
51. Pfeifer P, Suppes GJ, Shah P, Burress JW. High Surface Area Carbon and Process for its Production. US Patent US20080207442 A1.

52. El-Shakre ME, Saleh MM, El-Anadouli BE, Ateya BG. Applications of Porous FlowThrough Electrodes. J Electrochem Soc. 1994;141(2):441-447.

53. Alkire RC, Gould RM. An Engineering Model for Electro-Organic Synthesis in Continuous Flow-Through Porous Electrodes. J Electrochem Soc. 1980;127(3):605-612.

54. Trainham JA, Newman J. A Flow-Through Porous Electrode Model: Application to Metal-Ion Removal from Dilute Streams. J Electrochem Soc. 1977;124(10):15281540 .

55. El-Deab MS, Saleh MM, El-Anadouli BE, Ateya BG. Electrochemical Removal of Lead Ions from Flowing Electrolytes Using Packed Bed Electrodes. $J$ Electrochem Soc. 1999;146(1):208-213.

56. Trainham JA, Newman J. A comparison between flow-through and flow-by porous electrodes for redox energy storage. Electrochim Acta. 1981;26(4):455-469.

57. You D, Zhang H, Chen J. Theoretical analysis of the effects of operational and designed parameters on the performance of a flow-through porous electrode. $J$ Electroanal Chem. 2009;625(2):165-171.

58. Wei-Jun Z. Structure and performance of LiFePO4 cathode materials: A review. $J$ Power Sources. 2011;196(6):2962-2970.

59. Kear G, Shah AA, Walsh FC. Development of the all-vanadium redox flow battery for energy storage: a review of technological, financial and policy aspects. Int $J$ Energ Res. 2011;36(11):1105-1120.

60. ASTM. Standard Test Method for Measurement of Hydraulic Conductivity of Porous Material Using a Rigid-Wall, Compaction-Mold Permeameter. D5856 - 95. West Conshohocken, PA: ASTM International; 2007.

61. Koryta J, Dvořák J, Kavan L. Principles of electrochemistry. Chichester, England: Wiley; 1993.

62. Newman JS, Thomas-Alyea KE. Electrochemical Systems. 3rd ed. Hoboken, NJ: J. Wiley; 2004.

63. Newman J, Tiedemann W. Porous-electrode theory with battery applications. AIChE J. 1975;21(1):25-41. 
64. Doyle M, Newman J, Gozdz AS, Schmutz CN, Tarascon J-M. Comparison of Modeling Predictions with Experimental Data from Plastic Lithium Ion Cells. $J$ Electrochem Soc. 1996;143(6):1890-1903.

65. Fuller TF, Doyle M, Newman J. Simulation and Optimization of the Dual Lithium Ion Insertion Cell. J Electrochem Soc. 1994;141(1):1-10.

66. Doyle M, Fuller TF, Newman J. Modeling of Galvanostatic Charge and Discharge of the Lithium/Polymer/Insertion Cell. J Electrochem Soc. 1993;140(6):1526-1533.

67. Weber AZ, Mench MM, Meyers JP, Ross PN, Gostick JT, Liu Q. Redox flow batteries: a review. J Appl Electrochem. 2011;41(10):1137-1164.

68. Skyllas-Kazacos M, Chakrabarti MH, Hajimolana SA, Mjalli FS, Saleem M. Progress in Flow Battery Research and Development. J Electrochem Soc. 2011;158(8):R55-R79.

69. Srinivasan V, Newman J. Discharge Model for the Lithium Iron-Phosphate Electrode. J Electrochem Soc. 2004;151(10):A1517-A1529.

70. Srinivasan V, Newman J. Design and Optimization of a Natural Graphite/Iron Phosphate Lithium-Ion Cell. J Electrochem Soc. 2004;151(10):A1530-A1538.

71. Li X, Zhang H, Mai Z, Zhang H, Vankelecom I. Ion exchange membranes for vanadium redox flow battery (VRB) applications. Energy Environ Sci. 2011;4:1147-1160.

72. Berezina NP, Kononenko NA, Dyomina OA, Gnusin NP. Characterization of ionexchange membrane materials: Properties vs structure. Adv Colloid Interface Sci. 2008;139(1-2):3-28.

73. Salerno HLS, Elabd YA. Anion exchange membranes derived from nafion precursor for the alkaline fuel cell: Effect of cation type on properties. J Appl Polym Sci. 2013;127(1):298-307.

74. Salerno HLS, Beyer FL, Elabd YA. Anion exchange membranes derived from nafion precursor for the alkaline fuel cell. J Polym Sci Pol Phys. 2012;50(8):552-562.

75. Ye Y, Elabd YA. Anion exchanged polymerized ionic liquids: High free volume single ion conductors. Polymer. 2011;52(5):1309-1317.

76. Hilton R, Bick P, Tekeei A, Leimkuehler E, Pfeifer P, Suppes GJ. Mass Balance and Performance Analysis of Potassium Hydroxide Activated Carbon. Ind Eng Chem Res. 2012;51(26):9129-9135. 
77. Harris SJ, Timmons A, Baker DR, Monroe C. Direct in situ measurements of Li transport in Li-ion battery negative electrodes. Chem Phys Lett. 2010;485(46):265-274.

78. Ng S-H, La Mantia F, Novák P. A Multiple Working Electrode for Electrochemical Cells: A Tool for Current Density Distribution Studies. Angew Chem Int Edit. 2009;48(3):528-532.

79. Piela P, Springer TE, Davey J, Zelenay P. Direct Measurement of iR-Free IndividualElectrode Overpotentials in Polymer Electrolyte Fuel Cells. J Phys Chem C. 2007;111(17):6512-6523.

80. Takaichi S, Uchida H, Watanabe M. In situ analysis of oxygen partial pressure at the cathode catalyst layer/membrane interface during PEFC operation. Electrochim Acta. 2008;53(14):4699-4705.

81. Büchi FN, Scherer GG. Investigation of the Transversal Water Profile in Nafion Membranes in Polymer Electrolyte Fuel Cells. J Electrochem Soc. March 1, 2001 2001;148(3):A183-A188.

82. Hess KC, Epting WK, Litster S. Spatially Resolved, In Situ Potential Measurements through Porous Electrodes As Applied to Fuel Cells. Anal Chem. 2011;83(24):9492-9498.

83. Thomas K, Newman J, Darling R. Mathematical Modeling of Lithium Batteries. In: Schalkwijk W, Scrosati B, eds. Advances in Lithium-Ion Batteries. New York, NY: Springer; 2002:345-392.

84. Karthikeyan DK, Sikha G, White RE. Thermodynamic model development for lithium intercalation electrodes. J Power Sources. 2008;185(2):1398-1407. 


\section{VITA}

Michael Joseph Gordon was born on April 26, 1985 in Kansas City, Missouri. He graduated from the University of Missouri in May 2009 with a Bachelor's of Science Degree in Chemical Engineering. He then attended graduate school at the University of Missouri under the guidance of Dr. Galen Suppes. He completed the requirements for a Doctorate of Philosophy in Chemical Engineering at the University of Missouri in May 2013. 